Portland State University

PDXScholar

Summer 8-6-2019

\title{
Architectural and Philosophical 'Makerspace' Redesign Impact on Teacher Beliefs and Practices: a Case Study
}

Rurik-Rory James Nackerud

Portland State University

Follow this and additional works at: https://pdxscholar.library.pdx.edu/open_access_etds

Part of the Curriculum and Instruction Commons, and the Educational Leadership Commons Let us know how access to this document benefits you.

\section{Recommended Citation}

Nackerud, Rurik-Rory James, "Architectural and Philosophical 'Makerspace' Redesign Impact on Teacher Beliefs and Practices: a Case Study" (2019). Dissertations and Theses. Paper 5090.

https://doi.org/10.15760/etd.6966

This Dissertation is brought to you for free and open access. It has been accepted for inclusion in Dissertations and Theses by an authorized administrator of PDXScholar. Please contact us if we can make this document more accessible: pdxscholar@pdx.edu. 
Architectural and Philosophical 'Makerspace' Redesign Impact

on Teacher Beliefs and Practices: A Case Study

by

Rurik-Rory James Nackerud

A dissertation submitted in partial fulfillment of the requirements for the degree of

Doctor of Education

in

Educational Leadership: Curriculum and Instruction

Dissertation Committee:

Dannelle D. Stevens, Chair

Micki M. Caskey

Esperanza De La Vega

Yves Labissiere

Portland State University

2019 


\begin{abstract}
Current jobs in a global economy require more complex cognitive skills, such as critical thinking, cooperation, creativity, and collaboration, in addition to content knowledge. To address these areas, researchers have suggested the use of a 'makerspace' in schools. As with many other establishments, my school remodeled the primary school to create a makerspace for developing these skills. What impact might a makerspace - a physical as well as a curricular change - have on teachers' individual and collaborative learning? The purpose of this case study was to describe how the makerspace concept and changes to classroom or instructional space influence teachers' beliefs and practices as they develop the curriculum, follow the existing curriculum, revise ideas, and share knowledge with others. Our school branded the newest structural change 'Innovation Alley'. Under the leadership of the School Division Head, the concept of Innovation Alley was embedded in an effort to emphasize Science, Technology, Engineering, Arts, Math (STEAM) and the Library, and combine them for cross-curricular purposes.

Drawing on field observations, interviews, and analysis of artifacts, videos, and other documents, I worked with and interviewed four of my colleagues to describe features of the emerging classroom or instructional spaces to consider how we developed our practice in this environment. I found that teachers placed high value on community, administrative, peer support, and shared knowledge-building in mitigating the stressors related to the innovation. There also appears to be a relationship between teachers'
\end{abstract}


understanding of the makerspace development and their sense of control. When participants expressed interest in embracing the makerspace, they also indicated that they understood what they were doing. When they expressed a sense of loss of control or stress, they would often refer to using more traditional methods of teaching. 


\section{Acknowledgements}

Throughout the writing of this dissertation I have received a great deal of support and assistance. I would first like to thank my chair, Dr Dannelle D. Stevens, whose expertise was invaluable in understanding the process of taking a dissertation from research, data collection, and methodology, to the final writing and editing process itself. I would also like to acknowledge my mentors on the committee. A big thank you to Dr Micki Caskey for her invaluable support in improving the proposal and supporting my cohort throughout this process. I would also thank Dr Esperanza De La Vega who, as both a mentor and boss, introduced me to so many aspects of research by involving me in her work right from the beginning of my experience at Portland State University. I would also like to thank Dr Yves Labissiere for giving his time both to me, and to the school of education. You have all supported me greatly.

I would also like to thank my colleagues, the board, and the families at my school. They provided so much support and encouragement - I owe them a great debt of gratitude. Thank you for your excellent cooperation and for all of the opportunities I was given to conduct my research and further my dissertation. Our community is truly a 'tunnel of love' and support.

Finally, thanks are due to my friends, who were of great support in deliberating over our problems and findings, as well as providing a happy distraction to give my mind a break outside of my research. 


\section{Table of Contents}

Abstract

Acknowledgements

iii

List of Tables

vii

List of Figures

viii

CHAPTER 1: Building a Space

Statement of the Problem

Research Questions Introduced

Significance of the Problem

Presentation of Methods

Background of the Problem

Definition of Key Terms

Chapter Summary

Review of the Research Literature

Review of the methodological literature 
Research Methods

Instruments and Measures

Role of the Researcher

The New Space: The 'Makerspace'

Data Collection and Analysis

Chapter Summary

CHAPTER 4: Data, Data, Data

Data Sources

Participants

Addressing the research questions

Research sub-question 1

Research sub-question 2

Research Sub-Question 3

Limitations

Chapter Summary

CHAPTER 5: Interpretations and an Epilogue

Introduction 
Synthesis of Findings

Implications

Suggestions for Practices and Policy

Future Research

Concluding Remarks

Epilogue

REFERENCES

Appendix A Demographic Survey

Appendix B Interview Protocol 


\section{List of Tables}

Table 1. Research Questions \& Interview Matrix

66-68

Table 2. Data Collection Schedule

81-82

Table 3. Interview Schedule

82

Table 4. Demographics Survey Data

92 


\section{List of Figures}

Figure 1. Bandura's Social Cognitive Theory $\quad 24$

$\begin{array}{ll}\text { Figure 2. Before \& After Map } & 76\end{array}$

Figure 3. Temporary Wall: Art Side 76

Figure 4. Temporary Wall: Construction Side $\quad 77$

$\begin{array}{ll}\text { Figure 5. Temporary Wall Removed } & 78\end{array}$

$\begin{array}{lr}\text { Figure 6. Empty Solarium } & 78\end{array}$

$\begin{array}{ll}\text { Figure 7. Glass Walls } & 78\end{array}$

$\begin{array}{ll}\text { Figure 8. Glass Divider } & 78\end{array}$

$\begin{array}{ll}\text { Figure 9. Large Windows } & 78\end{array}$

$\begin{array}{ll}\text { Figure 10. Multi-Room Composite } & 79\end{array}$

$\begin{array}{lr}\text { Figure 11. Solarium Wide Angle } & 80\end{array}$ 


\section{CHAPTER 1: Building a Space}

According to Bidwell (2013), education in the United States no longer retains an exemplary reputation, as evidenced by students scoring significantly below other developed countries on international assessments. Industrial-age education, focusing on standardized skills for industrial-age jobs, provides low-level cognitive and social skills that fulfilled the requirements of $95 \%$ of jobs just 29 years ago (Calkins, Ehrenworth, \& Lehman, 2012). Yet, in addition to content knowledge, current jobs in a global economy require more complex cognitive skills, such as critical thinking, cooperation, creativity, and collaboration (Partnership for 21st-Century Skills, 2013; Manzo, 2000). As an educator and researcher, I found myself curious to discover in what ways my colleagues' and my practices in the STEM/STEAM (science, technology, engineering, arts, and mathematics) context could support these student cognitive and social outcomes, especially in the newly planned context of a 'makerspace'..

The National Science Foundation (George \& Bragg, 1996) put forward the acronym SMET (later redesignated STEM) as a branding tool to support an integrative education approach in the fields of science, technology, engineering, and math. This rebranding began as a campaign to link K-12 education subject areas. Science, technology, engineering, and math share concepts like problem-solving, arguing from evidence, and resolving conflicting views (Angier, 2010). This was the beginning of the STEAM acronym, which drives much of the work at my current school. An extended acronym of STEM, STEAM includes the idea that the arts fit within the skill sets 
developed in STEM. Integrated STEAM pedagogy includes ideals of curricular integration throughout learning environments.

STEM education is necessary to prepare students for the global workforce (Lantz, 2009). Lantz also indicated that STEM learning occurs through constructivist, project-based methods aimed at building skills and content understanding. These methods of constructivism and project-based learning reflect modern learning theories and ideals (Martin, 2015; Martinez \& Stager, 2013; Sheridan et al., 2015). STEM learning, problemsolving, and inquiry of this sort also fit into the fields of design and the arts, leading to an addition to the acronym for some proponents (and at my school). The STEAM team, in large part, was responsible for crafting school-wide design cycle definitions and modeling integration practices.

Our faculty refers to design, as well as science, technology, engineering, arts, and math integration, as STEAM (as do proponents of this definition). Angier (2010) noted that STEAM education (science, technology, engineering, arts, and math) may add unnecessary jargon, but there is evidence of a national interest in the integration of arts within the STEM framework (Piro, 2010; White, 2011). The STEAM versus STEM debates hotly contests various acronyms and how they impact the integration movement (Root-Bernstein \& Root-Bernstein, 2011; Sanders, 2009; Weissmann, 2013). The maker movement, known for interdisciplinary, integrated explorations of STEAM topics, furthers discourse suggesting STEAM as a coherent approach to problem-based learning (Sousa \& Pilecki, 2013). 
My work primarily related to the introduction of the makerspace concept, in addition to technology coaching, to educator's constructivist practices. 'Making' ideals fit within constructivism as a process of learning through creating and design. Papert's learning theory (1980), constructivism, the idea of multiliteracies (The New London Group, 1996), and situated learning (Lave \& Wenger, 1991) contextualize this as 'learning through making'. Expansion in technologies has, in this context, expanded the types of possible learning. To further solidify the relationship between STEAM and making, researchers Halverson and Sheridan (2014) have found that making inherently integrates artistic practices into STEM learning.

My school embraced Glover and Hope's (2013) challenge to support student learning in new and different ways, in order to achieve the skillsets demanded by a global workforce. Many schools have embraced makerspaces as an answer to this need. The Apple Tree School, a small Kindergarten through to eighth grade school, has, along with many independent schools on the East Coast of the United States, decided to address STEAM through structural change that include a makerspace. Over the last four years, a makerspace/technology lab had been developed in the upper school building, which is used by students from fifth to eighth grade. Primary-age students, while engaged in maker-style activities, lacked a similar space in the lower school. The school-wide STEAM initiative and master plan led to the school's development of Innovation Alley. This addition required remodeling changes to the lower school, which resulted in new classrooms, centralization of many STEAM content educators, and the creation of a 
makerspace for lower school students in the lower school building. Kindergarten students, currently housed in Chilton House, also had access to the new spaces.

The STEAM initiative and master plan focused on capital campaigns to improve school infrastructure, and sought to address the need for modern learning and 21 stcentury skills development. School instructional leadership wanted to build collaborative structures to support planning for integrated STEAM activities throughout the school. In addition to remodeling, faculty and instructional leadership took part in professional learning opportunities to build content knowledge, strengthen STEAM-related instructional strategies, support curricular understanding, and guide analysis of maker/integrated STEAM student learning.

\section{Statement of the Problem}

The purpose of this study was to describe how the makerspace concept and changes to classroom or instructional space influence teachers' beliefs and practices as they develop the curriculum, follow the existing curriculum, revise ideas, and share knowledge with others. Along with school leaders, instructional leaders, and vision leaders, I was concerned about how this innovation might affect educators. Through this research, I sought to understand the experience of teachers who implemented this innovation successfully. With this understanding, we hoped to better facilitate and advocate for classroom and STEAM teacher resources, professional development, and curriculum design in the lower school. Through the integration of STEAM through a makerspace, and an understanding of how the environmental change, renovations, and 
impact educator decision-making, the lower school educational community seeks to provide students with the necessary knowledge for success in a 21 st-century skill environment. Key to making this progress is understanding the teachers' interpretation and experience.

\section{Research Questions Introduced}

My study sought to understand how the change in environment at the lower school (i.e., adding a makerspace) influenced teachers' beliefs and practices in terms of pedagogical decision-making, curriculum development, following the existing curriculum, revising ideas, and sharing knowledge with others. To provide context for understanding the impact on the curriculum, the following research questions guided the study:

Central Research Question. What influence does the physical addition of the makerspace have on the teaching and learning beliefs and practices of primary school educators at a K-8 independent school on the East Coast of the United States?

Sub-question 1. What are the beliefs, practices and experiences of primary educators related to the change in the physical environments as teaching and learning tools?

Sub-question 2. In what ways do educators perceive the redesign as changing how they use physical space? 
Sub-question 3. What beliefs and practices, related to 21 st-century skills of collaboration, creativity, critical thinking, and communication, do educators identify as part of the new space?

\section{Significance of the Problem}

Beyond informing my specific work with educators, the investigation of these questions was intended to contribute to related areas of concern. Understanding the beliefs and practices of educators during and after remodeling the school spaces was essential to informing the STEAM initiative goals and future capital projects in any master plan. Understanding teachers' beliefs about, and readiness to use, the makerspace provided feedback in terms of: (a) who may have needed more support in curricular design; (b) who was receptive or resistant to change; and (c) who did not need support and why. The ability to assess the immediate impact of the redesign helped provide background knowledge about the master plan as it continued to unfold. This fostered greater equity between administrators and educators in sharing the vision for the future of the school. Finally, the methodology I pursued provided educators with a forum that allowed them to discuss both the environmental design and their practice.

\section{Presentation of Methods}

According to Caine and Caine (1994), we need to engage in qualitative research rather than using quantitative methods to benefit from emerging educational practices. In the setting and context of this study, the depth of the educational practices within the school and classroom setting cannot be represented appropriately via quantitative 
methods. Typical qualitative research methods, such as observations, provides a depth of understanding about the human experience in the learning environment (Babbie, 2007). Anderson and Arsenault (1998) described qualitative research as more appropriate for investigating natural settings, using multiple methods to gain insights and meaning from these settings. A participatory type of research, where teachers were provided the opportunity to explore shared problems, solutions, and pedagogical approaches, offered the chance to both actively study an emerging practice and take actions to make it useful to the school (Danielson \& McGreal, 2000). Because I was trying to understand teachers' beliefs and practices, I looked into the construction and reconstruction of teachers' professional knowledge and epistemological beliefs about teaching and learning as part of their narrative (Beattie, 1995). My research required a reflectivity that included examining how teachers construct their professional identity.

The research project and experience was, in itself, a journey of seeking meaning and discovering the self and one's identity within the world (Vygotsky, 1978). In this study, the 'self' was that of both me and my colleagues. The research methodology was not designed to silence my colleagues. Instead, in a situation of environmental change that, as already discussed, may lead to negative experiences, I sought to gain greater insights into the competency of educators. Several qualitative researchers and learning theorists encourage the challenging of perceptions and assumptions about educator competency (Dewey, 1980; Freire, 1998; Fromm, 1976; Noddings, 2006; Palmer, 1983; Rinaldi, 2006; Vygotsky, 1978). Referring to these theorists' work, I found many 
definitions from the participants in this study that offered a multitude of interpretations of what constitutes the 'identity' of an educator.

As an active participant, I used a social constructivist approach. This approach offers an awareness of the uncertainty and complexity of data gathering during the reconstruction (Dahlberg, Moss, \& Pence, 1999). In practice, adopting a social constructivist approach meant that I took into account that idea that knowledge is constructed by interacting with others. People work together, and through these interactions, we learn as individuals. I tried to avoid falling back on the safety of traditional practices of isolating behaviors to individuals (Gardner, 1994). The interactions that occurred were shaped by, and within, the group. As a member of the group, I contributed to shaping and being shaped by this study, as well as influencing others.

To address the research questions in the makerspace environment that I described, I used a narrative case study methodology (Clandinin \& Connelly, 1996; Clandinin \& Connelly, 2000; Riessman, 1993; Wells \& Ernst, 2012). Data collection is an exploratory phenomenon within the place and time, according to Creswell (2007), whereby participants' stories, context, and additional sources may be used to gain perspective on the experiences in a case. As a researcher, I collected interviews, observations, surveys, and additional data for the narrative case study. My task was then to analyze the data through categorization, direct interpretations, and generalizations of a naturalistic form (Creswell, 2007). Through this holistic approach I developed themes and theories. 
The methodology provided a means for educators to assert control over their understanding of renovations and innovations, share frustrations relating to task overload, and help resolve role conflicts, while asking critical questions and experiencing potentially transformative professional development. This occurred through a dialogic style of reflection and action (Freire, 1998) that was intended to overcome oppressive experiences within the school (Freire, 1982). This type of research creates a more active role for the subjects. Part of the appeal of my research was that it allowed me to do more than 'take' from those I am researching. The storytelling and reflections may actually have helped those who contributed to the study in their practice as educators.

To gain my desired level of clarity on my research, I could not rely on single data sources. Using the concept of triangulation (i.e., using multiple independent sources of data to answer questions), I compared and contrasted interview narratives to additional data points. This supported the multi-voice framework. The concept of triangulation is a useful research option (Denzin, 2006; Flick, 2002). Using triangulation to clarify interview responses and context helps to "corroborate one source and method with another" and "enhance the quality of the data" (Mason, 2002, pp 33). I used triangulation as a strategy to consider the phenomena revealed through the interviews through the analysis of these different data sources (Denzin, 2006). Through this I was better able to reveal the details of participants' experiences.

Two brief surveys complemented the narrative interviews. To avoid further burdening the participants, additional data came from the data-rich environment of the 
school. Aside from narrative interviews and surveys (i.e., sources requiring participants' time), I collected images, notes, and curricular products shared by the interviewees. Curricular products, images, and notes on practice composed one set of available data for analysis. These included items that were already collected by the school for publications, record-keeping, and planning purposes. They provided contextual insights and prompts during the narrative interviews as well as helped to corroborate the narratives provided. Most were provided by interviewees, but additional materials were collected from public records, such as the school's website and promotional materials.

Weekly grade and subject area meeting notes, which were already part of the routine of the school, were collected in order to gain insights into curricular planning. However, these were discarded as they mostly centered on construction tasks. It was hoped that the notes would provide material on space use, but due to various construction faults, they focused almost exclusively on construction and repair schedules. Some notes helped to identify or corroborate themes from interviews. Data was collected throughout the interview process to align the interview narratives with their context.

Primarily, my research relied on interpretations of narrative interviews. These were the heart of this case study. The school publications, images, and curricular products, and the weekly grade and subject notes, helped to triangulate these stories. The publications, images, and products represented past achievements and helped contextualize the historical facets of the stories. The meeting notes represented future 
planning and helped contextualize teacher and administrator stories about their interactions in the new space.

\section{Background of the Problem}

Implementing an innovation such as the makerspace, or attempting a construction project, is fraught with barriers. Parental buy-in, site-based councils with limited representation, teacher turnover, poor professional development, adverse school climate, and overworked teachers are just a few of these barriers. The stressors of a building project can magnify these issues. In this situation, the teachers were expected to demonstrate the advantages of the school's investment in the makerspace and Innovation Alley. Understanding teachers' needs, beliefs and practices may have assisted in manifesting the desired results of the construction project.

Wagner (2001) described teachers as “autonomous craftspeople.” Teachers take pride in their expertise and their products. They see innovations, at times, as fads (Wagner). Research-supported methods of teaching may have advanced, but teachers enter the profession with expectations of stability. Teachers expect to know why changes are necessary, what is being changed, and how they are expected to achieve the innovation. In this study I sought to discover what teachers understood about these expectations, as teacher beliefs and practices might have colored the way in which the innovations were implemented.

Parents and community members at the Apple Tree School had called for a place that encouraged children to create, invent, and experiment. Innovation Alley and the 
makerspace were the result. The space and innovations were further developed through teacher and administrative planning for an integrated science, technology, engineering, arts, and math (STEAM) initiative. This space resided within the lower school, the primary-age education building on the Apple Tree School campus.

A particular value of the school, in terms of curriculum, was the idea of adopting new ideas and curricular artifacts while retaining the best of prior instructional practices. The phrase 'the best of the old and new' frequently cropped up as the area for debate among the educational teams. Determining best practice was a contested subject within the school, however. The brunt of this discussion occurred among the specialist teachers in the context of an integrated STEAM education. In particular, this group was interested in being able to describe how the new space influenced teaching at the school. In light of the new space, they sought to understand the pedagogical decision making, new curricular developments, sustaining of the existing curriculum, revisions to ideas, and sharing of new knowledge with others.

\section{Introduction to STEAM Initiative}

Over the course of the two years prior to construction, the Apple Tree School invited administrators, parents, educators and board members to evaluate the science, technology, engineering, and mathematics programs for greater integration into other curricular areas. Lower school specialist educators in STEAM areas, as well as in physical education, music, art, and world languages, embraced the original initiative and 
continued to be the driving force behind many interests in this area during the study. The initiative, additionally, was a product of the national interest in STEM fields.

Philosophically, the Apple Tree School lower school used the term 'STEAM' both as an inclusive discourse for community members and to highlight community interest in the arts. To describe the applied practice at the school, I used integrated STEAM (Heil, Pearson, Burger, 2013) in this dissertation.

The Apple Tree School's STEAM initiative took advantage of these larger policy discourses as a framework for achieving an educational vision. The direct impact on the STEAM initiative included increased funding for STEAM-related tools, renovations to the lower school, and professional development for educators. The Apple Tree School, as a product of the interactions of these three tangible activities, developed a formative makerspace.

\section{Introduction to Makerspaces}

In the literature (see Blikstein, 2013; Martin, 2015; Sheridan et al., 2014), makerspaces are framed as problem-based, open-ended, playful, and performative learning, operating under the pedagogical influence of noted educators such as John Dewey (1938), Friedrich Froebel (1974), Maria Montessori (1965), and Seymour Papert (1980). Environments within these spaces are described, in line with the learning theories of Lev Vygotsky (1978) and Jean Lave and Etienne Wenger (1991) as including social learning, where participants shift roles as mentor and mentee. Paulo Freire's $(1982,1998)$ critical education theories are further borne out in makerspaces by the idea that making is 
grounded in personally- and socially-relevant problems, where students produce (rather than consume) knowledge. These positions continue to be advanced within maker-based education literature by Martin (2015), Sheridan et al (2014), and Martinez and Stager (2013).

Makerspace, in the Apple Tree School, was defined both by a physical space and by a pedagogical choice in how teaching occurs both inside and outside that specific space. The school's long-standing approach to curricular and pedagogical change focused on an idea of the best of the old and the best of the new. This frames a discussion where innovation and prior practice are equally debated. Further, ideas about makerspaces were heavily influenced by faculty members who had read, Invent to Learn: Making,

Tinkering, and Engineering in the Classroom by Martinez and Stager (2013).

\section{Pedagogical Vision at the Apple Tree School.}

Many of the long-standing curricular activities in the Apple Tree School's lower school have been argued to be 'maker' activities, even if aspects of these activities were more prescriptive. Interested in pursuing a more integrative and modern approach to learning, school leadership and educators have sought to reconcile traditional practices with modern learning. To achieve this goal, several frameworks were already familiar to, and referenced by, faculty and leaders at the Apple Tree School. These frameworks are introduced more fully in the literature review and will be briefly summarized here.

Teachers at the Apple Tree School may use features from both traditional and constructivist models. In line with many teacher preparation programs, the school has 
realigned teacher practices to be more consistent with constructivist principles (Marlowe \& Page, 2005; Woolley \& Woolley, 2004). To that end, these definitions provide a framework for understanding teacher decision making in the classroom. Teacher expectations for learning outcomes, as well as how they plan and structure learning artifacts, are directly impacted by their beliefs about knowledge acquisition as well as their professional development experiences (James, Applefield, \& Martinez, 2001). One such professional development experience that was ongoing at the Apple Tree School was developing a common language for describing design as a unifying feature of an integrative STEAM education.

\section{Definition of Key Terms}

The following is a list of terms used in this study. My definitions were specific to this study and are shared here in order to clarify their usage within my research. Some definitions are repeated, in the context of the study, through the literature review. In order to ease the reading experience, I include a summary of my use of these key terms.

21st-Century Skills - $21^{\text {st }}$-Century Skills refers to a set of cognitive, social and psychological student learning outcomes for schools. As a term, '21st-Century Skills' is a cluster of skills such as collaboration, digital literacy, critical thinking, and problemsolving. These are skills that educational advocates feel schools need to teach in order to support successful students. These advocates of 21 st-century skills favor student-centered methods - for example, problem-based and project-based learning - that allow students 
to collaborate, work on authentic problems, and engage with the community (Rotherham \& Willingham, 2009).

Constructivism - Constructivism is an example of a theory of knowledge.

Constructivism theory argues that humans generate knowledge and meaning from the interaction between their experiences and their ideas. A constructivist-inspired environment is designed to encourage collaboration, prediction, hypothesizing, manipulation of objects, asking questions, researching, investigating, and inventing (Dangel, 2013).

Constructionism - Constructionism is an example of a learning theory. It is characterized by co-learning theory and is a theory of instruction. Constructionist theorists state that knowledge-building best occurs through the creation of things that are tangible and shareable (Ackerman, 2009). In an early childhood program, this might translate as students using sand tables, markers, and block shapes to form the symbols for letters and numbers, then sharing their versions with one another. Elementary-level children might use manipulatives to show place value and compare their mathematical understandings. Older students might build a robot together in order to learn about engineering and coding.

Makerspace - A makerspace is an example of a way to design learning spaces for children. The makerspace is a physical location within an educational organization that is designed to foster learning. In Makerspace Magazine, Dougherty (2005) defines a 'makerspace' as a physical place where young people have an opportunity to explore 
their own interests, learn to use tools and materials, and develop creative projects. This place may be embedded within an existing organization, or a standalone space. It could be a simple room in a building or a separate space in an outbuilding, but the key to the makerspace that it can adapt to a wide variety of uses and can be shaped by educational purposes, as well as the students' creative goals. The Library as Incubator Project (2013) describes makerspaces as collaborative learning environments where people come together to share materials and learn new skills. Makerspaces are not necessarily born out of a specific set of materials or spaces, but rather a mindset of community partnership, collaboration, and creation.

Professional learning community (PLC) - A professional learning community is an example of a collaborative community designed to help educators be better teachers. The key purpose of a professional learning community is to ensure that educators committed to working collaboratively in the ongoing process of collective inquiry and action research achieve results for the students they serve (DuFour, DuFour, Eaker, \& Many, 2006). I describe the participant-community at the school through the theoretical lens of a professional learning community in the literature review and rely on this definition for framing my approach to my colleagues.

STEM - Science, technology, engineering and math (STEM) education is an area of study, but it is also a way of teaching and learning that is project-based, collaborative, and focused on solving real-world problems. STEM programs, in education, tend to emphasize students activities involving innovating, problem solving, critical thinking, 
and creating (Burke, 2014; Sanders, 2006; Sanders \& Wells 2005; Wells, 2008; Wells \& Ernst, 2012). Researchers refer to STEM both to indicate a belief in the importance of developing these topic areas and as a framework for teaching these subjects (RootBernstein \& Root-Bernstein, 2011; Sanders, 2009; Weissmann, 2013). STEM is used interchangeably to articulate ideas about careers and jobs as well as to refer to a wide range of educational beliefs (Angier, 2010; Lantz, 2009). STEM, in the context of education, more frequently relates to curricular aims rather than actual careers in STEM fields but may also have been used by participants to indicate the latter.

Integrated STEAM - Integrated STEAM is a more specific curricular lens for approaching STEM education, and includes content across all STEM fields and the arts. An extended acronym of STEM, STEAM includes the idea that the arts fit within the skillsets developed in STEM. Integrated STEAM pedagogy includes ideals of curricular integration throughout learning environments (Root-Bernstein \& Root-Bernstein, 2011; Sanders, 2009; Weissmann, 2013). Based on this definition, STEAM is a framework of beliefs around the teaching of these subjects.

Teacher Beliefs and Practices - Teacher beliefs and practices refers to beliefs that inform the choices teachers make, and the traits that teachers exhibit in their teaching practice that seem to align with these beliefs. In this study, 'teacher beliefs and practices' refers to the complex beliefs that underpin what they do in the classroom, i.e., their teaching practice. These beliefs impact how change occurs (De Corte, Vershaffel, \& Depaepe 2008). Teachers' beliefs and practices connect to their backgrounds, especially 
their professional education (Fullan \& Hargreaves, 1993). This background shapes the filter through which teachers perceive aspects of learning, teaching, assessment and environmental use, often through interpreting student activity and behaviors (Harootunian and Yargar (1980). Based on these ideas, as well as Fang's (1996) literature review linking beliefs and practices, I define teacher beliefs and practices as a single concept in order to articulate the agency of teachers in their use of the new space. I do this in part because the articulation of the use of space during interviews was mostly theoretical. There were few statements that indicated existing practices, but participants were able to articulate their planned practice. Additionally, participants were not always clear about the difference between their beliefs and their practices. By viewing these items as one concept, I was able to develop a stronger picture of the developing community within the context of the innovation.

\section{Chapter Summary}

The purpose of this narrative case study was to document teacher beliefs and practices of learning and teaching at the Apple Tree School lower school program, in light of the implementation of Innovation Alley and the makerspace. This study focused on teachers' voices, and on their beliefs and practices in interpreting the impact of this space. Drawing from interviews, curricular artifacts, meeting notes, and surveys of instructional leaders and educators, this study presented the developing framework of the STEAM initiative's makerspace and its influence on teaching and learning in a small independent K-8 school. My case study has been designed to help educators reflect 
deeply and thoughtfully on their curricular implementations. In addition, another goal was to serve as a guide for the school's instructional leadership in implementing further programs within the school. 


\section{CHAPTER 2: Theory and Background}

As I described in the previous chapter, my aim in this study was to discover how the makerspace and Innovation Alley (IA) renovations influence lower-school teachers' beliefs and practices. The purpose of this study was to describe how the makerspace concept and classroom (or instructional space) physical changes might have influenced teachers' beliefs and practices as they developed the curriculum, sustained the past curriculum, revised ideas, and shared knowledge with others. Specifically, I wanted to understand what, if any, changes occurred in my colleagues beliefs and practices within a changed environment. Gaining my desired understanding required exploring the epistemological literature, theories of teachers' professional development, and studies on the impact of environment on learning. This understanding helped in the advocacy and facilitation of science, technology, engineering, arts and mathematics (STEAM) activities. My perusal of research on this topic, as interpreted in this literature review, explained the context of STEAM at our school at the time. While the goal was to see how teachers integrated the STEAM curriculum in the makerspace and environment, the ultimate objective was to leverage these findings towards helping students achieve success in the modern, 21 st-century skills environment.

Due to the emergent and developing nature of the context, I chose to follow a qualitative research methodology. Narrative case study allowed me to privilege educator voices and helped me in seeking to situate and represent these interactions. In this 
chapter, I describe the literature that pertains to the wider context, the literature supporting narrative case study, and the specific methodology I employed.

This chapter is constructed in three sections. In the first section, I present the theoretical framework based on the literature. I then describe how I used the theoretical framework, and end with a critique of this framework in relation to the problem. In the second section, I review research that relates to how the makerspace concept and classroom physical changes might have influenced teachers' beliefs and practices as they developed the curriculum, sustained the past curriculum, revised ideas, and shared knowledge with others, showing the utility of this study in relation to the current body of scholarship. I also reviewed current themes, inconsistencies, and the significance of the research into makerspaces, physical space, and teachers' beliefs and practices. In the third section I look at the methodological literature related to my chosen method, the narrative case study. In this final section, I provide the justification for my research method and transition this narrative from the literature into Chapter three, which describes my methodology.

\section{Theoretical Framework}

In this section I divide my theoretical framework between two constructs. First, I share my overarching framework, which is social cognitive theory. In this section, I set out to frame the idea of this new innovation as an interaction between the physical space, the people, and the curriculum. In the second section, which deals with teachers' learning and professional development community, I describe the process framework I used with 
the metaphor of a lens to articulate the specific way in which I approached the study. In this second section, I describe the process of experiencing the space, each other, and the curriculum.

\section{Overarching Framework: Social Cognitive Theory}

My overarching theory relies on three factors or behaviors influencing learning. Bandura (1989) described a process where personal factors and social environment interact, with the environment influencing behavior and behavior impacting the environment. These three spaces (people, environment, and curriculum) are illustrated in the diagram (Figure 1). The social cognitive theory described by Bandura (1989), when placed in an educational context, may be used to interpret the makerspace, renovations, and teachers' epistemological beliefs and practices. 


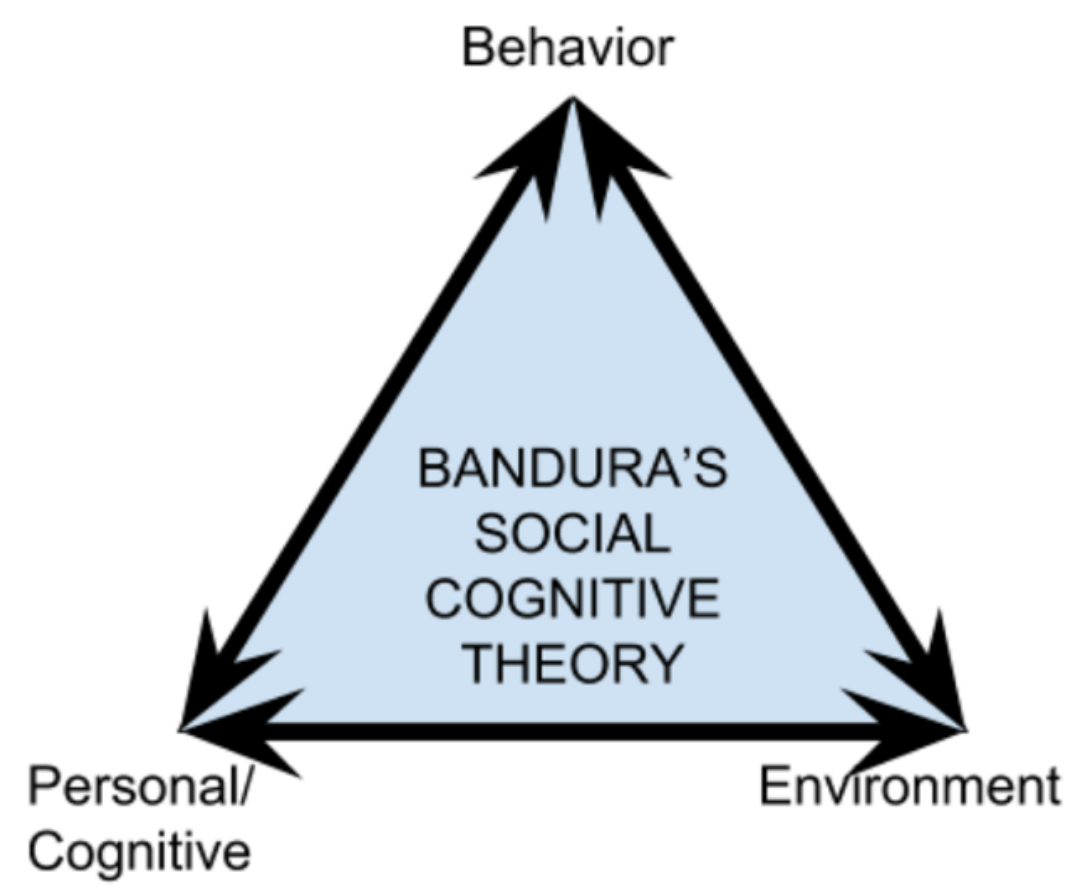

Figure 1. Bandura's social cognitive theory. Based on: Bandura, A. (1989). Human agency in social cognitive theory. American psychologist, 44(9), 1175.

In his social cognitive theory, Bandura $(1977,1989)$ describes learning contexts of three facets that interact dynamically and reciprocally. This framework, however, views some of these facets as more influential than others and does not see them as simultaneous. Specific behaviors, situations, and individuals will have varied interactions (Bandura, 1989). This creates a complex system, social cognitive theory, in which finding the dominant interaction of an outcome requires careful investigation. 
In social cognitive theory there are three bi-directional interactions. The personalcognitive to behavioral interaction involves a person's thoughts, emotions, biological makeup, and actions intersecting with behavior and affects their thoughts and emotions (Bandura, 1977, 1986). In my study, the focus was on the remaining two bi-directional interactions. There is also a bi-directional interaction between environment and personal characteristics, where a person's expectations, beliefs, and cognition are impacted by the physical environment (Bandura). In this process, social influences confer information and affect a person's emotional response through modeling, instruction, and social interactions. Perhaps most interestingly, Bandura (1986) describes the social environment as capable of evoking different reactions due to demographic differences such as age, size, race, sex, and other physical factors. In the third and final interaction between behavior and environment, Bandura describes people as products and producers of their environment. Behavior impacts the facets of environment to which a person is exposed. In turn, behavior is modified by environment. Selective attention, preference, and competencies influence people's choices regarding activities they participate in and who they interact with. Behavior also influences the environment - for example, when someone acts with aggression and creates a hostile environment. In this way, behavior determines environmental outcomes, and environment determines the development and activation of behaviors.

In the context of this study, the latter bidirectional attributes of this model provided me with a direction in which to focus my literature review. I began with types 
of curricular behaviors and theories of curricular behaviors that most-suited the principles and values at my school. Our school culture encourages continued professional development, a move towards projects and constructivist teaching, and an embrace of the marriage of science, technology, engineering, and math (STEM) with the arts (STEAM) as well as languages and social sciences. As the integration of STEAM was a fairly recent objective, I also reviewed literature in this area. One output from the STEAM initiative was the journey towards crafting a makerspace, so I conducted a review of the literature in this area as well. The makerspace was a part of the remodeling project that brought the change in environmental factors. The literature in the area of environmental factors also needed to be reviewed. In the following section, I detail my review of each area. Teacher learning and professional development community. Knowledge acquisition, supported by theories of learning that perceive social participation as key to cognitive growth, requires a community (Bruner \& Anglin, 1973; Coles, 1989; Lave, 1988; Mehan, 1983; Norman, 1980; Rogoff, 1994). This concept was well-represented in my school community. Educators, to varying degrees, responded to the need to participate in community. These varying degrees of interaction had caused some inequities in acquisition of understanding. These inequities bring up questions about what constitutes quality of community.

According to Vygotsky (1978) a community requires both interactions and negotiations. Additional theories describe learning as requiring authentic experience as well as trials with learning artifacts and ideas (Bruner \& Anglin, 1973; Coles, 1989; 
Dewey, 2007). In the context of the remodeling, these interactions and negotiations was magnified. There may also have been a retreat from interactions and negotiations due to stress. Regardless, the remodel is now no longer a theoretical concept in the teacher experience and, hopefully, will influence curricular spaces, even if this was not captured during this case. This assumption was maintained by the study, in that my supposition was that individual faculty members would remain engaged in their community.

In principle and value, the individual educators needed to be engaged, but the means of engagement differed by educator. Individual action is a product of sociocultural context and cultural practices (Newman, Griffin, \& Cole, 1989; Pea, 1993). The school was one part of this socio-cultural context. Teachers at the Apple Tree School shared a common domain, and regularly shared knowledge and experiences as a community of practice (Lave \& Wenger, 1991; Wenger 2003). Work groups or communities of practice $(\mathrm{CoP})$ create and develop ideas based on their context (Lave \& Wenger, 1991; Pea \& Gomez 1994; Wenger, 2003). At the same time, there were additional contexts beyond the culture cultivated at the school. Training programs, specific ethnographic backgrounds, and other specific circumstances brought behaviors into play that transgressed the local, school, and socio-cultural experience.

In the context of schools, teachers exist in a space of formal, informal and independent learning (Jones \& Dexter, 2014). Professional development happens in multiple ways. Formal learning about the makerspace and STEAM initiatives occurred during faculty workshops as a community. Informal learning took place through just-in- 
time learning or team-level research to solve a problem. Independent learning included conference attendance, coursework, and individual research efforts. These examples indicate that learning is fluid, and may flow between formal, informal and independent learning spaces and additional situations not adequately captured by this terminology. Additionally, individuals may very well reject learning opportunities for a variety of reasons. As a result of the confluence of formal, informal and independent learning, the school encouraged and promoted a community of practice (CoP) model.

As a CoP with open educational practice, the Apple Tree School afforded teachers the opportunity to collaborate in different ways (Schreurs et al., 2014). The construction efforts recontextualized the environment to align with our collaboration ideals. Riel and Polin (2004) describe professional development within the CoP context as task-based, practice-based, or knowledge-based (where knowledge becomes explicit through artifacts). During the remodel, this learning may have had more to do with adapting to the demands of construction and interpreting a new environment. Knowledge, practice, and tasks may have been privileged in new ways and restricted in others. Teachers' beliefs, practices and interpretations may greatly help in identifying the agency of CoP during this transition.

Given this professional development context and ideals at my school, I must include the existing research on teachers' beliefs and practices about their curricular success. Harootunian and Yargar (1980) suggest that teachers see their success through the lens of their students' behaviors and activities instead of in terms of themselves or 
external criteria. Fullan and Hargreaves (1993)also found this to be true. Teachers pursue professional development that they believe will improve their effectiveness with students. According to Fullan and Miles (1992) they tend towards pragmatic experiences that relate to daily classroom operations. The school has invested heavily in professional development that addresses these needs, but we are often left wondering about the process of change.

School supported professional development was one avenue pursued by administrators in order to change teachers' beliefs, practices, and focus around some components of teaching. The leaders of the STEAM initiative, in particular, sought to shift beliefs and practices about the desirability of a particular area of curriculum and the makerspace as an instructional innovation.

The relationship between the outcomes sought, and the goals of the integrated STEAM initiative, makerspace, and renovations was detailed and highly complex, with multiple factors that might obfuscate the change process (Guskey \& Sparks, 1996). The initiative, space, and renovations were deliberate and purposeful endeavors that our school instructional leadership had defined fairly well. Referencing the reciprocity of the social cognition model, Guskey and Sparks (1996) indicate that this consideration of outcomes helps to facilitate the desired changes. How teacher perception aligned or did not align with these efforts was undetermined before or during my study.

In some areas, the involvement in planning and commitment from teachers (Jones \& Hayes, 1980) may have been less than optimal. According to Guskey (1989), the 
achievement of a change in teachers' attitudes and beliefs requires clear evidence of improved learning outcomes. Based on these earlier studies, it is possible that not enough time elapsed for teachers to gather enough evidence to change their beliefs based on student learning outcomes. In this case, a follow-up or continuation of the study may be needed in the future. However, this is not practical in the current context, and so my study aimed to find themes that provided a more practical timeframe for evaluating the effectiveness of both curricular and instructional innovations. Still, several studies indicate that teacher commitment, beliefs and practices only change after they are actively engaged in using innovations in their classroom (Bolster, 1983; Huberman, 1995).

Huberman (1995) also suggested that the process of teacher change is more cyclical than linear. As I collected the narrative data for this study, we were experiencing a continually disrupted teaching environment. We were too early in the adoption of the STEAM concepts and too recently exiting the construction phase. If teachers' attitudes and beliefs are, primarily, based on a change in learning outcomes of students, this may point to a stronger relationship between behaviors and the personal/cognitive in Bandura's (1986) model than between either of these features and the environment. The vagueness around these interactions is precisely why this study had the potential to be so valuable to the school in seeking to grasp how STEAM and the makerspace add value to the learning experience.

\section{Content Framework}


For this section, I reviewed definitions and research in four areas of importance to my study. Compared to the previous section on professional development, this portion of the framework is much more concrete. Initially, I reviewed definitions and research relating to the history and ideas of STEM, STEAM, and the integration movement, and the ways in which these notions are important for schools. Integrating STEAM disciplines in the classroom, as revealed by the current literature, requires more study. Next, as a way to provide a framework for understanding the classrooms in this study, I compared traditional and constructivist classrooms. I examined background research on the history and effectiveness of constructivist classrooms (such as project-based classrooms, open classrooms, and other environments). Drawing on this understanding, I reviewed research that seeks to understand the setting that provides the greatest benefit to the STEAM goals described previously. Specifically, I described research into environments that house makerspaces, and those that examine how these environments resonate strongly with STEAM curricular efforts. Teacher beliefs, as evidence indicated in describing professional development, remains of paramount importance in the success of any innovation.

\section{STEM to integrated STEAM}

STEM, as a curricular movement, seeks to integrate and apply knowledge of math and science to create technologies and solutions for real-world problems, using an engineering design approach (Burke, 2014; Sanders, 2006; Sanders \& Wells 2005; Wells, 2008; Wells \& Ernst, 2012). This concept, initially termed 'SMET', was coined in the 
1990s but did not gain wider use in education until 2003 (Friedman, 2005). Originally, STEM was used as a political tool to encourage investment in the fields of science, technology, engineering and math. Since then, fueled in part by concerns that America would fail to compete with China and India's growing economies, funding for education in STEM areas has grown enormously (Friedman, 2005). STEM, as originally understood, did not include an integrative approach. Technology educators claimed the T and $\mathrm{E}$, science educators claimed the $\mathrm{S}$, and math educators claimed the $\mathrm{M}$.

Sanders (2008) redefined STEM as an integrative area and began as a graduate program at Virginia Tech called 'Integrative STEM Education'. Using Learn Science theories of learning (Ormrod, 2012), Sanders and Wells (2005) defined integrative STEM education as the intentional practice of using the concepts of science, math, technology and engineering together, as well as with other subject areas such as languages, social studies, and art. This reframing of STEM that breaks away from the idea of from separate learning disciplines excludes teaching and learning that does not situate purposeful teaching and learning of STEM topics. Technology, by this definition, had to be integral to the learning and not just a mode of instruction. For example, a PowerPoint on cell division does not constitute an integrative STEM learning experience. This reframing, and the inclusion of additional school subjects, moved the notion of STEM from its original meaning as a grouping of disciplines towards a description of a wider pedagogical approach. This move allowed for a shift in the acronym, and the explicit inclusion of the arts as also embodying a design approach. 
STEAM seeks to integrate the arts into STEM by locating natural connections between the different areas of STEM and the arts. While Sanders and Wells (2005) set the agenda for an integrated pedagogy, Bequette and Bequette (2012) made the case for the arts in STEAM as a design discipline. They describe the methods of learning, the concerns of the disciplines, and reliance on design as key dispositions across STEM and art disciplines. Bequette and Bequette's argument rejects the claim that STEAM is just additional jargon by making a strong theoretical claim about both national interest in arts inclusion and the intentions of STEM and the arts.

In seeking to incorporate the arts, STEAM becomes a more integrated model seeking to add greater components of creativity and design into these subject areas. The integrated STEAM concept anticipates a more interdisciplinary model as well as increased student initiative in shaping learning experiences. Integrated STEAM, as described above, supports a variety of learning contexts, especially the informal maker movement.

\section{Review of the Research Literature}

Research in the specific context of redesigning the learning environment to include a makerspace and the impact this has on the teachers' beliefs and practices is fairly sparse. To gain greater focus on the issues of changing the environment I needed to investigate literature discussing moves to STEAM through makerspaces. Additionally, I needed to uncover studies around the use of architecture to affect changes in behavior. I 
then looked at the literature around the types of behaviors I observed. Themes I identified from the data heavily influenced the literature reviewed in the following sections.

\section{Environment: From STEAM to the Maker Movement and Makerspaces}

As defined in the previous chapter, makerspaces provide both formal and informal learning contexts for students to explore technology in relation to STEAM and other interdisciplinary areas (Ferguson, Faulkner, Whitelock, \& Sheehy, 2014). It remains to be seen if teachers' beliefs and practice will shift as students' behaviors in relation to STEAM change. Additionally, enactment of the integrated STEAM and makerspace environment is still in the formative stages. While Ferguson, Faulkner, Whitelock, \& Sheehy (2014) suggest that the learning contexts exist, there is not a definitive statement about the equity of these spaces in achieving the learning objectives.

Dougherty (2005) and Martin (2015) emphasize the democratizing nature of 'making' through cheap hardware, easy access to digital fabrication, and shared software and designs. While this ethos does begin to resolve issues of equity in terms of exposure to a wide range of experiences, it does not address concerns about student growth. If, as the studies on changes in teacher belief suggest, teachers do not see evidence of success in learners through the use of these innovations, then affordable devices, tools, and ideas will not, in themselves, bring success. Luckily, there are studies that have shown the value of the activities that are now being implemented in makerspaces.

Over the last few decades, educators have paid increasing attention to the importance of building or 'making' in education. Papert (1980) critiqued various 
technological tools in the 1980 s according to a collaboration between Resnick, Ocko, \& Papert (1988). In addition to the creation of artifacts as an outcome of learning, researchers distinguish between 'learning through making' and 'school learning'. Papert's (1980) work indicates that the process and innovations around building led to increased attainment of curricular goals. Specifically, informal learning environments such as libraries, museums, and independent non-profits widen our understanding of informal learning in makerspaces. Given this, there does appear to be the opportunity for makerspaces to provide teachers with evidence of increased attainment, which may lead to changes in teachers' beliefs.

Makerspaces focus on the interests of students, and on understanding integrated learning through projects, rather than isolated skills (Halverson \& Sheridan, 2014). This emphasis on process and production over learning tools and skills requires a big shift in mindset for educators. The biggest challenge in integrated STEAM being delivered via a makerspace is the school-based need to define what works, which may lead to a fear of the potential institutionalization of the maker movement (Doughterty, 2005). This fear centers on the concern that the process of adopting a makerspace in a school environment will result in losing the learning benefits and specific practices of successful integrated STEAM makerspace learning. Educator beliefs, resistance to changing practices, and institutional factors may hamper the enactment of this kind of curriculum. At my school we are actively seeking to embrace this innovation but have yet to establish whether 
teacher beliefs and practices have shifted enough to avoid these fears of institutionalization.

The maker movement is described as democratizing STEAM-based learning, and researchers, despite expressing concerns, see potential for empowerment and consciousness raising (Anderson, 2006; Blikstein, 2013). In these studies, the authors show that the scalability, tiered costs, and variety of interests mean that there are plenty of avenues for engaging in STEAM topics through makerspaces. This means that educators can forge their own path in using a makerspace. They can start by implementing ideas that closely align with their current beliefs, and subsequently experiment to a greater degree.

Makerspaces invite varied identities of participation (Wenger, 1998), individualism, and freedom of movement to bring personal identity into learning. In addition to leading the makerspace, educators can be led in the makerspace by students, other faculty, and community members. Experimentation and mistakes, personal meaning making, and building for oneself or for others privilege a wider variety of styles of participation. There is also the ability, through the personalization of the building experiences, to choose to engage in STEAM topics within a personal and cultural context that works for each participant. Whether one is a member of a dominant or marginalized group, a makerspace offers multiple potential ways of approaching learning.

Makerspaces occur in the contexts described above and engage participants in learning engineering, sciences, circuitry, design, programming, and other principles that 
fit into modern learning expectations (Jacobs \& Buechley, 2013; Kafai, Peppler, \& Chapman, 2009; Resnick et al., 2009). Skills such as collaborating with others, effective communication, and the ability to reflect critically are some of the learning outcomes, while abstract STEAM concepts are tackled simultaneously in a concrete way. Students gain the learning outcomes teachers are seeking to identify, although it must be noted that these studies do not cover how teachers identify these outcomes.

\section{Use of space: Architecture and the Influence on Educators}

Returning to Bandura's (1977) idea of self-efficacy and the influence of space, the makerspace's addition to the school may influence teachers and the teachers may influence the space in varied ways. According to this theory, there is an interaction. Cooper (1981), however, explains that a relationship between the design of a space and the behavior of the occupants does not necessarily exist. This disagreement has led to speculation on how much influence the environment actually exerts over the behavior of people in a space.

Additional research suggests that behaviors related to coping may emerge, rather than active management of environments (Horne, 1999). These indications leave room to ponder the significance of social cognitive theory in terms of environment. Coping, as a strategy for dealing with change, may provide clear themes to begin describing the impact of the environment. According to both studies, ignoring changes, retreating to safer instructional practices, and even attrition may be the result of environmental change. 


\section{Traditional versus constructivist classroom environment}

The redesign of the lower school derives from the architect's understanding of open and collaborative spaces (Pellegrini, F. JCJ, personal communication, January 13, 2016). Concepts from architectural literature support open spaces and integrative education environments. This literature provides a useful way to identify markers of progress towards desired philosophical change within classrooms. These markers help greatly, according to Horne-Martin's (2002, 2004; see also Horne, 1999) observational studies in classrooms which suggest that, while pedagogy and environmental organization are linked, it is not clear which is cause and which is effect. Because the school has undergone both physical changes and philosophical shifts; the literature in this area is of great importance. Specifically, the school has long sought to grow in constructivist ideals and provide spaces that match those ideals. This aim has informed efforts at integrated STEAM and, now, the makerspace.

Ahrentzen and Evans (1984) suggested that open classrooms impact educator teaching practices. Their work indicates that, over time, open classrooms led to changes in teachers' behaviors. Agrentzen and Evans (1984) study promises an impact of environmental change on teacher behavior but was unable to detail either the magnitude or the breads of impact. While the architecture company, JCJ (Pellegrini, F. JCJ, personal communication 2016, January 13), described the new space at my school as an 'open classroom', my study does not identify enough characteristics to make comparisons possible. Still, the literature seems optimistic about a connection. 
An earlier study by Rivlin and Rothenberg (1976) found the degree to which environment resulted in change was not as great as expected. Teachers in Rivlin and Rothenberg's study continued to teach from the front and forgo experimental environmental arrangements. It is unclear from the study whether or not the institution as a whole actively embraced these arrangements. This factor may play an important part in the greater, tri-lateral interactions of social cognitive theory.

Educational philosophy, and physical elements that support breaking from traditional environments, are needed in tandem for change to occur, according to another study (Weinstein \& David, 1987). In the study, the authors suggest that it is not enough to merely implement an environmental change, and then expect a subsequent behavioral change. This study provides encouraging evidence, which suggests the efforts of my school may have more of an impact than is suggested by the less-than-positive study preceding it. The specific context of both an environmental change and a cognitive change may result in the desired reciprocal interaction of a change in behavior.

With this in mind, it is valuable to review aspects of the physical classroom environment related to constructivism, as well as components aligned with more traditional beliefs and practices. According to Gray (1995), a constructivist classroom environment is one which consists of learner-driven instruction, in which the teacher provides the experiences and appropriate context for learning. Constructivist teachers strive to encourage inquiry by asking thoughtful, open-ended questions, while encouraging social collaboration among students. Learning experiences are designed to 
challenge students to delve beyond surface information and form a deeper understanding (Sprague \& Dede, 1999). A constructivist-inspired environment is designed to encourage collaboration, prediction, hypothesizing, manipulation of objects, asking questions, researching, investigating, and inventing (Dangel, 2013). In this setting, the teacher's role is to create the context for such experiences, as evidenced through physical indicators such as seating configurations, displays, overall classroom layout, and so on (Gray, 1995). Current research asserts that an environment based on constructivist teaching practices should provide meaningful, activity-based experiences for all learners (Buomova, 2008; Cadwell, 2002; Carter, 2008; Cunningham, 2006; Dangel, 2013; Jones \& Brader-Araje, 2002; Hausfather, 2001).

The traditionalist classroom environment shows characteristics useful for early American industrial skills. Classrooms are typically whole-group, arranged in rows or a U-shape, and are teacher-directed, with content taught in isolation and with little connection between topics (Brooks \& Brooks, 1999). Traditional classrooms give the appearance of efficiency, with limited peer-to-peer interaction (Heckman \& LaFontaine, 2010; Prince, 2004). Teachers moving away from traditionalism may still fall into conventional organizations of space and time (Melhuish, 2011; Upitis, 2004; Usher, 2002). Traditional teaching environments also reduce access to the teacher through separations of space via teacher desks, offices, and other 'non-student' areas as a form of control (Gislason, 2007). In a constructivist classroom, the traditional hierarchy is broken down further, not just in teacher-student interactions, but in professional development 
interactions amongst colleagues (Alterator \& Deed, 2013). Using these concepts as evidence of traditional and constructivist education as markers may help identify a teacher not yet ready for the transition to constructivist curricular efforts.

\section{Introduction to the traditionalist-constructivist continuum}

Educators, faculty, and instructional leaders at the Apple Tree School have varied backgrounds in and philosophies of curriculum and instruction. Professional development activities may focus on constructivist ideas, but not everyone subscribed to this theory of teaching and learning. The community typically defined itself along a continuum of traditionalist and constructivist teaching methods. In this section, I provide characteristics of traditionalist and constructivist methods to help clarify how educators at the school see their role as instructors. The literature in this area may provide context for expanding on and explaining teachers' beliefs and practices.

Traditionalism, defined in large part by direct instruction, step-by-step, and scripted approaches to teaching (Barbash, 2012; Dewey, 2007) confines the student and teacher roles to specific learning interactions. According to Barbash (2012), traditionalism views learning as being the same for all the learners. Teachers plan for, and manipulate environmental variables to achieve learning that is the same for all learners. Features include direct instruction, rote memorization, and repetition to gain the desired response from the learner. In contrast to the goals of a 21 st-century educational outcome, traditionalism does not typically include creative thinking due to the unilateral nature of instruction (Khalid \& Azeem, 2012; Miller, 2008). 
Learning, under traditional pedagogy, is most effectively achieved through lectures, and through designing classrooms that center the teacher-student interaction, rather than peer learning (Barbash, 2012; Beck, 2009). This may involve rows of desks, rather than partner or group desks, and arrangements that orient students towards the teacher on whom they will focus their attention during the lecture. Other features of traditionalism might include worksheets and commercial peripherals (Beck, 2009; Khalid \& Azeem, 2012). Typically, the traditional classroom will lack student projects or documentation of learning. Instead, standardized assessments to measure growth and academic achievement will be used (Khalid \& Azeem, 2012). This may seem to contrast with a constructivist approach, but features of both approaches can be found within the Apple Tree School's primary school learning spaces.

Constructivism, according to interpretations of Piaget's (1977) work, is a theory of learning as a process, with new information reacting to, or interacting with, knowledge gained from previous experiences. Piaget describes knowledge acquisition as creating meaning from environment. The expression of constructivism in a classroom varies, and may be interpreted widely, yet there are several tenets typically associated with constructivist education (LaRochelle, Bednerz, \& Garrison, 2009; Reese, 2001).

Constructivist educators seek out and value each learner's point of view. The educator seeks to know what students think about ideas and concepts. Incorporating student thinking helps teachers plan learning experiences and develop individualized student learning based on interest. Evidence of student learning becomes explicit and 
documented through displays and projects (Evanshen \& Faulk, 2011). Constructivism expects that student enter school with personal experiences that shape their worldview. Educators seek to challenge these suppositions and create environments that encourage students to construct their understanding in a way that is relevant to their own life and experience (Brooks \& Brooks, 1999).

Problem-based learning and real world material are other features of a constructivist learning environment (Applefield, Huber, \& Moallem, 2001; Marlowe \& Page, 2005; Wilson, 1996). Active learning is encouraged, with learners gaining knowledge and skills that they apply to reality. Piaget (1977) described this as a process of meaning-making, with learners actively interpreting their experiences in light of new or pre-existing knowledge. Learners integrate and apply knowledge to gain deep understanding of concepts (The Marzano Center, 2013). There is a high demand on cognitive and critical thinking skills, according to Daggett and Gendron (2010). This body of ideas and research implications guided the identification of themes in my data analysis.

\section{Summary of the literature}

In this literature review, I have gathered the studies that seem to have the greatest significance for the phenomena of renovations, the makerspace innovation, community building, and shifts in teaching (traditionalist to constructivist) I encountered or had ongoing questions about. The framework of the social cognitive model provides latitude for interpretation and privileging the teacher's voice. However, no particular study stands 
out as examining the beliefs and practices of teachers through the context of a renovation and concurrent curricular change as I attempted in my study.

As stated previously, I sought to understand how the makerspace and Innovation Alley renovations influenced lower-school teachers. I wanted to understand their beliefs and practices around teaching and learning. In doing so, I hoped to better plan for professional development, provision of resources, and curricular design. While some research has been done on the integration of STEAM through a makerspace, none has specifically sought to understand how changing the environment in such a drastic way impacts educator behavior.

My data collection highlighted the need for additional areas of inquiry (and a reduction of some areas) in the process of moving from my dissertation proposal to the dissertation itself. I found that I needed to define teacher beliefs and practices more carefully. I also found areas of my literature review that became superfluous on looking at the data. Some areas I removed due to incongruencies, and some I retained because I believe they help to frame this study and indicate potential areas for continued research. This specific population and interaction required the utilizing of environment studies, which went beyond the available research on educational spaces, in order to understand potential themes. This additional research into teacher belief formation and architecture helped me understand and discard themes as I gathered and analyzed data. The curriculum played a lesser role in finding contradictions which helped to explain these themes and facets of the interaction between teacher behavior, environment, and 
cognition. The following sub-questions provided a broad scope for gaining potential insights:

Sub-Question 1. What are the beliefs, practices and experiences of primary educators related to the change in the physical environment as teaching and learning tools?

Sub-question 2. In what ways do educators perceive the redesign as changing how they use physical space?

Sub-question 3. What beliefs and practices, related to 21 st-century skills of collaboration, creativity, critical thinking, and communication, do educators identify as part of the new space?

These questions were intended to help me target the primary question. If there appears to be a negative interaction with my colleagues and the space, my school needs to resolve it quickly. Should there be a positive interaction, we can celebrate this and accelerate other work. Either way, more investigation beckons. Additionally, I expect that teachers' beliefs and practices relating to how the space may support collaboration, creativity, critical thinking, and communication will have a direct impact on future building plans. Our school is in the midst of trying to make future-oriented decisions and this feedback may be vital to the continued growth of the school. The methodologies I chose needed to provide data that would allow the pursuit of these questions and increase the specificity of my research literature.

\section{Review of the methodological literature}


The positioning of narrative research, sometimes referred to as narrative methodology, is described as coming from a literary or narrative theoretical standpoint. It is sometimes considered an extension of ethnography, or even an emergence from the field of psychoanalysis. As interpreted by Galvão (2005), narratives are a way to create new configurations, paradigm-wise, while maintaining existing paradigms. Bolivar (2002), in reviewing the systematization of narratives for research, describes narrative as a way to tell history through narrative reason. Narrative reasoning is a philosophical framework that is both on a par with mathematical reasoning and simultaneously, a resistance to the hegemonic culture of mathematical reasoning (Brum, 2015) I have summarized these ideas (barring errors in my translations) as the notion that knowledge being transmitted through narrative has a place in ethical, methodological and epistemological psychoanalysis for understanding social phenomena.

Addleson (2000) and Craig-Lees (2001) both described narrative research, within these references, as part of modernist thinking. Others view postmodernist thinking, or social constructionism, as the foundation for applying and understanding narrative (Gergen, 1998). Ferrier (1998) moved from a modernist interpretation to one closer to social constructionist thought by describing reality as consisting of multiple perspectives with truth as daily life and social interactions. According to this approach, life is text, and thinking is interpretive. Facts and values, as paired and inseparable concepts, lead to research and human activities that is value-laden. The following methodologies support the use of narrative to gain insight into organization or cultural change (Faber, 1998). 
Riessman (1993) describes narrative as multidisciplinary action matching a qualitative enquiry. The idea is that surveys, questionnaires, and quantitative analysis of behavior are not enough to gain an understanding of meaning within a story. According to Riessman, the focus is on how individuals and groups make meaning from occurrences through an examination of their story. Polkinghorne (1998) provided points in favor of narrative methodology that has led to an embrace of narrative methods by many. Narrative is a literary reconstruction of an occurrence or event that accepts the ideology of an individual and their culture. Literary elements are a network of relationships, not a cause and effect model (Polkinghorne, 1998). Stories provide a holistic understanding of context to allow individual to, through reflection, share personal, historical, and cultural experiences (Gill, 2001). Methodologies should construct human experience and they will be limited in terms of objectivity. Due to the nature of this research as a case study at the beginning of the historical narrative, the findings act more as an outline of the initial few chapters in the story.

To broaden my understanding, I sought studies that specifically dealt with teacher beliefs and practices. Janet Alsup (2006) has conducted research about teacher identity. She collected the stories of six preservice teachers. By examining their educational experiences, family, friends, and teaching experiences, she found various themes relating to their formative professional identity. Her result excited me as to the potential for this case study during a narrative inquiry. In a second study (Sleeter, 2001), I found evidence of the application of narrative research in teacher education through a multiculturalism 
lens. The way this study drew participants into discourses that made experiential interludes connect to strategies though both a narrative and case study lens. Research that offers immediate benefits to those being studied is very appealing both to me personally and in terms of the context of my research. Research that supports practice in an ongoing way is more likely to find traction with my colleagues. Personally I enjoy seeing an investigation yield immediate benefits to participants and the institutions I work with. McNess (2009) conducted a study of four teachers from two different contexts, relating to standardized testing as part of policy. The teachers from different countries (and thus from different contexts and environments) had vastly different responses based on those contexts. The implementation of standardized tests, while the same event type, had a vastly different impact. This study demonstrated the role of context and made me curious about differences in how teachers from a similar school context, but different training contexts, have reacted to the new makerspace.

Knowing and learning, through the lens of narrative, is another additional facet to social cognitive theory. Richert (2002) conducted research on two teachers working with students that did not share their background. The results of the narrative showed that the teachers, through reflection, felt they knew little about their students and lacked opportunities to gain additional knowledge. The teachers in this study were able to articulate both where they were willing to grow and what knowledge they had about teaching. Self-reflection of this sort is already born out in research on teacher education 
(Ball, 2000; Howard, 1999; Villegas \& Lucas, 2002). Self-reflection continues to support the potential for narrative inquiry into my particular problem.

Narrative inquiry has been shown to be effective whether the focus is on place (environment), an idea (curricular innovation), or cognitive context (personal pedagogical beliefs (Clandinin \& Connelly, 1986). Within this case study, the flexibility of focus during the inquiry supports the use of a narrative case methodology under my theoretical framework. These researchers conducted a later study that showed narrative research was effective in drawing out the personal identities of teachers (Connelly \& Clandinin, 1999). Analyzing narratives, as represented by these studies, convinced me that narrative inquiry fit the objective of my study with one outlying problem - time. I have a narrow collection window for this dissertation and no clarity on when the overall inquiry might end. Due to this I choose to frame this dissertation as a case study of the earliest, formative explorations of the overall narrative inquiry. Bounding the research in this way allows for continued exploration of complexity while trying to analyze early data.

In order for this study to be practical, I needed to link the phenomenology to an interpretation method that both allowed for the understanding of a complex issue and focused on a particular time period. Yin (2003) supports the idea of using case studies in this context, and of using multiple sources of evidence as, the method in narrative inquiry. Furthermore, several researchers support case studies as a method of taking something complex and interpreting it within a particular event, subject, or setting (Bogdan \& Bilken, 2003; Soy, 1997). 
Case study design, according to both Creswell (2007) and Yin (2003) supports multiple cases. This is important because in this specific study multiple people are impacted, each with their own case (Stake, 2006). This interpretation of 'case', as well as Clandinin \& Connelly's (2000) explanation of 'narrative case' lead me to using a narrative inquiry to examine a time-bound, multi-case, experiential interaction.

I used multiple, specific methodologies in this study. First, I needed to contextualize teachers' lives within the context of the school and renovations (ChiseriStrater \& Sunstein, 2006). I used multiple collection methods to gain these insights. Observations in the classroom, as supported by Glesne (2011), and the idea that increased participation increases chances to gain knowledge, topped the list. Additionally, I collected documents including slideshows, notes, lesson plans, and photographs that documented classroom activities. Pink (2007) recommended these items that represent the context as aids for the researcher. I used this data to triangulate my classroom observations and interviews, in accordance with Chiseri-Strasser and Sunstein (2006). I also kept a log to monitor my thinking, revisit my observations, and support follow-up on visits.

Interviews are an obvious source of data in a case study. Qualitative researchers generally agree that interview questions need to be open-ended and framed using everyday, common language (Creswell, 2007; Elliot, 2005; Glesne, 2011; Merriam, 2009; Chiseri-Strater \& Sunstein, 2006). As I began with a narrative inquiry framework, I tried to refrain from disrupting the natural emergence of conversations (Elliot, 2005). To 
support natural conversations, Agar (1996) suggested informal interviews. The goal of the interviews was to collect autobiographical narratives, stories that related to renovation experiences and sharing of classroom experiences related to the implementation of integrated STEAM and the makerspace (Clandinin \& Connelly, 2000). As I moved towards a case study methodology, I chose an interview method recommended by Dr Esperanza De La Vega.

In the interview phase of this research, I used a semi-structured format with open ended questions based on Seidman's (1998) suggestions. Seidman suggests a threeinterview format, seeking information about participants' past, current, and future experiences. Interviews in this style, according to Seidman (1998), allow for reflection on experience. Researchers agree that asking participants to share themselves, their experiences, and their stories requires a great deal of trust and respect for all involved (Clandinin \& Connelly, 2000; Glesne, 2011). As I was studying how educators experienced renovations and curricular shifts, I was not expecting simplicity (Connelly \& Clandinin, 1996). Experiences are complex and messy, and the educators I studied were living the stories they were relating. It was important for me to acknowledge the presences of multiple stories and to seek to uncover and interpret the construction of meaning in these.

\section{Summary of Research Literature and Application to the Study}

Narrative methodology is a unique way to go about uncovering teachers' beliefs and practices relating to environmental factors. It also privileges the educators' voices in 
a context where they may feel silenced. Renovation projects are stressful and can cause distancing between those responsible and those who are expected to benefit (Gray, 1995). This research approach offers an initial insight into whether or not educators are picking up on past and present school-directed initiatives. The narrative case study method, in conjunction with the three-interview format, has given me the opportunity to both study and support the participants and the wider school community.

In the next chapter I will discuss the specific methods I used to understand how teachers' beliefs and practices were influenced by the new space, makerspace, and STEAM program. In addition, I will provide greater detail about how I interpreted and shared my colleagues' beliefs and practices. 


\section{CHAPTER 3: Research and the Space}

This dissertation discusses both a change in the school environment (the building of Innovation Alley) and a curricular innovation (the makerspace). I sought to examine primary school educators' beliefs and practices in teaching and learning at a K-8 independent school, the Apple Tree School, on the East Coast of the United States. The purpose of this study was to describe how the makerspace concept, and physical changes to the classroom or instructional space, influenced teachers' beliefs and practices as they developed the curriculum, sustained the existing curriculum, revised ideas, and shared knowledge with others.

The prior chapters set the background for this research. In Chapter One, I described both my own narrative and the school's narrative, highlighting the significance of doing this research. In Chapter Two, I built on this framework, outlining a literaturebased conceptual framework within which to work, and described other research that helped to inform this study. In Chapter Three I discuss the structure and methodology with which I examined and shared my colleagues' and my school's narratives. I have previously described the setting (Innovation Alley) and the topic (how teachers' understanding of their pedagogy and practice may be influenced by changes in environment) and will now discuss the details of this study. This narrative inquiry influenced case-study (situated within the field of educational research, methodology, and the specific context of the Apple Tree School) examined potential interconnectivity between environments and teacher practice. 
The physical classroom environment may potentially impact student engagement and skill development (DeVries, 2002; Heller, Calderon, \& Medrich, 2003; Klem \& Connell, 2004). Considering the demand for learning that aids students in developing 21 st-century skills such as cooperation, critical thinking, communication, and creativity, a makerspace (as a constructivist-inspired environment supporting integrated STEAM educational ideals) may be a valuable tool for meeting the needs of learners developing these skills. This research aimed to gain an understanding of the perceived role of the space and reactions of teachers to the addition of these spaces. More simply, when do teachers control the space and when does the space control the teacher? To attain this understanding, I triangulated data focused on teacher practices and beliefs, evaluations of the use of the physical environment, and field notes and photographs of the physical environment. In this first section I will discuss research methods, instruments and measures, the researcher's role and participants' roles, the procedures used, and the data collection and analysis.

\section{Research Methods}

In previous chapters, I expanded on my rationale for choosing qualitative methods, as I found myself less interested in the use of discrete variables to measure teachers' reactions to a change in environment or their epistemological beliefs. To understand the affective impact of these changes, I felt that quantitative methods were inadequate in understanding the social component of the experience of change. To gain 
insight into how social interactions played into teachers' beliefs and practices, I used research methods from a social constructivist perspective.

In his social cognitive theory, Bandura $(1977,1989)$ describes learning contexts of three facets that interact dynamically and reciprocally. This framework, however, views some of these facets as more influential than others and does not see them as simultaneous. Specific behaviors, situations, and the individual involved will have varied interactions (Bandura, 1989). This creates a complex system, social cognitive theory, where finding the dominant interaction of an outcome requires careful investigation.

To understand teachers as active agents of curriculum development and classroom experiences during and after construction, I needed to use methods that allowed for detailed exploration while being supported evidence-based research (Creswell, 1998; Elbaz, 1983). Lacking specific variables, but using Bandura's social cognitive theory as a lens to understand teachers' personal knowledge and the impact during an environmental change, emergent qualitative methods allowed this exploration. Quantitative methods would be insufficient to address and reveal answers with such exploratory research questions, or would require a prohibitively large research base (Creswell, 1998).

My goal in this research was not to detach from the experiences of this group of educators, but rather to listen, observe, document, and share the experiences of this specific group, both in the context of the group and in the context of their interactions with the space. Qualitative research, in this case and generally, takes place in a naturalistic setting, with the researcher studying naturally occurring events (Bogdan \& 
Biklen, 2003). My job, as narrator, was to describe the experiences of teachers in adapting to a new space (Innovation Alley) and the experiences that impacted my colleagues' beliefs and practices. This narrative needed to clearly highlight teachers' voices, broaden understanding of the impact of environmental change in teaching and learning, and reflect the personal journeys of meaning-making of the teachers in relation both to each other and to the space (Eisner, 1998; Elbaz, 1983). Lincoln and Guba (1985) described this as naturalistic inquiry; that is, to make sense of an experience and share stories.

Knowledge and theory emerge within the context of inquiry through qualitative research methods and naturalistic inquiry, and not through an a priori theoretical framework (Lincoln \& Guba, 1985). Directions, themes, and knowledge are allowed to emerge in an open-ended naturalistic inquiry without strict parameters. Absolutes are discarded as a concept (Clandinin \& Connelly, 2000) and this allowed me to stay open to complexities and possibilities within the experiences of educators. Qualitative methods allowed me to exist with ambiguity and to learn as the research progressed (Bateson, 1994). Collecting and analyzing participant stories in the setting of the environmental change provided context and allowed narrative data to emerge, develop, and unfold (Lincoln \& Guba, 1985). In making the beliefs, practices and processes of this group of teachers visible as they reacted to the change in environment, I witnessed the process as their personal knowledge emerged, shifted, and developed (Lincoln \& Guba, 1985).

\section{Narrative Case}


The research design for my study was a qualitative approach, using a narrative case study. The intention was to explore the change experiences of four lower school educators, as they experienced construction work and the addition of a makerspace, in terms of their beliefs and practices. This study took place over two months, with participants who were directly impacted by the construction and the addition of the makerspace. The research procedure for each case study was replicated and, although this resulted in non-generalizable results, the user of the research may determine potential transferability (Yin, 2003). The study was limited by the selection of the participants, my relationship with each of the participants, the participants' level of meaningful interaction with the space, and the school's scope for allowing research and data collection. An additional limitation existed in the unanticipated incomplete nature of the actual construction by the time the study was scheduled to begin.

Engaging in the natural school setting, I was able to actively make sense of the teacher's experiences with them (Denzin \& Lincoln, 1994). I also expanded my knowledge of the environment and of makerspace. Greene (1995) supports the use of case studies in this instance, by privileging multiple modes of seeing, interpreting and experiencing the influence of the new space. The questions and issues of significance to the participants were also addressed in this type of study. This narrative case study demanded active and knowing involvement in the inquiry. Participants shared their narratives and exposed multiple perspectives, knowledge, and thought, through interviews, observations, notes, and surveys. 
Participants included members of the STEAM initiative, such as instructional administrators and special subject area educators. Each participant was a volunteer. As this was a narrative case study, participants had an influence over the areas of focus, data collection, the organization of data, the analysis and interpretation of the data, and taking action during the course of the study (Clandinin \& Connelly, 1986).

Over the course of engaging in this study, and as a result of advice from colleagues and mentors, my plans for interpreting the data shifted. My original approach to this study was one of pure narrative inquiry. Instead, in order to investigate a specific point in the process more thoroughly, a case study was used in conjunction with the narrative approach (Clandinin \& Connelly, 1996; Clandinin \& Connelly, 2000; Riessman, 1993; Wells \& Ernst, 2012). Due to this, the participants in the study were instrumental in adding their voices in a pluralistic understanding of constructing knowledge and enacting change (Chambers, 2008), but the results were collected within a specific case during a specific time. The school's climate and culture required participant involvement in the research process. This allowed participants to reflect on their curricular choices and experiences amidst the ambiguities of a remodeled space, and to share their own theories and questions. According to Chambers (2008), this deepens feelings of ownership and control, which in this case helped transform this research from an additional stressor to a potential support structure. The nature of the study allowed for the narrowing of the scope to a specific moment in the process. The research design for my study was a qualitative approach using a narrative case study. The intent was to 
explore the change experiences of four lower school educators, as they were influenced by the addition of a makerspace and new construction, in terms of their beliefs and practices.

This study took place over two months, with participants directly impacted by the construction and makerspace. The research procedure for each case study was replicated and, although this resulted in non-generalizable results, the user of the research may determine potential transferability (Yin, 2003). The study was limited by the selection of the participants', my relationship with each of the participants, the participants level of meaningful interaction with the space, and the school's scope for allowing research and data collection. An additional limitation existed in the unanticipated incomplete nature of the actual construction by the time the study was scheduled to begin.

The change in environment at the Apple Tree School provided an opportunity to examine how environment impacts educator thoughts and practice. This context calls for research methodology that relied on traditional qualitative methods. As a researcher, I must show what I discovered in the course of this study in some way (Eisner, 1998) and maintain fidelity and reliability in relation to my topic and research questions. Language is a common medium that provides the primary way to broker and express change for me and the teachers with whom I conducted the study (Eisner, 1998). I used the narrative case to express my experiences and those of teachers in this qualitative research study. According to Polkinghorne (1995), narrative is the best etymological mode for representing situated experiences of individuals and constructs in qualitative research. 
Narrative, as discourse, frames events and experiences into a classifiable whole (Polkinghorne, 1995). I felt that narrative provided a research context in which I could document events, experiences, and knowledge from a specific group of educators within the changed environment and teaching context (Clandinin \& Connelly, 2000; Polkinghorne, 1995). As a narrative case study I gained less story and more of an outline for the rising action in a longer story. Narrative, as an etymological mode, serves to explain teacher experiences and the connections they make between the environment, teaching, and learning, while allowing me to embody the knowledge and information about teaching in a changed environment from the perspective of a teacher (Polkinghorne, 1995). In this case study I had some of that benefit but focused more on the emerging themes as related to the research questions to better understand the emerging plot outline.

The elements of narrative, plot, scene, dialogue, and point of view allowed me to represent the confines and strains between personal knowledge and practice (Clandinin and Connelly, 2000; Pokinghorne, 1995). My goal was to use instruments that provide data for filling in these elements. I used interview for the narrative, images to set the scene, and other measures outlined below to achieve this vision of narrative inquiry. I sought to share the story enacted by me and my colleagues in the new space. Human interaction, according to Polkinghorne (1995), is best ensconced in narrative, because narrative is able to capture the classifiable whole: motivations, chance events, and changing interpersonal and environmental contexts. Rinaldi (2006) further describes the 
benefits of the narrative case, from a social constructivist viewpoint, as helping to illuminate learning that is not linear or predictable. Through a narrative case study, I was able to address the complexity of teaching and learning within the context of a changing learning environment. Through this interpretive, naturalistic, narrative approach, I was able to engage with subjects in a natural setting and make sense of the meanings that subjects made of specific phenomenon, while expanding my own knowledge and understanding of the topic (Denzin \& Lincoln, 1994).

\section{Instruments and Measures}

As the researcher, I was an active listener; the means of opening the space for the sharing of assumptions, experiences, contextual understandings, common knowledge and aims. A variety of qualitative data and documents were collected. The following data collection instruments were triangulated: a) field records, including participant observations and documents; b) semi-structured interview transcripts; and c) document analysis of teaching practices through survey and demographic information relating to my colleagues. All items collected were analyzed to examine the emergent phenomena of this study (Coffey \& Atkinson, 1996; Lincoln \& Guba; 1985). Finally, I recorded my reflections in a research journal. The multiple data sources collected throughout this process were collected with the signed consent of the participants and in full compliance with the Human Subjects Review Board guidelines and the past head of school and school board's review. 
In accordance with qualitative research tradition, and more specifically with the storied narrative of qualitative textual data and an inquiry-based approach to education and research, this research seeks to "contextualize experience and personal knowledge through narratives and other genres" (Coffey \& Atkinson, 1996: 54). Documentation is a collection of documents and data that is interpreted and used as a valuable tool for recalling, and provides a space to reflect upon and tell the story of a learning experience (Rinaldi, 2001; Stacey, 2011). Given the collaborative nature of this study, documents, data, and analysis were grounded in the everyday realities, meanings, and interactions between me and the teachers, none of which were predetermined or prescribed (Lincoln \& Guba, 1985). Given the nature of this particular study, and the established relationship between me and my participants, data collection and analysis was a collaborative process with varied levels of participation. Additional items were also shared by the teachers as part of the learning process.

The intention was, of course, to answer the research questions, as follows:

Central Research Question. What influence does the physical addition of the makerspace have on teaching and learning beliefs and practices of primary school educators at a K-8 independent school on the East Coast of the United States?

Sub-Question 1. What are the beliefs, practices and experiences of primary educators related to the change in the physical environments as teaching and learning tools? 
Sub-question 2. In what ways do educators perceive the redesign as changing how they use physical space?

Sub-question 3. What beliefs and practices, related to 21 st-century skills of collaboration, creativity, critical thinking, and communication, do educators identify as part of the new space?

I collected data throughout the course of the study in a variety of forms, including: my researcher journal; a survey of teacher demographics; three semi-structured interviews; observations; and participant documents. Below, I describe each of these data collection instruments. Figure 3.1 illustrates how the questions connect with specific interview questions.

Researcher journal. I kept a reflective journal, separate from other data, that helped me process my own construction and reconstruction of knowledge throughout the data collection period and throughout the analysis process. These notes were kept separately from other documents in an electronic file on my personal computer. Records from the field included agendas for meetings. Meeting records themselves were rare due to the nature of interruption and the variety of non-Innovation Alley topics that were discussed, as well as non-study-based involvement in these meetings.

Survey of teacher demographics. Participating teachers shared demographic data through a survey I developed (see Appendix A). This instrument was offered after the interviews and the survey responses, as the last part of the data collection. This researcher-developed survey collected the following information: 
Name

Level of education

Highest degree earned

Formal makerspace or STEAM education and explanation

Years in elementary education

Years at the Apple Tree School

Years in STEAM education

Number of renovations or classroom moves experienced

Satisfaction with the Innovation Alley project (scale of 1-10)

This survey was developed for the purpose of collecting basic demographic information, such age and education, from participating teachers. Additional questions sought information that described participants' experience in the field and in specific contexts, as well as a general prompt about their satisfaction with Innovation Alley. Questions were short and require concise responses in order to ensure accuracy and completion of the surveys. I also reviewed the questions in order to evaluate the appropriateness and necessity of each question. The demographic information provided context for the participant experience. Pseudonyms were used to identify participants in order to maintain confidentiality.

Each component described above provided an indicator of teacher preparation and experience, and was an important factor to examine in relation to teacher beliefs and practices. According to Horm-Wingerd and Hyson (2000), an awareness of the impact of 
teacher demographics is of value to the study and the implications of teacher beliefs and practices.

Semi-structured Interviews. Interviews are a purposeful conversation, according to Kahn and Connelly (1957) and a way of formalizing the everyday practice and interactions between individuals involving asking and answering questions into a research method (Mischler, 1986). This is a common data point in qualitative research (Marshall \& Rossman, 1999). Using Seidman's (1998) three-interview format, seeking information about participants' past, current, and future experiences, I planned for three, forty-five minute, interviews (Appendix B). Both the recordings and transcriptions were saved as electronic files on my computer and on an external hard drive. Transcribed interviews were shared with participants to allow for member checking, and to support the extension and continuation of the continuum of experience and dialogue between me and the participants (Lincoln \& Guba, 1985).

I sought interviews that reflected conversations, rather than formal events, and tried to allow the participants to shape the conversation for the most part (Marshall \& Rossman, 1999). The discourse of the interviews was shaped and organized by the posing of questions and the emergent dialogue between me and participants - a focused conversation (Marshall \& Rossman, 1999). Appendix C (Table 1) provides a table representation of how the interview questions focused the research questions towards this desired dialogue. Conversations reflected a level of equality between participants not 
found in formal, structured conversations with predetermined questions. Instead, they allowed questions and topics to emerge (Clandinin \& Connelly, 2000).

\begin{tabular}{|c|c|c|}
\hline Central Research Question & & Interview One Questions \\
\hline \multirow{2}{*}{$\begin{array}{l}\text { What influence does the physical } \\
\text { addition of the makerspace have } \\
\text { on teaching and learning beliefs } \\
\text { and practices of primary school }\end{array}$} & SQ 1 & What is a good teacher? \\
\hline & SQ 1, 3 & $\begin{array}{l}\text { How would you describe your beliefs regarding } \\
\text { teaching? }\end{array}$ \\
\hline \multirow{4}{*}{$\begin{array}{l}\text { educators at a K-8 independent } \\
\text { school on the East Coast of the } \\
\text { United States? }\end{array}$} & SQ 1, 3 & What is a good student? \\
\hline & SQ 1 & Describe your preparation for teaching. \\
\hline & SQ 2 & $\begin{array}{l}\text { Discuss your previous teaching space and how } \\
\text { you feel about its success and your ability to use } \\
\text { it. }\end{array}$ \\
\hline & SQ 1 & $\begin{array}{l}\text { What would you consider most important to your } \\
\text { practice as an educator? }\end{array}$ \\
\hline Sub-Question 1 (SQ 1) & & Interview Two Questions \\
\hline \multirow{2}{*}{$\begin{array}{l}\text { What are the beliefs, practices } \\
\text { and experiences of primary } \\
\text { educators related to the change in }\end{array}$} & SQ 2 & $\begin{array}{l}\text { What is your understanding of the Innovation Alley } \\
\text { Project at this point? }\end{array}$ \\
\hline & SQ 2, 3 & $\begin{array}{l}\text { How does Innovation Alley make you think about } \\
\text { teaching and learning? }\end{array}$ \\
\hline
\end{tabular}




\begin{tabular}{|c|c|c|}
\hline \multirow[t]{3}{*}{$\begin{array}{l}\text { the physical environments as } \\
\text { teaching and learning tools? }\end{array}$} & SQ 1 & $\begin{array}{l}\text { How does it support your ideas and beliefs about } \\
\text { teaching and learning? }\end{array}$ \\
\hline & SQ 3 & $\begin{array}{l}\text { How does the makerspace fit into the curriculum } \\
\text { of your current classroom? }\end{array}$ \\
\hline & SQ 2 & $\begin{array}{l}\text { What aspects of the renovation do you feel most } \\
\text { comfortable with? }\end{array}$ \\
\hline & SQ 2 & $\begin{array}{l}\text { Discuss the new space and how it fits (or does not } \\
\text { fit) with your teaching practice: }\end{array}$ \\
\hline Sub- Question 2 (SQ2) & SQ 3 & $\begin{array}{l}\text { How does the makerspace or STEAM initiative } \\
\text { help (or not help) your progress in learning how to } \\
\text { use the space? }\end{array}$ \\
\hline \multirow{2}{*}{$\begin{array}{l}\text { In what ways do educators } \\
\text { perceive the redesign as changing } \\
\text { how they use physical space? }\end{array}$} & SQ 2 & $\begin{array}{l}\text { Currently, what teaching practices do you find } \\
\text { yourself relying on the most? }\end{array}$ \\
\hline & SQ 2 & $\begin{array}{l}\text { Does anything about the space influence your } \\
\text { beliefs about teaching? }\end{array}$ \\
\hline Sub-question 3 (SQ3) & & Interview Three Questions \\
\hline \multirow{2}{*}{$\begin{array}{l}\text { What beliefs and practices, } \\
\text { related to } 21 \text { st-century skills of } \\
\text { collaboration, creativity, critical } \\
\text { thinking, and communication, do }\end{array}$} & SQ 1 & $\begin{array}{l}\text { What would further support your understanding of } \\
\text { the makerspace or Innovation Alley? }\end{array}$ \\
\hline & SQ 1,3 & $\begin{array}{l}\text { What materials would further support your work in } \\
\text { Innovation Alley? }\end{array}$ \\
\hline
\end{tabular}




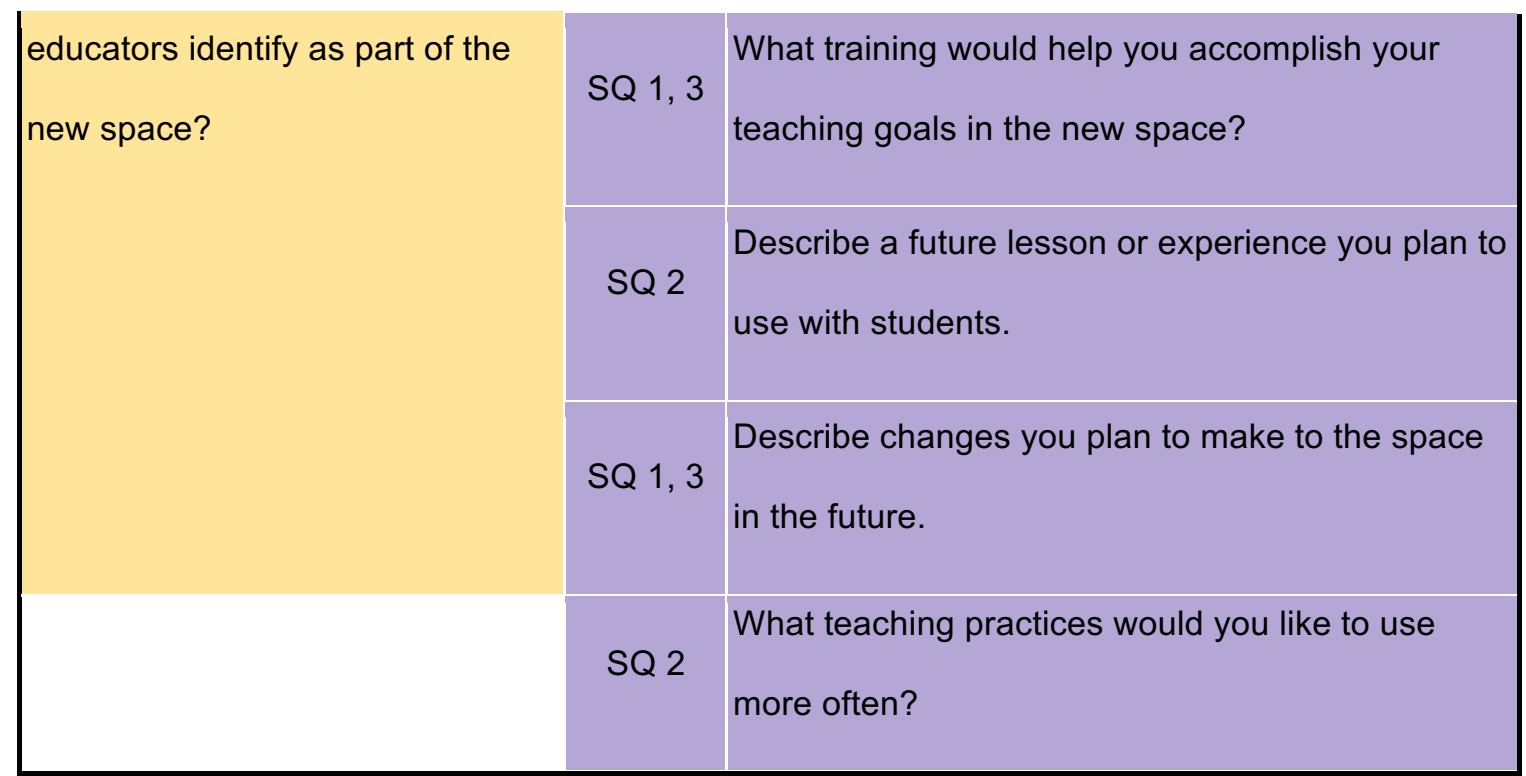

Table 1. Research Questions \& Interview Matrix, showing the research questions aligned with the various interview questions.

Observations. A variety of field notes and observational records support, and are more consistent with, a narrative case study (Clandinin \& Connelly, 2000). This diversity was supported by my reliance not only upon my own observational field notes, but that of the participants. I, as participant observer within the context of meetings, continued to take detailed running notes of the conversations, questions and interactions that occurred relating to our use of Innovation Alley. Due to already being embedded in this context, I was a “complete participant observer" (DeWalt, DeWalt \& Wayland, 1998).

My field notes taken within the environmental/classroom setting preserving context for participant interviews, with a focus on the environment, and were taken in a variety of forms. 'Field notes' in this context are qualitative notes that I recorded during 
my research into teachers' beliefs and practices in relation to the changed environment, and were intended as evidence to aid in understanding these beliefs and practices (Clandinin \& Connelly, 2000). Taking into account that my field notes placed the participants at a single moment within the classroom, I recognized the need to complement my field notes and texts with those taken by the participants, allowing for multiple perspectives and also providing a broader lens through which to interpret our experiences. Multiple reporters of participant observation notes helped open up the research space to support the "ambiguity of working within an open and boundless threedimensional inquiry space" (Clandinin \& Connelly, 2000, p. 95) between the researcher, the participants, and the pedagogical space. I collected this information throughout the data collection period in a variety of forms, both electronic (saved in electronic files on my computer and backed up on external high drive) and hard copies (kept within a project research binder), as volunteered by the participants.

Participant observations. Participant observation supported my immersion into the setting, allowing me to truly experience the reality of the participants' experiences by spending considerable amounts of time with them. This also gave me the opportunity to learn directly from my own experiences within the research setting (Marshall \& Rossman, 1999). In this case study, participant observation through narrative inquiry established a relationship through which field notes and texts could be interpreted and collaboratively constructed, as opposed to researcher driven or controlled (Clandinin \& Connelly, 2000). Participant observation field notes were kept by me to both reflect the 
emergent content of meetings and interviews and to document the events, discussions, and experiences that occurred.

Participant data collection and records. To maintain consistency and reliability to my research questions and the nature of this inquiry, this research did not rely on my singular data collection and documentation. I requested documentation volunteered by participants as a means of contextualizing this research as much as possible, making the voice of teachers heard, and maintaining the need for multiple perspectives and interpretations of our joint experiences (Clandinin \& Connelly, 2000). This included lesson plans, images, and other documents that my colleagues deemed valuable. Documentation made visible the learning that occurred as the result of the teachers intentionally and systematically planning for such learning experiences. The specific choices of items shared also reflected the beliefs and practices of participants.

\section{Role of the Researcher}

As the author-researcher, I was the primary data collector and interpreter of the research. Creswell (2007) describes the responsive human component of this setup as both an advantage and disadvantage. This responsiveness is an advantage in terms of my ability to understand verbal and nonverbal communication, process reflectively, and request clarification. Disadvantages include my potential biases and subjective perceptions (Creswell, 2007). Narrative perspective introduces some uncertainty and tentativeness, given the multitude of alternative interpretations of events and ways of explaining phenomenon. As researcher, I tried to draw together multiple beliefs and 
practices, events, and actions within my setting (Polkinghorne, 1995). Due to this, it is important that I address my relationship to the phenomenon I hope to study.

Before beginning the study, I had 19 years of experience in a variety of educational contexts, experience from previous research activities, and a curiosity and interest in teachers' beliefs and practices relating to the makerspace and Innovation Alley's impact on teaching and learning. This comes from my varied environmental experiences and from witnessing adaptations made by educational professionals. Adaptations (or lack of adaptations) seemed to relate to educators' beliefs, but I would also notice, especially early in my career, that some architectural influences were ignored. These dynamics both confused and greatly interested me. My training and experiences certainly led to a lot of exposure and fed this curiosity.

In some ways, my formal training has enhanced my opportunities to see multiple contexts. I hold a Bachelor of Arts degree in sign language interpreting with a minor in special education and rehabilitation counseling. As an interpreter with these credentials, I have interacted with hundreds of classrooms and teacher styles. Additionally, I have a Masters in the Art of Teaching and have previously held certifications for teaching in the state of Oregon. These experiences created certain prejudices and biases, and it is important to share these in order to contextualize the way in which I tell this story (Polkinghorne, 1995). As the instrument of the study, my perceptions are also part of the context. 
My interest in this study was piqued by observations of, and participation in, diverse physical classroom designs and varied teaching philosophies of teachers as manifested in classroom layout. Moreover, as one of the educational team tasked with supporting educators in their use of Innovation Alley and the makerspace, I had professional motivation and interest in gaining insights into how I might better support educators within the school's context and goals. Additionally, in conducting my review of the literature, I noticed that the majority of the literature focused on environmental changes that impacted the social and emotional climate such as airflow and lighting, rather than looking at the physical environment as an affordance for teaching and learning, especially in the area of integrated STEAM and makerspaces (Evanshen \& Faulk, 2011; Giachino, 1992 Horne-Martin, 2002; Rivlin \& Rothenberg, 1976). Based to the minimal research linking the physical classroom environment to teaching and learning, I identified a need to include the makerspace concept's role in teaching and learning integrative STEAM. Furthermore, with the continued efforts to achieve the master plan at the Apple Tree School, I am interested in understanding teachers' beliefs and practices in response to changes in the classroom environment.

I am far from objective in this role. Rinaldi (2006) challenges me to take responsibility for my point of view while being aware that I am also shaping my own meanings, deriving some of these conclusions from personal knowledge, observations, and documentations. My actions are not independent variables, since they directly impact 
the pedagogical space of the group and the narrative itself. Neither is this subjectivity isolated.

In my analysis and narrative, the process and meaning-making occur within the context of my school and colleagues' constructions and interpretations of knowledge. Personal and collective knowledge emerges through interactions, relationships, and social construction of understandings. Rather than seek objectivity, I must seek "rigorous subjectivity, by making perspectives and interpretations explicitly and contestable through documentation in relationship with others" (Rinaldi, 2006: 16).

\section{Participants' role}

My colleagues at the Apple Tree School were already involved in the space. They helped me to develop this study by providing ideas, questions, and experiences. They also suggested areas to cover in the literature review and specific avenues of inquiry. After signing the informed consent documents, participants allowed this research to occur while I observed, listened and documented our experiences (Elbaz, 1983; Rinaldi, 2006). Simultaneously, they participated in driving the research. Following the idea that the purpose of this research was to make the complexity of teaching and learning in a changing or changed environmental context visible, removing their contributions as involved participants would have ill-served the narrative (Creswell, 1998; Lincoln \& Guba, 1985). My colleagues listened, documented, and observed their experiences in the school. Their own documentation and subjectivity allowed for sharing observations, photos, text, and additional artifacts that they felt told the story of the environmental 
change in Innovation Alley. Their documentation guided discussion and developed our personal and collective knowledge.

\section{Participant recruitment}

Recruitment relied on purposive sampling, choosing subjects that maximized my ability to discover, understand, and gain knowledge (Merriam, 1998). I hoped to gain understanding and meaning from a select group based on the strength of professional relationships and mentorship, as well as rapport and respect within this membership. Additionally, since there is a vulnerability inherent in agreeing to engage in the research process, a random selection would not be possible within the small context of the Apple Tree School and those few educators involved in Innovation Alley.

As a narrative, this stage introduced the participants (or main characters) as well as additional individuals who played significant roles within the context of this study. All participants were employees of a non-profit, independent school, the Apple Tree School, on the East Coast of the United States. This setting provided the bounded system for the research. The school had recently made significant shifts in vision, and the ongoing construction project was a part of that. 2016-2017 was the second year of construction projects targeting specific capital improvements. The previous year, 2015-2016, had included disruption in an area of the school, known as mid-campus, that was experienced differently by teachers depending on their longevity with the school, according to the divisional administrators. The previous project ended with a renovated community field. 
The Innovation Alley project impacted specific educators in the lower school, furthering the need for purposive sampling.

Involvement with Innovation Alley did not correlate directly with participation in the study. All participants actively chose to participate by signing consent for the data collection, recordings, and the interviews used to retell their experiences in this narrative case study. Participants are identified by pseudonyms. Selection sought for a multitude of perspectives in relationship to Innovation Alley, education background, and professional title. To further protect identities, the school will be referred to as the Apple Tree School, rather than the actual name of the school.

\section{The New Space: The 'Makerspace'}

In this section I will share images and information about the construction and layout of the space. Images and diagrams are intended to help the readers of this study understand the context of the data in the next chapter. The first diagrams detail the change in layout. The images following include some construction pictures, as completion of the project and this study overlapped.

It can be seen in Figure 2 that there was a narrowing of the hallway to increase the width of the resulting reading pod. In addition, the classrooms were reconfigured to create the Think Tank. Finally, the Solarium was added on, eliminating part of the hallway and increasing the size of the entrance to the science room. 


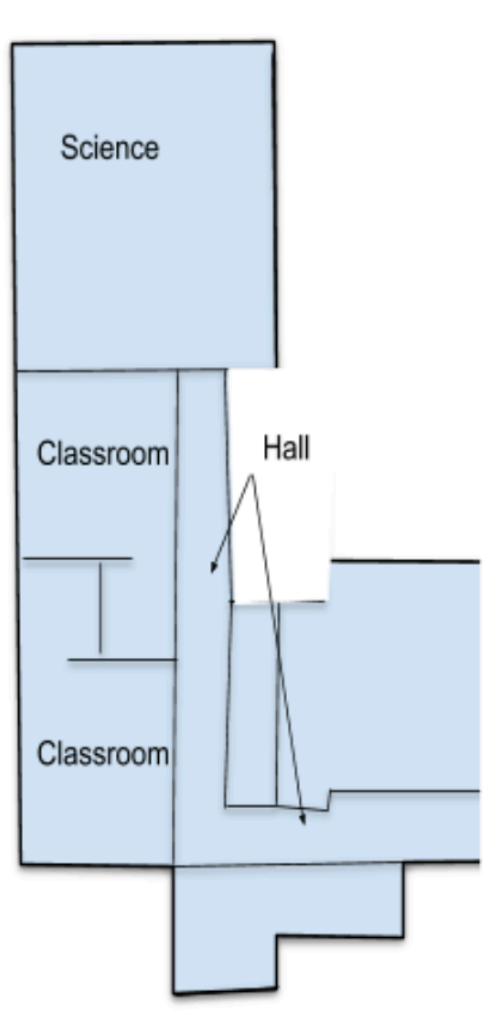

Before Construction

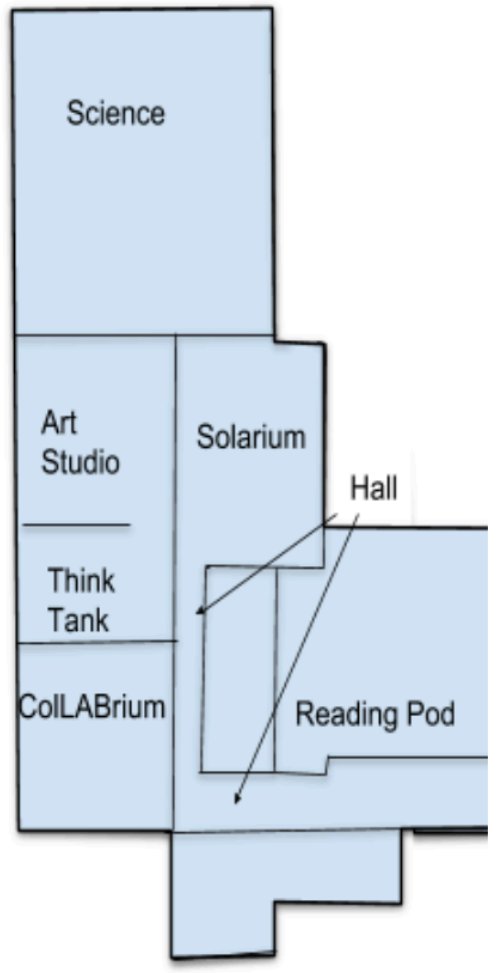

After Construction

Figure 2. Before and after map. These are simplified diagrams to point out the most obvious structural changes. (Nackerud, 2019)

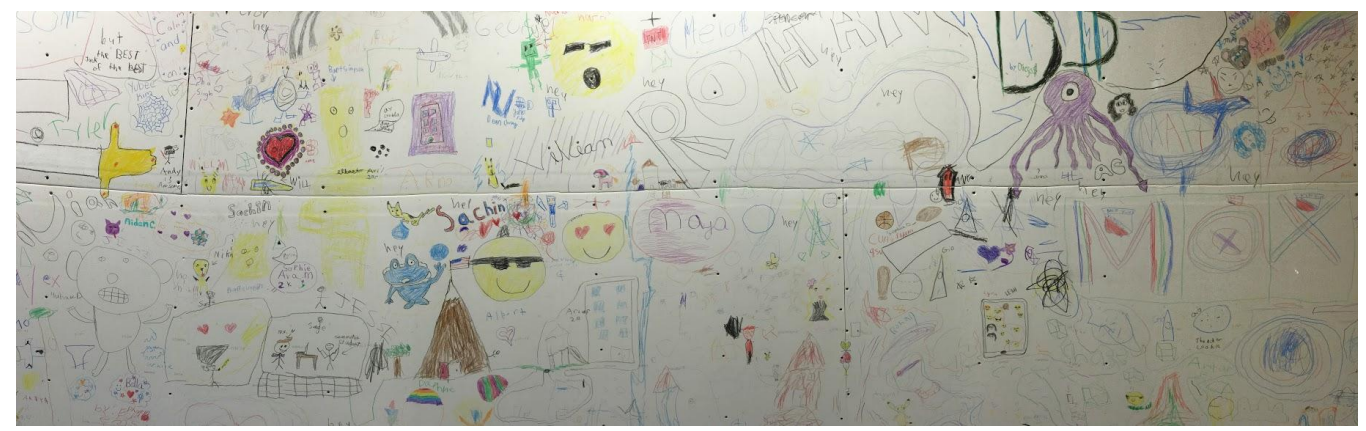

Figure 3. Temporary Wall: Art Side. Temporary walls were decorated as construction went over schedule. (Nackerud, 2016) 
The teachers were invited to move into the space before construction was finalized. Due to this, participants were exposed to construction noise and debris as they moved in and began using the spaces. Figure 3 is an image of one of many temporary walls that became temporary art repositories as we awaited the end of construction. Figure 4 is an image of the same wall from the construction side. I include it here to acknowledge the in-process nature of the construction work and the associated challenges. Throughout the day, teachers and students were subject to construction noise, occasional debris piles, dust, and interruptions related to bringing the spaces together.
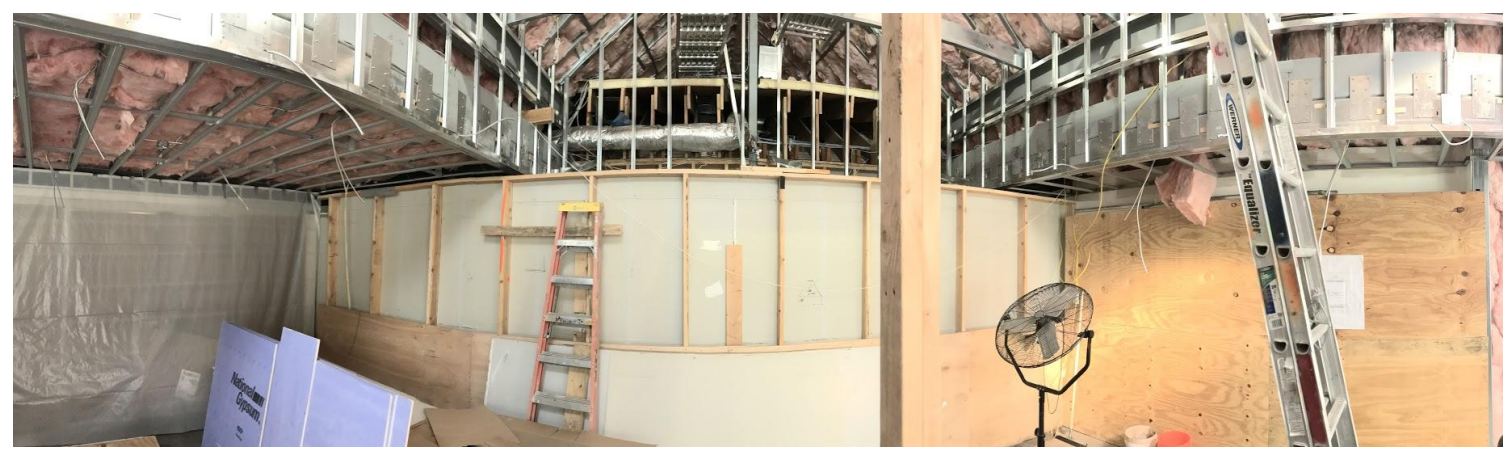

Figure 4. Temporary Wall: Construction Side. Temporary walls protected the school from some construction issues. (Nackerud, 2016) 

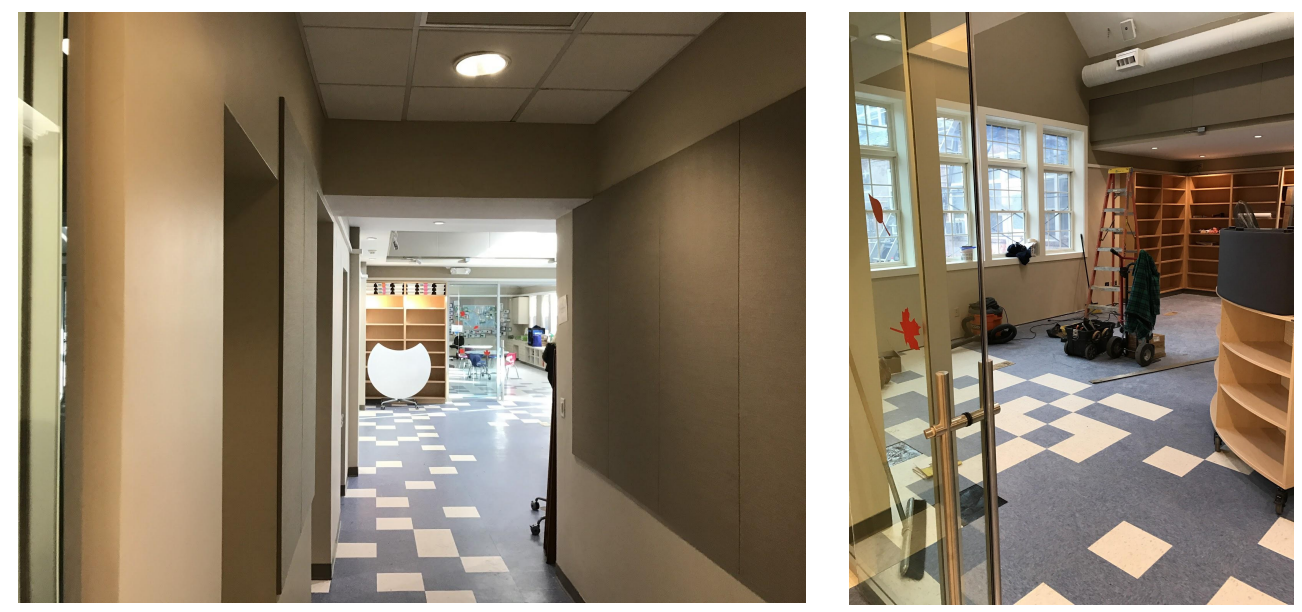

Figure 5. Temporary Wall Removed; and Figure 6. Empty Solarium. When the Solarium was completed, teachers started exploring the use of the space. (Nackerud, 2016)
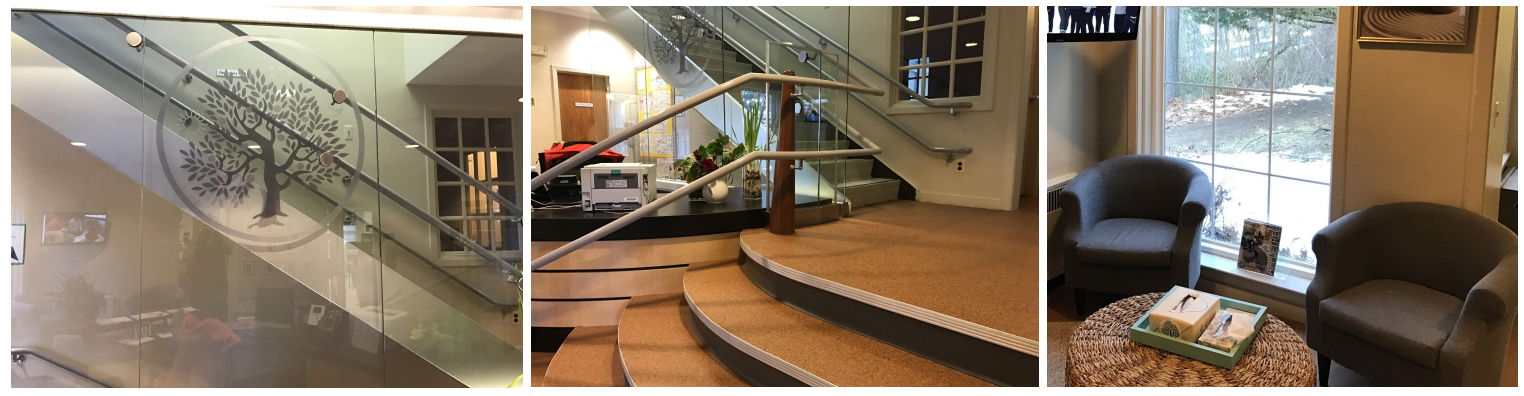

Figure 7. Glass Walls; Figure 8. Glass Divider; and Figure 9. Large Windows. These images showcase the ample use of glass and windows to increase natural light. (Nackerud, 2016)

The renovation resulted in several new spaces and opportunities. In Figures 7, 8, and 9, you can see the extensive use of glass to open up the spaces and increase natural 
light. Furnishings were purchased that allowed for flow between rooms, and many items had wheels. The Solarium, the final addition to the space, provides a central meeting area from the reading pod, art studio, and science room. The Think Tank, a room just off the Solarium, provides a shared teacher workspace. Figure 10 demonstrates the resource availability in the new space, showing some of the available technology, research materials, and flexible furniture use.

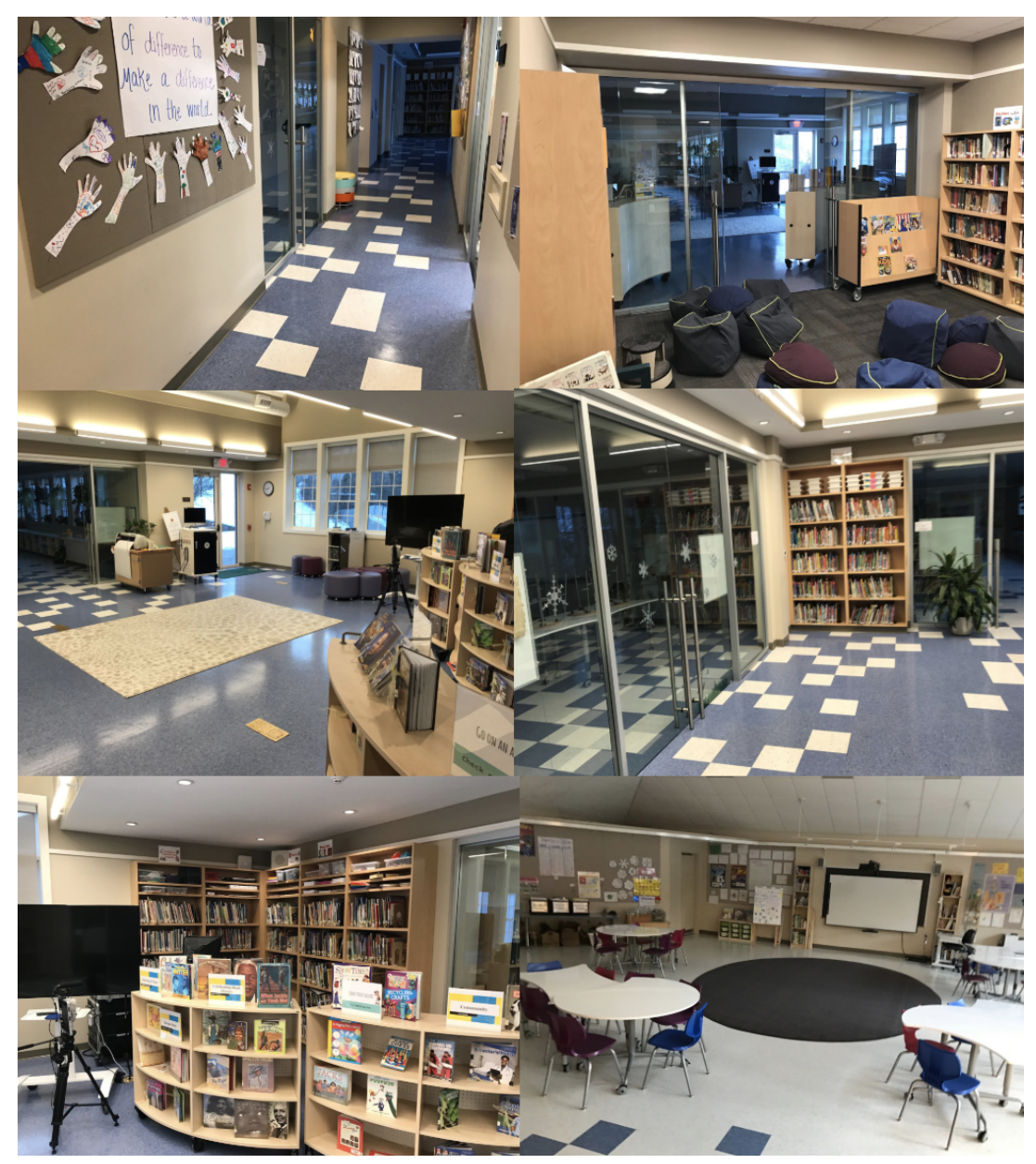

Figure 10. Multi-Room Composite These photographs show the integration of the library collection, makerspace tools, and flexible furniture in all rooms. (Nackerud, 2016) 


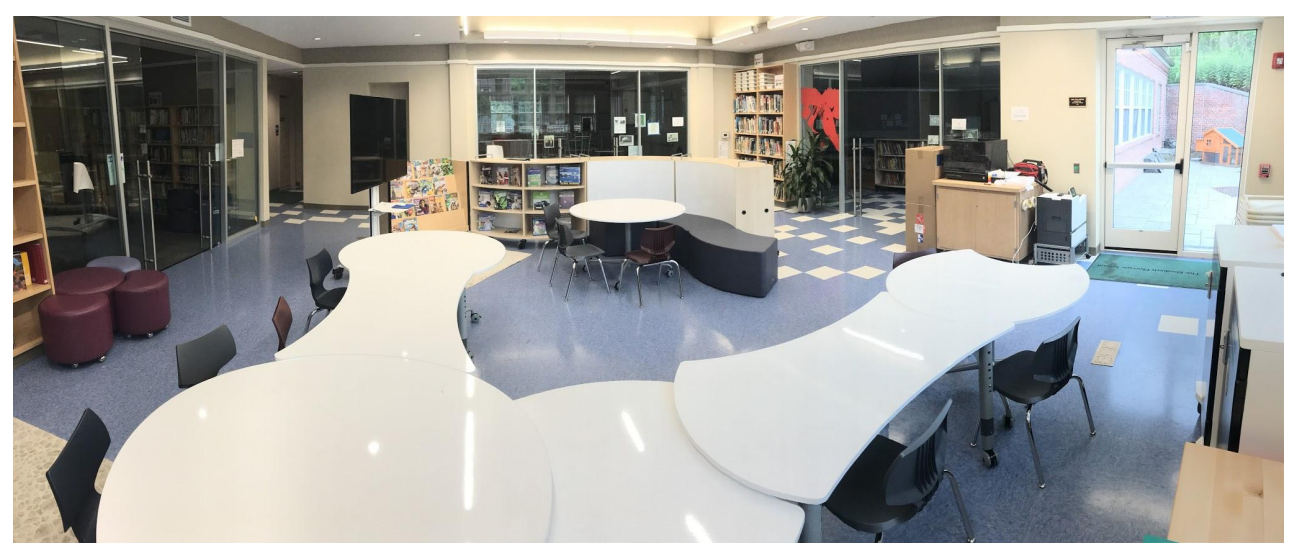

Figure 11 Flexible furniture setup for a whole-class project. (Nackerud, 2016)

Flexible furniture, light, and open spaces were major goals of the renovation, according to JCJ (Pellegrini, F. JCJ, personal communication 2016, January 13). As seen in Figure 10, the collection from the library was distributed throughout the space.

Constricting the hallway allowed for the widening of a previous space into the reading pod, with full double-windowed doors looking into the Solarium, as seen in Figure 11. These double-windowed doors were mirrored on the science room and art studio.

\section{Data Collection and Analysis}

Data analysis describes the process of organizing information to gain improved insights for making judgments and interpreting a study (Glesne, 2006). Initially, I planned to organize my data by participant. I created files of observations, documents, transcripts, and demographics for each teacher. I transcribed each interview using a clean transcript (Elliot, 2005). This form of transcript eliminated pauses, intonations, false starts, and utterances common in everyday speech. A clean transcript focused on the 
participants' input and made it easier to read. I then began coding the data. In the process of coding, I reorganized the data by theme before trying to understand the experiences of the participants.

\section{Schedule}

The schedule for data collection was subject to the vagaries of school events. Data collection began in late May 2016, in the form of data collection during grade-level meetings. Scheduling of interviews was also completed by this time. The request for demographic information, while a known quantity, was not made until the end of the interview process. Interviews began in early June. Throughout this period additional data points were accepted. I encouraged my colleagues to bring documents, images, and additional data sources to the interviews. These documents, as additional points of data, were formally collected at that time, but were also accepted before and after the interview period. Finally, the survey was shared after the interviews. Tables 2 and 3 detail the data collection period.

Table 2 Data Collection Schedule

\begin{tabular}{|cc|}
\hline Date & Item \\
\hline Friday May 19 & Participant Recruitment Begins \\
Began Interview Scheduling \\
Began Data Collection \\
\hline Tuesday May 23 & End of Participant Recruitment \\
& STEAM Meeting
\end{tabular}




\begin{tabular}{|lc|}
\hline & End of Interview Scheduling \\
\hline Thursday June 1 & STEAM Meeting \\
\hline Friday June 16 & Final Day of Data Collection \\
\hline
\end{tabular}

Table 3 Interview Schedule

\begin{tabular}{|ccc|}
\hline Date & Interview & Participant \\
\hline Monday May 22 & 1 & $\mathrm{~K}$ \\
Tuesday May 23 & 1 & $\mathrm{C}$ \\
Wednesday May 24 & 2 & $\mathrm{~K}$ \\
Friday May 26 & 1 & $\mathrm{~L}$ \\
Tuesday May 30 & 1 & $\mathrm{~B}$ \\
Wednesday May 31 & 2 & $\mathrm{C}$ \\
Thursday June 1 & 2 & $\mathrm{~L}$ \\
Thursday June 1 & 3 & $\mathrm{C}$ \\
Monday June 5 & 2 & $\mathrm{~B}$ \\
Tuesday June 6 & 3 & $\mathrm{~B}$ \\
Friday June 9 & 3 & $\mathrm{~K}$ \\
Wednesday June 14 & 3 & \\
\hline
\end{tabular}

\section{Coding}


I based my data analysis plan on the constant-comparative method. I started by reading and rereading the transcripts. Communicating the intention of the story was my focus at this time. To do this required coding raw data and constructing categories that embodied the relevant themes or characteristics of each item's content (Merriam, 1998). First, I completed an initial coding of the data. This first coding defined what would occur in the data, i.e., what the data actually showed. This is referred to as grounded theory coding by researchers, and describes close reading of data and examining the data for ideas (Charmaz, 2006; Glesne, 2011; Merriam, 2009). With this method I tried to avoid attaching my preconceived ideas to the data. I followed the recommendations from Charmaz (2006), coding lines using gerunds and describing the data by action. Using Invivo, I was able to gain insights into dominant codes and was able to complete the coding fairly quickly. This program allowed me to code a section of data in multiple categories. The program also gave me access to the number of times that a code was applied across participants. Next, I crafted categories for the initial codes. Glesne (2011) described coding repeated sorting, defining and sort data towards the research purpose. I recoded the data again in order to see if the major categories were present under the lens of codes developed while coding the first few times. After compiling a list of initial codes, I formed categories that emerged out of the initial codes. At this stage I removed or recoded codes that only occurred in a single instance in order to focus on the major codes and categories. Reading through the data, I identified what I saw as emerging 
stories. Coding categories helped in identifying patterns. Those patterns then became the stories I share in Chapter 5.

Narratives take shape in different forms, from self-contained stories to narratives that expand across meetings and topics. During the coding process, I encountered a major personal prejudice towards seeking something of significance in relation to my study. I had to work hard to achieve an oblique data analysis and to privilege participant stories. The tightness of the case study and the restriction of the specific time period left some questions obfuscated without more time to see participants develop their knowledge.

I read, reread, identified, described and interpreted as part of my data analysis. As part of this, I engaged in what Merriam (2009) calls axial coding. Also called analytical coding, axial requires interpretation and reflection. I did this in part to deal with my issues of personal prejudice with regard to the three semi-structured interviews. In addition, I triangulated the data from my log, demographic information, teacher-shared items, and the interview transcripts. I reviewed the data for each individual relating to classroom environment use and teaching approach, and assigned named categories based $\mathrm{n}$ characteristics that seem most prevalent across participant data sources. Instead of studying each teacher as their own case, I ended up using themes across the cases to construct the story of this specific moment in the process of experiencing the new environment, makerspace, and STEAM program.

\section{Chapter Summary}


This study sought to interpret stories indicating understandings (Dewey, 1980). This focus on the storied narratives of a specific group of educators is supported by the naturalistic inquiry, allowing for the possibility for multiple meanings to unfold out of the context of this study (Clandinin \& Connelly, 2000; Lincoln \& Guba, 1985). The unpredictability of what emerged could not be known in advance, and trying to predict ahead of time caused a contradiction to my praxis and conceptual framework, where I had to review my coding and analysis to correct the unintentional behavior (Lincoln \& Guba, 1985). As we must approach environmental change as ambiguous, I needed to equally accept the emergent nature of the data (Lincoln \& Guba, 1985). As the researcher, I did not know the outcome, or how my interactions influenced or were influenced over the course of the research (Lincoln \& Guba, 1985).

There were a lot of rewards and emergent ideas that came out of the analysis. Catching myself in unintentionally trying to predict the outcome of the research was a great surprise and led to a deeper analysis. There are still many unknowns and new questions for pursuit, both in terms of this study and in terms of using narrative case studies. This is an exciting yet daunting study in terms of the many unknowns. Further data collection might help in making sense of vague themes and non-intersecting ideas which I was not in a position to include for analysis at this time. If anything, my own subjectivity and the limits of the narrative case study furthered my interest in exploring the study questions. 


\section{CHAPTER 4: Data, Data, Data}

The purpose of this study was to describe how the makerspace concept and classroom (or instructional space) physical changes might have influenced teachers' beliefs and practices as they developed curriculum, sustained past curriculum, revised ideas, and shared knowledge with others. Alongside school leaders, instructional leaders, and vision leaders, I am concerned about how this innovation affected educators. With this understanding, we can better facilitate and advocate for classroom resources, science, technology, engineering, art, and mathematics (STEAM) teacher resources, professional development, and curriculum design in the lower school. Through the integration of STEAM through a makerspace and a deeper understanding of how the environmental changes and renovations impact educator decision making, the lower school educational community will better provide students with the necessary knowledge for success in a 21st-century skill environment.

Chiefly, I asked: what influence does the physical addition of the makerspace have on teaching and learning beliefs and practices of primary school educators at a K-8 independent school on the East Coast of the United States? Subquestions included: (a) what are the beliefs, practices, and experiences of primary educators related to the change in the physical environments as teaching and learning tools? (b) in what ways do educators perceive the redesign as changing how they use physical space? and (c) what beliefs and practices, related to 21 st-century skills of collaboration, creativity, critical thinking, and communication, do educators identify as part of the new space? 
These questions will be further addressed in the data analysis portion of this chapter. The data were collected through three one-to-one interviews with each participant, a demographic questionnaire, and observations of the physical use of classroom space.

In this chapter I first give a description of the data sources, followed by participant data, interview data, and a synthesis. I briefly describes the interviews, the data used for triangulation, and the observational data. In the participant data section, I used data from my triangulation sources to help explain each participants' context within the study. When addressing the interview data (the richest source of information) I consider ideas and themes raised by the research questions. In the section covering the central research question, I also include the sub-questions for reference, as well as repeating each sub-question in its specific section. Finally, I share a synthesis of my findings.

\section{Data Sources}

The primary data sources used in this study were three sequential, individual, open-ended, semi-structured interviews (see Appendix C) with each of the four participants. The interviews lasted approximately 30-45 minutes each. Participants' three interviews were crafted around three reflective themes. The first interview used openended questions around their past experiences as educators, the second interview used questions targeting reflection on current experiences, and the third interview used questions about their future thoughts and ideas. Participants selected the location of the interview and the time of participation. Additionally, probing and clarifying questions 
were used for the purpose of allowing participants to share their personal experiences and helping me, as the researcher, to gain a deeper level of understanding. All interviews were audio-recorded. The participants were informed that they were being recorded for the purpose of transcribing the interviews.

Observations of the uses of space, where appropriate, were documented in order to understand participant interview responses. Additionally, the teacher beliefs survey and demographics instruments were used. The observations, surveys, and demographics helped me to triangulate the data. This method allowed me to gain deeper contextual understanding in conjunction with the interview data. The concept of triangulation supported a multi-voice framework that Denzin (2006) and Flick (2002) value as useful to research. Through this method, I was able to dig deeper and enhance my research by using the different data sources (Mason, 2002). Teacher beliefs, as reflected in the survey, were checked against participant statements, helping me to ensure I was correctly attributing vague statements. The demographic survey also served as context to compare the four very different voices of the participants.

\section{Participants}

The participants of the study were four female educators in elementary grades (K4). All names used here are pseudonyms. Three participants self-identified as White/Caucasian and one participant identified as Hispanic. Duration of teaching experience varied between 6 and 24 years. One of the participants identified as a career changer, and two of the four stated that they had experienced major renovations that 
changed their teaching practices in the past. These details helped me to place interview statements within the traditionalist to constructivist practices continuum I developed following my literature review, utilizing the theories of teaching described by Dewey (2007) and Barbash (2012), and the indicators of traditional versus constructivist practice described by Khalid \& Azeem (2012) and Miller (2008). To arrange the data I looked at each participant in turn:

\section{Brenda}

Brenda was a veteran teacher and administrator with thirty-two years in elementary education. Brenda had her Master's degree in teaching and was working on an additional leadership credential during the course of the research period. She had worked at the Apple Tree School for 15 years at the time of the study. She had taken workshops to further her experience with makerspaces and STEAM and had spent 10 years working in this area. She referred to having experienced 20 renovations or classroom moves during her career. Brenda indicated a high degree of satisfaction with the Innovation Alley project.

Brenda is, definitively, a leader at the school. She also had the most knowledge of the history of the school, plans for the innovation, and the goals for the space. As a leader she had a vested interest in the success of the space. That leadership mantel also meant that she was pulled in many different directions and was not always able to provide direct oversight. Additionally, toward the end of the construction project, she sought to relinquish control to the other participants as leaders. 


\section{Laurie}

Laurie had taught for 34 years in elementary education. She had a Bachelor's degree equivalent and had taught at the Apple Tree School for the last 17 years. She had no STEAM experience and no formal educational experiences related to makerspaces or STEAM. She referred to experiencing only 1 renovation or classroom move. Laurie indicated a high degree of satisfaction with the Innovation Alley project.

Laurie brought a very different perspective to the voice on this project. Her international background and limited experience in STEAM meant her story was strongly flavored by these differences. Laurie had the most questions. She also was the least tied to the tradition of teachers in the United States. Despite her years in education, she tended to emote more enthusiastically even while expressing concern or confusion.

\section{Katie}

Katie had taught in elementary education for three years at the time of the study. She had also taught middle school aged students previously. She had taught at the Apple Tree School for 2 years. Katie had a STEAM education-specific Master's degree and had taught STEAM for 5 years. She had experienced 6 renovations or classroom moves during her career. Katie indicated moderately high levels of satisfaction with the Innovation Alley project.

Looking strictly at the survey numbers Katie seems comparable to Cammy in experience. The intensity of her experience and her connections to STEAM communities beyond the school meant that she had much more practical experience in STEAM 
disciplines. Additionally, unlike the others who had foci outside of STEAM, her entire career was built on teaching STEAM. This intense knowledge and understanding of STEAM meant she shared enthusiastically and deeply on the topic of the new space.

\section{Cammy}

Cammy was in her 4th year of working in elementary education. A mid-year hire the previous year, she was just past her first full year at the school. Mid-year hires generally need to develop connections with the school without the traditional supports a school provides to those beginning their relationship at the school at the onset of the school year. She had two Master's degrees. Cammy described MAT coursework that somewhat covered STEAM education. She indicated that she had experienced 5 renovations or classroom moves. Cammy indicated moderate to moderately high levels of satisfaction with the Innovation Alley project.

Cammy came to the school mid-year in the previous school year. She switched careers from the business world to education just past the mid-point in her professional life. Her experiences with the business world directly colored her perceptions. Her interactions with colleagues and expectations differed from the practices a school observes. The comparisons of educational experiences with for-profit business added to the diversity in the case study.

With the exception of Brenda, all of the teachers' spaces were to be enclosed in Innovation Alley. Each of the teachers expected to use the new spaces, both together and separately, to develop a new curriculum and pilot constructivist pedagogical ideals. Each 
of the four teachers, including Brenda, taught in and used the space with students during the course of data collection. In order to aide with interview coding and analysis, I used the data shown in Table 4 to recall contextual clues.

Table 4 Demographics Survey Visualized

\begin{tabular}{|c|c|c|c|c|c|c|}
\hline & Makerspace & $\underline{\text { Years in }}$ & $\underline{\text { Years at the }}$ & $\underline{\text { Years in }}$ & $\underline{\text { Number of }}$ & $\underline{\text { Satisfaction with }}$ \\
\hline$\underline{\text { Participant }}$ & or STEAM & elementary & Apple Tree & $\underline{\text { STEAM }}$ & $\underline{\text { Renovations or }}$ & the Innovation \\
\hline Pseudonym & education & education & $\underline{\text { School }}$ & education & $\underline{\text { classroom moves }}$ & Alley project \\
\hline Brenda & Yes & 32 & 15 & 10 & 20 & 9 \\
\hline Laurie & No & 34 & 17 & 0 & 1 & 10 \\
\hline Katie & Yes & 3 & 2 & 5 & 6 & 8 \\
\hline Cammy & Yes & 4 & 2 & 1 & 5 & 6 \\
\hline
\end{tabular}

Table 4 shows that two of the participants had taught at the Apple Tree School for almost half of their very long careers. Brenda and Laurie are the 'veteran teachers' in this study; however, Brenda and Katie have the highest number of years' reported experience in STEAM education. Laurie and Cammy, on the other hand, reported little or no experience with STEAM education. Laurie also had the least experience with renovations, yet her satisfaction with the Innovation Alley project was highest. Cammy, who had both limited experience in STEAM education and at the Apple Tree school, ranked her satisfaction with the project the lowest of all the participants. The range of 
responses shows that this is a non-homogenous grouping. Lower satisfaction scores amongst the teachers with less experience may stem from lack of experience, but they could also be a result of having undergone more recent teacher training and therefore may have less traditionalist teaching views.

\section{Addressing the research questions}

\section{Themes}

After analyzing the interview data, I identified three themes: rejection of the influence of space; experiential change due to the influence of the space; and thinking about the potential of the space.

Rejection of the influence of space. Participants cited several reasons that suggested a rejection of the influence of the makerspace. While Bandura's (1988) notion of self-efficacy and influence of space indicated that there was a likelihood of teacher influence on the space and the space's influence on the teacher, some teachers demonstrated something more akin to Horne's (1999) coping behavior as opposed to active engagement with the space. This also might support Cooper's (1981) theory that a relationship between the design of space and occupant behavior might not necessarily exist. When participants indicated they were coping with, or were unaffected by the space, I classified this as rejection of Bandura's (1988) framework of an interaction between the social, environment, and curriculum.

All the participants were clear about the space not quite being finished as one reason for rejection. Some also indicated that they had yet to experience enough teaching 
opportunities in the space to adequately describe whether any changes had occurred. In general, these statements appeared to be driven by stress, keeping the participants in the study from embracing the new environment (Upitis, 2004). I link these statements more closely to Horne's (1999) notion of coping as a sub-theme of rejection:

"There is still a lot to do and we have new curriculum too." (Brenda)

"I have no place for my files." (Laurie)

"I had a ceiling fall on me." (Cammy)

"I had to move in while teaching classes" (Katie)

Participants also rejected a change in experience due to the lack of control (Gislason, 2007):

"We will see in the fall how it goes." (Brenda)

"They changed contractors and things were forgotten." (Brenda)

"When can I use your room?” (Laurie)

"Innovation Alley will be exciting when it is done." (Cammy)

"They let us in only for the rugs to be flooded, thankfully I didn't have the collection in there." (Cammy)

"I can't get maintenance to bring the right books in for the collection." (Cammy)

"It is what it is." (Katie)

Finally, one participant explained that she felt the results of the construction failed to live up to her expectations and requirements:

"The shelves weren't built to library standards." (Cammy) 
"My office is hot and the Think Tank is cold." (Cammy)

These four expressions were used to describe participant rejection of the influence of the space of practice, yet were often caveated by themes of hope.

All the participants described unfinished aspects of the project that hindered their ability to see the space influencing their teaching. Cammy shared her frustrations with unfinished and inadequate furnishings. Katie, who indicated that her space experienced the least change, described how utility issues were inhibiting her:

"I don't have what I need and there are little things like the outside electricity and the heaters that keep me from what I want to do with the space.” (Katie)

“Shelves are incomplete and I can't even begin to think about what I will do when I haven't been able to unpack.” (Cammy)

The temperature in the space was frequently mentioned by all the participants. Brenda also shared in the frustration of having such an important project still in limbo, rather than feeling complete. Finally, Laurie talked about the destructive aspects of the space still not being fully complete:

"My files and props are covered in dust, some are ruined." (Laurie)

The prior concepts are categorized as inconsistencies in the project's physical completion. Participants commonly expressed this rejection of influence.

Three of the participants described another rejection sub-theme. This was more closely linked to Cooper's (1981) idea that there might not be a relationship between a space's design and people's behaviors. Participants felt that it was too early to know if 
the Innovation Alley project was having (or was going to have) any influence on their practice and beliefs:

"I haven't been using the space at all. Only some of my files are even here." (Laurie)

Cammy described the ongoing process of getting her materials into the space, and also described feeling like she was just, "trying to survive the year." Katie made a couple of statements that paralleled and elaborated on Cammy's stance:

"Moving in mid-year means that I am just doing what I did last year. I am unpacking. The kids need to learn to be in here. I haven't thought." (Katie) Teachers were still moving in and setting up for a school year that was almost over. They did not feel that they had time to reflect on their experience in the space because they did not yet feel that they had experienced the space.

As a new space, the school community was highly invested in the makerspace being utilized. Non-instructional uses of the space were frequently pointed out as inhibiting their ability to use the space. "Everyone wants to have their meetings in the Solarium," said Katie, describing how meetings in that space meant that classrooms in the surrounding spaces had to be kept quieter and that students were not able to walk out and use the shared instructional space. Brenda indicated that it was hard for teachers to have their instructional uses of the space come after community events. Longer term activities were difficult to manage due to the potential for interference and occupation of the space by community groups and morning meetings that wanted the excitement of 
using the new facilities. Laurie described her frustration with not have clear limits for her desk space and supplies. "Is that mine or hers?" she questioned, while pointing from one section of counter to another. Cammy said that participants in an event that had occurred one or two nights before her interview "left wine bottles in my recycling bin. That isn't school-appropriate."

Participants stated that the sharing of the space beyond their instructional team was an important factor in rejecting the influence of the space on their teaching practices. These event-based uses of the new space caused them to avoid planning anything too complex or experimental.

Space needs were also a major component of this rejection of the space as influential. Cammy found that the new space did not respond to her instructional requirements. She was the most critical of the space with frequent mentions of, "inadequate shelving," "need more space," and "wasn't designed right for..." as she described limitations where the space did not conform to her beliefs about teaching and learning.

Experiential change due to the influence of the space. In addition to professing rejection of influences arising from the addition of the space, participants articulated hopes for future influences on their practices. These discussions were more in line with Bandura's ideas of self-efficacy and the influence of space (Bandura, 1988). Participants shared items of interest that points Horne's (1999) more desirable active managing of the space by the participants. 
Participants discussed their hopes for training, resources, and time. Two participants discussed their hope for more collegial interaction that had occurred in their previous spaces. One of the participants was very clear about advocating for the space to the rest of the school community. Training, resources, and time were frequently mentioned together, and I would classify these as internal expectations for those in the new space. I classified the hope for collegial interactions and efforts to champion the project to the rest of the school as expectations of social influence.

Internal expectations were common. All participants expressed the hope that they would be able to obtain resources in line with the makerspace and STEAM components. Katie talked about her excitement at having a wealth of books, technology resources, and materials readily available:

"We're all right here and can share supplies." (Katie)

Laurie mentioned her excitement about having easy access to iPads:

“Anytime I need them, just boop, grab what I want." (Laurie)

Brenda also commented on the wealth of resources:

"It's great, every book is where it is most needed." (Brenda)

Cammy shared her enthusiasm about having easy access to electronic devices and various ideas she had about using them:

“iPads and laptops are nearby." (Cammy)

"Screens on wheels have potential. (Cammy) 
Access to resources, participants said, was vital for them, both for inspiring new learning methods and helping them collaborate on new curricular ideas. Material resources were not the only internal expectations; training opportunities and time were also discussed. Laurie mentioned a workshop she was attending, and Brenda talked about opportunities for peer to peer professional development:

“Growing STEAM team's pools of knowledge with each other.” (Brenda) Cammy and Katie brought up the value of having colleagues in closer proximity:

"In the same spot every morning." (Cammy)

"We meet more often now than we would have been capable before." (Katie) Brenda was adamant about the importance of time to collaborate with colleagues as a major principle of the project:

"Two dedicated meeting times and close proximity to one another is going to do more than anything else we could have done." (Brenda)

Participants shared that time and training would be important in creating new ways to teach:

"Everything we learn in Innovation Alley will be a model for the rest of the school.” (Brenda)

The expectation of social influence was the other item most frequently mentioned, after time, training, and resources. Participants alluded to future opportunities to collaborate with grade level groups, other STEAM team members, and with the school as a whole:

“Classroom visits that teachers can see different ways." (Katie) 
"See what STEAM really looks like." (Katie)

"I hope I can work with you <author> on some activities." (Laurie)

"Starting research with fourth grade." (Cammy)

These statements were all related to changes in teaching and learning practices that had yet to be developed.

Thinking about the influence of the space. The analysis of the interview responses demonstrated internal and external experiences as influential. The new space was described as impacting personal thinking about teaching and learning. Statements indicated that the personal impact was stirring ideas, but was not yet influencing practice. At the same time, external factors were described as generating both negative and positive thinking about the space. As a new space, the campus-wide excitement led to uses that two participants described as frustrating. These reflections tended towards emerging experiences of the new space's influence on teaching and learning practices. Each participant discussed the ways that they perceived the new space was starting to impact their teaching and learning ideas. Thoughts on the intentions and reality of the project were shared by all the participants in the future-focused final interview:

"Design thinking will play out in shared spaces." (Brenda)

"Using the process developed by the STEAM team, develop learning opportunities." (Brenda)

Participants attempted to articulate both perceived opportunities and confusion about the space: 
"I don't understand constructionism or STEAM for my teaching. But I like your makerspace. Can we use it?" (Laurie)

Laurie, while lacking the training in constructionism and STEAM, recognized something useful in the space. Other participants also described their vision for the space thus:

"Continuation of lessons and projects but adding more curriculum connections and provide some real-world application." (Katie)

"This is a space where $<$ students $>$ will develop empathy and compassion." (Cammy)

The above comments highlight the positively-portrayed expectations for the space from personal reflections. These positive portrayals were tempered by external pressure, as well. I began to think of this as the school community coming upon a 'shiny new toy'.

Viewing the space from a campus perspective, participants were both excited and wary. Katie summed things up:

"Everyone is going to want to be here, whether they should or not." (Katie) Brenda was the most positive about this outcome. She described the experience as the rewarding result of dedicated work by the school:

“Getting the attention we deserve." (Brenda)

Other participants were less than pleased. Their statements indicated frustration with the attention:

"We can't use the space effectively. There is always an event." (Cammy)

"Why isn't the makerspace ever open?" (Laurie) 
Both statements highlighted that spaces had yet to be dedicated to their original purposes under the project plan. This shiny new toy syndrome led to dissatisfaction amongst the participants. In addition, as interviews began and before a question could be asked, participants often expressed concern that showcasing the space would preclude their hope to use the space to try out teaching and learning strategies.

Observations. Participants offered their notes on emergent planning. It was clear from both my own observations and the early lesson planning that the participants and their colleagues were attempting a concerted effort in shifting teaching and learning practices. Laurie, in particular, shared a list of ideas she had for the makerspace, including crafting projects, a material resource library, and teacher training. Other participants allowed me to read through their observations and take my own notes on their planning. It appeared that an emphasis was being placed on the opportunity for collaboration, especially by Cammy and Katie. They worked with additional colleagues outside the participant group to compile a list of project ideas. Cammy, in particular, shared an extensive list of hoped for collaborations both within and beyond the STEAM team. Participant shared data points, and my own observations support the idea that there was a developing influence of the space of beliefs.

\section{Summary of data addressing the central and sub-research questions}

What influence does the physical addition of the makerspace have on teaching and learning beliefs and practices of primary school educators at a K-8 independent 
school on the East Coast of the United States? Responses to this central research question revealed several themes, and interpretive codes within these themes.

It was clear that several factors could lead to rejection of the space's influence. Time to settle in, control over their spaces, and feelings of incomplete construction influenced participants' receptivity to allowing the space to influence their beliefs and practices. Construction that did not meet expectations was also cited as another factor by participants.

Within the theme of hope for experiential change, participants described two potential influences of the space. Participants expressed hope for training and growth in their practice, both personally and in collaboration with each other. They were also excited about increased proximity, not just to one other, but also to educational resources. The theme of thinking about, but not yet acting, on the potential of the space highlighted the potential for future explorations to understand how the space might influence teacher practices and beliefs. Participants described a variety of teaching and learning goals that they had, as well as the current limitations on pursuing their goals.

\section{Research sub-question 1}

What are the beliefs, practices and experiences of primary educators related to the change in the physical environments as teaching and learning tools?

Themes. A dichotomy was present when analyzing this question. Respondents either responded with explanations of relatedness, or by indirectly relating beliefs, practices and experiences. I labeled these two themes as 'the act of consciously relating 
the environment as a teaching and learning tool' and 'indirectly experiencing environmental influence on teaching and learning, while not articulating the connection'.

\section{Consciously relating the environment as a teaching and learning tool.}

Conscious relating was limited to two of the participants. Brenda and Katie frequently discussed the opportunities within environmental space and related them to their practices and beliefs. Brenda described her first experience in an experimental learning space as a new teacher: "At the beginning of my career we taught as a team." She also related experiences and practices as teaching and learning experiences: "I was new, but I could tell who couldn't..." (as she described an open space and the difficulty her more experienced colleagues had with applying their beliefs as educators to the environment). She reflected on the experience and described the struggle to learn to work as co-teachers rather than alone. Brenda's experience related a belief in a community of practice.

Brenda also, more broadly, described how environments challenged her to develop new practices. "When I started.....I had a small resource room," Brenda said of her first year at the Apple Tree School. She also experienced the most renovations and classroom moves of all participants: "different, pull-out, new rooms every year." She explained further that her practices had to change for each space, and such changes led her to new discoveries about education. "It's hard to change classrooms or undergo renovations," she explained, "and then which new ideas to use.” Brenda related experiences of changing environment directly to her practices from a past perspective. 
In talking about environmental components that she valued, Brenda discussed tables, open spaces, and light. "I like flexible tables," she said, while describing opening teachers to new instructional practices. Open spaces and light were commented on frequently ("Room to reflect and breathe"). She went on to talk about how she hoped the students experienced a sense of "mindfulness" and clarity in the open space of the new classrooms.

Katie, with less experience and fewer historical moves in her career, also described and applied her beliefs and practices to the physical environment in which she taught. "When I got my classroom," she said, "I realized I had three times as much space as my old school - I didn't know what to do with it." Katie reflected that her old space had constricted the types of activities and experiences students could participate in. "Projects could be left out," she said, explaining that the classroom had invited her to embrace more project-based experiences with the students. "The new space, and the Solarium (indicating the large glass doors and windowed room beyond) mean I can pull $<$ names of two teachers $>$ into projects."

\section{Indirectly experiencing the environment influence as a teaching and learning}

tool. Laurie and Cammy did not directly address, during their interviews, the idea that their teaching spaces influenced their beliefs and practices. When I started coding, I noticed that Cammy and Laurie, during the first interview, were most likely to deflect questions relating to either their teaching practice or the space they uses in the past. When 
asked to discuss their previous teaching space, they both choose to talk about student experience. Cammy did provide a brief comment on teaching environments:

“Make any space work.” (Cammy)

In addition, when asked the final question of the first interview ("What would you consider the most important to your practice as an educator?") both Cammy and Laurie went off-topic. Curious, I decided to look at the other interviews and code for statements that indicated some type of interaction of beliefs and environments across all questions and interviews. During the third interview Cammy made a comment, that, without this lens, I might have missed:

"Well, I can't use that space because there are too many distractions." (Cammy) This, in combination with frequent criticisms of the space, made me think that there might be a 'messier' theme, where participants were not able to answer direct questions about teaching and learning as it relates to the environment. Looking more closely, I noted that both Laurie and Cammy aligned their teaching practices to environmental opportunities:

"All the open space would be great for scavenger hunts." (Cammy)

"Students can use the patio." (Cammy)

"I can have students make the things I show them." (Laurie)

"We can walk in the woods." (Laurie)

Knowingly or not, both of these participants shared that their beliefs and practices relate to the teaching environment. 
Observations. As the interviews progressed, I noted that the participants became more willing to critique the physical learning environment. Most often the critiques were positive. Another observation I made was that over the course of the three interviews I found many of the potential codes around sub-question one were in fact more relevant to sub-question two. There was also a trend towards more detailed revelations as the interviews progressed.

Many of the participants became more comfortable over time, but my distribution of questions was not as effective as I had hoped over the three interviews. Cammy, in particular, began sharing insights towards the final interview. I noted that this may have been more due to late construction, a major leak, improperly-built shelves, and other issues having had more of a direct impact on her and her levels of stress. All the participants' willingness to interact with the space increased over the course of the case study. Observation data from the participants, and my own notes, indicate that experiments with class setup and frequency of trialing different furniture configurations seemed to increase near the end of data collection.

Summary of research sub-question 1. The first research sub-question examined participants' beliefs, practices and experiences related to the change in the physical environments as teaching and learning tools. It might have been more appropriate to ask if there were explicit perceptions of relatedness between environment and practice. In the course of my coding, I realized that I wanted to know if teachers were conscious of these interactions, if they existed. I think reframing this question might have led to better 
interview questions that may have revealed more about the two themes. Consciously relating the environment to teaching and learning, and indirectly experiencing environmental influence on teaching and learning, made for interesting themes for analysis of the research sub-question.

Two of the participants were able to actively relate the two concepts; they articulated how beliefs and practices related to the space. They consciously shared how different spaces in their history shaped their practices. Additionally, these two participants were able to describe how saw their current beliefs and practices in the new spaces.

The alternative theme of indirectly relating practices and beliefs may have had been related to participant distraction and stress. These two participants clearly related their beliefs and practices to the environment, but not when queried about these relationships directly. Both participants described the environment as offering opportunities for them to explore and challenge their beliefs and practices as educators.

\section{Research sub-question 2}

In what ways do educators perceive the redesign as changing how they use physical space?

Themes. After analyzing the interview data, four themes emerged as most appropriate for capturing the major points of data analysis: increasing challenges and opportunities with communication, increasing availability and access to resources, 
innovating through curricular and communal programming, and expanding community for happiness and advocacy. I discuss each theme in the sections that follow.

Increasing challenges and opportunities with communication. Two participants discussed communication, specifically increased communication. All four participants described the support they felt due to community interest and increased visits from colleagues. However, one participant shared that the change in space had opened up some miscommunications as well. The new space brought many of the STEAM team members into the same space, and proximity played a major role in increased communication experienced by the participants:

"I think there was an assumption from the beginning on other people's part that, because we were specials, we somehow got together on our own more often." (Katie)

Previous spacing meant that getting together required coordination and planning that close proximity had eliminated:

“Oh you've always had an easier time <meeting with colleagues>, you have breaks between groups of kids." (Cammy)

She explained that her 10 to 15 -minute transitions were barely enough time to change her curricular materials to the next age group:

"I am seeing faculty interact with each other more. I've never seen $<$ name redacted $>$ smile so often!” (Brenda) 
Participants were happy with close proximity and secure meeting spaces, and Laurie shared a powerful thought on the matter:

"Day-to-day in the classroom, I think it's all about who you can call on, how you treat each other, and how many ideas you can exchange." (Laurie)

Support from administrators and community members was also a feature of the participants' experiences:

"We have daily visits from current and past community members curious about the space." (Brenda)

Visitors often expressed enjoyment of the space and also offered to be involved, according to Brenda:

“Administrators keep coming up to me to ask what I need." (Katie)

She, Cammy, and Laurie all felt that the leadership team was very vocal about finding out what they needed.

One participant made a very salient point about miscommunication as a result of the new space:

"Supposed to be instructional but we never know what meeting or event is happening." (Cammy)

Communicating with various school bodies about when the space was available was a major concern. Cammy also pointed out the difficulties of being part of a "new showpiece" for the school: 
"We have to make concessions but no one knows who is in charge of what and sometimes we aren't told they are meeting." (Cammy)

Cammy explained they were working through this, but that sometimes she would prepare to bring in a class, only to see maintenance putting together a table for hosting a PTA or an administrator meeting taking place in the teaching space she planned to use.

Increasing availability and access to resources. Availability of resources appeared to be a key factor for the participants in the study to explore how the redesign changed their use of space. All the participants described how proximity meant tools were easy to share and access. Two of the participants talked about how to use the new spaces. The other two talked specifically about the proximity of library books. Resources were a major area of discussion throughout the interviews. Brenda encapsulated the resource theme well when she said:

"In Innovation Alley you have all the books of the library, computers and iPads, machines to make things, printers, and the faculty library all easily accessible and ready to use.” (Brenda)

Cammy talked about tools and materials being easy to gather from nearby rooms for students' projects:

"I know there are dry erase markers in that room, I can grab an extra table from the art room, and you have the dry erase wipes." (Cammy)

“Grab an iPad or two when I want." (Laurie)

"Need for a tech intervention." (Laurie) 
"It's great, we have all the non-fiction science books in the science room or just outside it." (Katie)

Participants shared that tools and materials were important factors in starting to see the potential in the space. Katie and Cammy both brought up concerns about some of the more novel spaces in the redesign:

"How are kids going to sit in the reading pod for example." (Cammy) Cammy was considering several scenarios at the time, and had recently priced floor cushions. Katie talked about occupying the largest room, and discussed how to make others feel welcome to use the space, balanced against the needs of her classes.

"I know ensemble needs it but I have Kindergarten too." (Katie)

Both Cammy and Katie frequently discussed ideas for using the Solarium in their interviews, and mentioned how its dual instructional and student transition space nature were at odds:

"It's a hallway." (Katie)

"Anything going on in there is distracting." (Cammy)

Innovating through curricular and communal programming. Programming was another theme in discussing how the redesign was changing how the participants used the physical space. Brenda, who had led the planning that finally resulted in Innovation Alley, shared her excitement to finally see what new experiences the students had in the space: 
"We have some stale teaching practices that don't meet millennial parent expectations." (Brenda)

She wants to ensure that teachers adopt proper and rigorous programs for instruction:

"I need to try something new, no more old." (Laurie)

Ensuring quality programming was a component of all four participants experience in the new space. Katie shared that the space meant new challenges in terms of implementing instruction:

"We can work together to do projects, we can have an entire grade level together in the same space." (Katie)

Brenda made a comment that agreed with this and expanded the idea:

"We can design new experiences together and with the classroom teachers." (Brenda)

"We are growing closer as a faculty." (Brenda)

"We are our own best support." (Brenda)

"There is a community of teachers forming. We will have opportunities to come together, collaborate, and keep driving forward." (Brenda)

Expanding community for happiness and advocacy. Participants cited advocacy for the space, curricular goals, and each other as crucial in creating a community:

"It's great how invested we are in supporting the goals of the space, the STEAM initiative, and the students." (Katie) 
Laurie talked about how the faculty were supporting a colleague in trying something new:

"The energy in the space is exciting and I see that on all the teachers' faces." (Laurie)

Colleagues were frequently mentioned as significant in creating community:

"My colleagues play a significant role in my ability to engage students." (Cammy)

Collegial working relationships provided social and professional benefits. A learning community was forming, according to Brenda:

"They are a great team of colleagues." (Brenda)

Katie cited proximity created through the Innovation Alley project as a huge factor in her feelings of wellbeing:

"We can support each other." (Katie)

"We are always sharing ideas." (Katie)

"The STEAM team made it through construction." (Katie)

"Our design language will go a long way to providing a framework for us." (Katie)

She felt camaraderie through shared construction frustrations helped everyone. She also described relationships becoming more closely cemented as she and her colleagues coordinated to surmount challenges:

"I think we have a solid grasp of what we need to do." (Katie) 
Perceptions of non-STEAM colleagues (even while the participants expressed satisfaction with "getting to know what we do", according to Cammy) were of concern to Katie and Cammy:

"There are a lot of positives but we are realizing there are some missed communications with colleagues." (Katie)

Katie and Cammy were both concerned that those not in the building did not have a significant enough understanding of the work going on in Innovation Alley:

"The classroom teachers don't see how much work we have." (Cammy)

Observations. My notes indicated that, while not constant, there was a generally strong feeling of support and positivity. The participants were also involved in setting up several opportunities to share their work and hopes for the space with colleagues in other buildings. Katie provided slides which shared high aspirations for collaborations across content areas and with other grade levels.

Summary of research sub-question 2. The second research sub-question examined participants' perceptions of the redesign as changing how they used the physical space. The four themes were: communication, resources, programming, and community. Responses to this research question were amongst the richest interpretive codes I found.

Communication, both in terms opportunities afforded by the space and challenges brought on by the change, was cited as part of the experience of using the new physical 
space. Participants felt that their communications were changing. This was due both to being located in closer proximity and needing to articulate how the space was used.

Participants referred to both resources and programming as factors in their perceptions of the new space. Books, devices, furnishings, and spaces influenced their ideas and plans for using Innovation Alley. The participants were also planning to both achieve the programming visions behind the space and to implement new programs based on the affordances of the space.

The community was the final theme addressed by the second sub-question. Participants perceived the space as changing how they created a community of practice. Additionally, they shared that there were some successes and struggles with connecting with faculty outside of the space. They were also taking steps to communicate their experiences to the rest of the school community.

\section{Research Sub-Question 3}

What beliefs and practices, related to 21 st-century skills of collaboration, creativity, critical thinking, and communication, do educators identify as part of the new space?

Themes. After analyzing the interview data, two thematic categories best described participant responses. They were not able to describe current practices, but rather predicted what types of practices would be hosted in the space. Of these predicted practices, there were statements indicating an understanding how to use the space to build 21 st-century skills, and statements indicating the need for professional development 
before being able to identify opportunities within the space. I coded these items as 'ready for action' and 'preparing for future'.

Readying for action. Participants cited several ways in which the space would support their beliefs and practices relating to 21 st-century skills:

"Working in open spaces means students see teachers collaborating as well as having the room to create groupings to work together." (Katie)

Cammy and Brenda both shared similar statements about communication and creativity:

"We can improve student research." (Cammy)

"We built Innovation Alley to focus on 21 st-century skills.” (Brenda)

Brenda went on to describe ways in which the various spaces, and makerspace in particular, could address collaborative work, critical thinking, and communication. Laurie, very much invested in using the makerspace, indicated that she was excited to see what students would make.

"It is all for doing." (Laurie)

While all the participants expressed enthusiasm, when asked about specifics there were a lot of questions about how to enact or teach each other what they needed to know.

Preparing for the future. Understanding that there was a need for training and preparation was apparent as questions became more detailed:

"We know kids needs to develop 21st-century skills." (Brenda) 
She went on to discuss gaps in her knowledge about facilitate this and how to support teachers in gaining those skills. Katie, with the most training and experience in STEAM education, said that she needed to share her knowledge with colleagues:

"Help everyone keep up with practices in the field." (Katie)

All of the participants discussed that need to share the tenets of their discipline with their colleagues while also pursuing additional skills and knowledge:

"What are the standards for art, math, music," (Katie)

"Do we have the right biographies, at the right reading levels?" (Cammy)

Laurie, who expressed high levels of enthusiasm at first, worried about all that she needed to learn:

“Am I part of this?” (Laurie)

"Is there a workshop?" (Laurie)

While very positive about the redesign, Laurie worried that she needed a lot of training or help from colleagues to support the program goals.

Observations. Participants did not share documentation that directly related to this sub-question. I did include two notes about participants using shared space. In one instance an interview was cut short because the interviewee was preparing, with other colleagues, to facilitate 10 fourth grade teams in undertaking a gravity car challenge. The other note concerned the frequency with which participants mentioned the creative aspect of the makerspace. 
Summary of research sub-question 3. The third research sub-question examined participants' beliefs and practices with regard to 21st-century skills, and whether they identified them as part of the new space. What I found were varying levels of ability to identify collaboration, communication, creativity, and critical thinking within the spaces, but a common concern about preparedness for facilitating 21 st-century skill development. In general, participants expressed enthusiasm. Individually, they indicated varying concerns about gaining the knowledge to support student 21 st-century skill development.

\section{Limitations}

This case study had several limitations, which I note here. First, the questions themselves did not serve the case study as I hoped. Participants were not ready for the questions asked by this research when they were still moving into the space and dealing with construction woes rather than planning curriculum and organizing the space to their instructional goals. Including the voices of participants who felt unprepared to participate in the study should be considered in this light. It should also be noted that one of the four participants had significant responsibilities and duties outside of the space. Recruiting more participants who had less involvement may have enriched the results. Additionally, I am acquainted with all of the participants in the study. I have professional relationships with all four participants, which include non-academic event planning and fundraisers. This familiarity may have had some impact on the participants' comfort with sharing their thoughts and opinions. 
My intimacy with the space and people also lends itself towards unique observations and access that an outside interpreter would be unable to obtain. Even knowing the details of curriculum and outside obligations, the latest in construction woes, and participant recruitment options would be difficult for an outsider to have for describing limitations. An outside researcher would have encountered significantly more resistance to getting interviews and sharing the significance of the research for the participants' own practices.

Finally, the small independent school environment means that the study's conclusions may not be extended to general ideas and theories of innovations through environmental change. A further limitation connected to this is that the results of this study may be published, and other employees at the school may be able to identify participants. This may have affected the way the participants responded to questions and how they interpreted their experiences. Simply participating in the study may have changed how the participants behaved.

While conclusions may not be used to generalized from this study the methods can inform future researchers into developing research at their own schools. The conclusions in this very specific context can also be used internally, by the school, to develop plans for future innovations. This and the concern over identification and changes to participant behaviors through participation can also be used to predict the effectiveness of reflection embedded in research at the school. The study sought to 
change behavior and feedback over the potential for identification may help refine further studies.

\section{Chapter Summary}

The purpose of this study was to describe how the makerspace concept and classroom (or instructional space) physical changes might have influenced teachers' beliefs and practices as they developed curriculum, sustained past curriculum, revised ideas, and shared knowledge with others. School leaders, instructional leaders, vision leaders, and I are concerned about how this innovation affects educators. Through this research, I sought to understand the experience of teachers to implement this innovation successfully. With this understanding, we can better facilitate and advocate for classroom and STEAM teacher resources, professional development, and curriculum design at the lower school. Through the integration of STEAM through a makerspace and understanding how the environmental change, the renovations, impact educator decision making, the lower school educational community will be better able to provide students with the necessary knowledge for success in a 21 st-century skill environment.

Similarities and differences among the four participants became apparent during data collection and analysis. The participants varied in their years of teaching experience and the number of moves or rebuilds they had experienced prior to the renovation and creation of Innovation Alley. Two participants were extremely experienced as educators, with over a decade and a half of experience at the Apple Tree School. The other two participants were not inexperienced, but had only taught at the Apple Tree School for two 
years. All four participants described their excitement for the new space. Additionally, all four were actively engaged in using the space and in developing relationships with their colleagues. The participants were split evenly in terms of hoe they related their beliefs and practices to the physical environment; two spoke explicitly about this relationship and two referred to the relationship indirectly.

Participants were much more likely to theorize, rather than describe current practices, about their interactions amongst all the experiences in the space. They felt pressure and scrutiny in a space where they were still trying to resolve construction issues. Despite this, none of the participants indicated an inability to turn theory into practice. They shared that they felt the inner team would provide support, additional professional development would catch missing components, and time would result in future practices that would take advantage of the new environment. All four participants shared, in one way or another, that they would not trade the experience for the previous spatial layout.

It is too early, based on the data, to assess the full impact of the physical addition of the makerspace on the teaching and learning beliefs of the participants. There are clear indicators of influence on thought and future decisions. Further study and data collection may reveal the specifics and depth of impact.

In chapter five, I discuss the findings of each research question and place them in the context of previous research in the field. I share a synthesis of this study and the contributions of this study situated in the larger context of education and curriculum and 
instruction. I also discuss implications in terms of limits of the study, implications for policy and practice, and recommendations. 


\section{CHAPTER 5: Interpretations and an Epilogue}

\section{Introduction}

The purpose of this study was to describe how the makerspace concept and classroom (or instructional space) physical changes might have influenced teachers' beliefs and practices as they developed curriculum, sustained past curriculum, revised ideas, and shared knowledge with others. School leaders, instructional leaders, vision leaders, and I are concerned about how this innovation affects educators. Through this research, I seek to understand the experience of teachers to implement this innovation successfully. With this understanding, we can better facilitate and advocate for classroom and STEAM teacher resources, professional development, and curriculum design at the lower school. Through the integration of STEAM through a makerspace and understanding how the environmental change, the renovations, impact educator decision making, the lower school educational community will be better able to provide students with the necessary knowledge for success in a 21 st-century skill environment.

I seek to understand how the change in environment at the lower school influenced making pedagogical decisions, development of the curriculum, sustaining of the past curriculum, revising ideas, and sharing knowledge with others - impacts teacher beliefs and practice. Specifically, what happened with the introduction of the makerspace. To provide context into understanding the impact on curriculum, the following research questions guide the study. 
Central Research Question. What influence does the physical addition of the makerspace have on teaching and learning beliefs and practices of primary school educators at a K-8 independent school on the East Coast of the United States?

Sub-Question 1. What are the beliefs, practices, and experiences of primary educators related to the change in the physical environments as teaching and learning tools?

Sub-question 2. In what ways do educators perceive the redesign as changing how they use physical space?

Sub-question 3 . What beliefs and practices, related to 21 st-century skills of collaboration, creativity, critical thinking, and communication, do educators identify as part of the new space?

In this chapter I discuss the previous findings from Chapter Four, as related to the original research questions that guided the inquiry. This chapter also relates these findings to existing literature and includes a discussion of the implications of my research for policy and practice, and recommendations. I begin with a synthesis of the findings organized by question. In the second section I discuss the implications, followed by my suggestions for practice and policy. I also share potential future areas of research and offer my concluding thoughts.

My school, the Apple Tree School, is seeking to support student learning in new and different ways. The school-wide STEAM initiative and master plan led to the school's development of Innovation Alley. This addition required remodeling changes to 
the lower school which resulted in new classrooms, centralization of many STEAM content educators, and the creation of a makerspace for lower school students. Kindergarten students, currently housed in Chilton House, also had access to the new spaces.

The STEAM initiative and master plan focused on capital campaigns to improve school infrastructure, seeks to answer the need for modern learning and 21 st-century skill development. School instructional leadership wanted to build collaborative structures to support planning for integrated STEAM activities throughout the school. In addition to remodeling, faculty and instructional leadership have, and continue to, attend professional learning opportunities to build content knowledge, strengthen STEAMrelated instructional strategies, support curricular understandings, and guide analysis of maker/integrated STEAM student learning.

The narrative case study took a snapshot of a specific time period as the teachers used the new Innovation Alley with the makerspace and enacted the STEAM initiative. The results provided some insights into the specific experiences of those teachers during the period of data collection. The study investigated how teachers' beliefs and practices related to a changed physical environment as tools. It also examined at the perceptions of teachers in terms of how the new space changed their practice. Finally, the study examined how beliefs and practices related to 21 st-century skills were identified as being enabled through the new space by the teachers in the study. My unit of study was focused on four participants, all of whom were teachers directly using the space. 
My participants were non-homogenous in their responses to the survey, which made coding, and also organizing this section, a little complicated. As I began placing similar statements together, I eventually discovered enough congruency to recode and label themes by research question and relatedness to that question. I organized this synthesis based on that framework. After the synthesis, I share implications, suggestions for practice and policy, and areas for future research.

\section{Synthesis of Findings}

I organized this section by subsection starting, with the central research question and then each sub-question. In each section I restate the question as well as the related themes. I end with a general synthesis. By sorting this section by question, I hope to maintain the clarity around each set of themes and the questions themselves.

\section{Central Research Question: Impact of Space on Thought}

What influence does the physical addition of the makerspace have on teaching and learning beliefs and practices of primary school educators at a K-8 independent school on the East Coast of the United States?

Themes from data analysis in Chapter 4:

- Rejection of the influence of space,

- Experiential change due to the influence of the space

- $\quad$ Thinking about the influence of the space.

The first question sought to understand the influence the physical addition of the makerspace had on the teaching and learning beliefs and practices of four primary school 
educators at the Apple Tree School. I asked participants to share the experiences that brought them to where they are today, and where they plan to go in the future in relation to the space. While the findings were of interest, the results were inconclusive at the time of the case study.

The central research question seemed premature under analysis. Teacher responses to questions about the influence of the space on their teaching and learning beliefs had yet to mature. Many expressed what I termed a 'rejection of the influence of the space' based on Upitis's (2004) discussion of retreating to comfortable teaching methods when stressed. My interpretation of the responses is that teachers had not yet satisfied an experiential understanding of the space, which limited their ability to construct detailed responses. I am not ready to conclude in favor of Cooper's (1981) denial of a relationship between space design and occupants, but the reported experiences did support Horne's (1999) concept of coping, at least initially. Incomplete construction, problems with space, and 'newness' definitely led to a degree of ignoring the spaces' affordances and even of retreating to more comfortable teaching practices. There was a tension between the still unfinished space and a community interest in the shiny new toy. There were some community-wide interactions during this case study that tokenized the space as a 'shiny new toy'. In entrepreneurial circles in professional makerspaces I have been part of discussions where makers describe new tools, ideas, and contexts as shiny new toys. A new laser cutter becomes the obsession of the masses, developing games for education becomes a fad, and laundry mats with a coffee bar rises 
as the most exciting way to wash your laundry. Like a physical meme, the space took on the imagination of the community. Sometimes imagination exceeded the capacity of the space.

Based on the initial case study (i.e., not taking into account potential future experiences) I might have concluded that there was little influence of space on the teachers. Instead, due to the statements I coded as 'hope for experiential change as a result of the influence of the space', I saw a need to continue evaluations beyond this study. These declarations of hope, which included predictions, forecasting supports, and conversations about resources, indicated that the process of self-efficacy and influence of space (Bandura, 1977) had begun. Following up on the study may reveal the specific nature of these interactions.

The spaces, with exception of the climate control issues noted in the findings, seem to have potential in supporting constructivist education, challenge learning norms, and draw out new roles for teachers, according to the theories covered in the literature review (Gray, 1995; Sprague \& Dede, 1999; Weinstein \& David, 1987). The commentary on the themes of hope and reflection supports the idea that teachers have interests related to constructivist beliefs and practices even if they did not claim such practices during the interview process.

There was significantly more discussion on the three sub-questions as the interviews wrapped up. The early interviews were fairly sparse in term of responses to the interview questions. The final interviews held the richest data. This may have been 
due to growing comfort with the research process, the innovation's language, or because construction had reached completion. If a future time period is required before participants can enact their plans, then I would avoid placing my evaluations as final results. Instead, each section is a snapshot, that may or may not capture a stage in a process. I think it is also possible that continued learning by the participants may increase the frequency of discussion relating the space to teaching practices.

\section{Sub-Question 1: Thoughts on Space}

What are the beliefs, practices and experiences of primary educators related to the change in the physical environments as teaching and learning tools?

Themes from data analysis in Chapter 4:

- Consciously relating the environment as a teaching and learning tool

- Indirectly experiencing the environment influence as a teaching and learning tool

The first sub-question sought to relate beliefs, practices, and experiences to the new space's physical assets as teaching and learning tools. Due to the nature of the responses, I split my coding into two themes. The first theme ('consciously relating the environment as a teaching and learning tool') was embodied by two of the participant voices. The second theme ('indirectly experiencing environmental influence on teaching and learning, while not articulating the connection') was used to categorize comments 
that indirectly showed an interaction between participants and the space. While I expect further themes might be identified in time, those are beyond the constraints of this case study.

There was a clear split between the four participants. Two articulated their beliefs and practices within the new space (consciously relating the environment as a teaching and learning tool). The other two made comments that showed that they indirectly related their beliefs and practices to the environment (indirectly experiencing environmental influence on teaching and learning while not articulating the connection). As a case study, this moment and time might indicate that something in the participant demographics (such as having had less training in STEAM) might explain this division. Diagnosing this would require tools that were not part of the case study. Alternatively, I might propose that this indicated that the act of articulating a relationship between practices and beliefs to physical space is an emerging skill. It could also be that participants were stressed by the recent nature of the construction and by other current concerns. Either situation may reveal less about relatedness and more about the stresses of teaching in a space under construction.

Despite this limitation, I am able to make some conclusions relating to this question. There was an emerging effort being made to notice ways in which the space might be used for teaching. The beliefs and practices of teachers may not have fully developed in this respect but, as reflected in the central research question, might fit in with Horne's (1999) notion of coping. Focusing on the renovations and on the process of 
resolving issues with the construction and moving experience may have resulted in a temporary state where the participants prioritized factors other than their pedagogical concerns in relationship to the space (e.g., resolving a heating issue rather than innovating teaching methods. Even when indirectly articulated, participants' views were not in line with how Barbash (2012) and Dewey (2007) described traditional teaching. Teachers were not necessary retreating to traditionalist teaching methods; instead they were in more of a 'holding pattern'. Both response types indicated that the teachers were either moving along the traditionalism to constructivism trajectory, or were already constructivist in their incorporation of the environment with their teaching beliefs (if not their practices) (Melhuish, 2011; Upitis, 2004; Usher, 2002).

\section{Sub-question 2: Ideas on New Uses}

In what ways do educators perceive the redesign as changing how they use physical space?

Themes from data analysis in Chapter 4:

- Increasing challenges and opportunities with communication

- Increasing availability and access to resources

- Innovating through curricular and communal programming

Sub-question 2 targeted participant perceptions of how the redesign changed the way they used space. What I found here were themes relating to an internally-generated professional development community. The themes were: increased challenges and opportunities with communication; an increase in the available resources; and innovation 
through curricular and communal programming. Participants shared what they felt were the benefits of the project and communicated their struggles with communication and community expectations. They also discussed programming and resources as a collaborative effort. Collopy (2003) has shown that teachers' perceptions and use of materials is not as effective without professional development. The community of practice that developed was a clear response to the teachers creating their own professional development in order to address this need.

The teachers' dialogues and community interactions indicated that, while they were performing under more traditionalist instruction methods, they were planning and predicting for a more creative, constructivist experience (Khalid \& Azeem, 2012). The stressors of recent construction were in conflict with all four participants' expressed interest in cooperative learning and inquiry. Dialogues about future instructional planning were clearly on the rise. Participants' sense of professional community, and their interest in using space and materials collaboratively, provided indications that they were invested in the tenets of constructivism and in mediating the environment for students. (Brooks \& Brooks, 1999). In order to learn in context, educators must create and use environments that encourage constructivist learning. During the case study participants were much more likely to be mediated by the environment rather than mediating it for the students.

\section{Sub-question 3: Space and the 21st-Century}


What beliefs and practices, related to 21 st-century skills of collaboration, creativity, critical thinking, and communication, do educators identify as part of the new space?

Themes from data analysis in Chapter 4:

- Readying for action

- Preparing for the future

The third subquestion provided an opportunity to evaluate how closely the participants felt the space came to fulfilling the vision for the pursuit of STEAM topics and leveraging the makerspace concept. I coded responses as 'ready for action' and 'preparing for the future'. Participants' beliefs indicated that two of them felt they had expertise, while two had enthusiasm and interest but a lack of feelings of readiness. Two individuals were ready to work on $21^{\text {st }}$-century skills and the other two participants were preparing for this work. Harkening back to the community-building evident during the case study, I saw potential here for enacting collaboration, critical thinking, communication, and creativity-based practice.

Collegial relationships, and the development of a sub-community of practice working directly in the space, were in evidence. In education research, developing a community of practice is a precursor to developing new ideas and practices within a context (Lave \& Wenger, 1991; Pea \& Gomez 1994; Wenger, 2003). There are also indications that collaborations occur in various ways (Schreurs et al., 2014). Some participants discussed space-use collaborations, while others indicated their need to share 
content knowledge. To this end, I interpreted the current state as one where the participants are in the midst of recontextualizing their experience. Their professional development will most likely need to focus on task-based, practice-based, and knowledge-based activities. This is likely necessary, according to Riel and Polin (2004), due to the embedded nature of the environment and participants' need for practical experiences. They will need to experiment and adapt. Participants' beliefs and practices will be challenged, and this case study was too early to confirm whether beliefs and practices around any aspect of the construction, much less the specific 21 st-century skills discussed, relate to the change of physical space. The process of change is not instantaneous with the introduction of a new environment.

Another consideration in evaluating whether teacher beliefs and practices are changing (or are likely to change) is the need for evidence of improved learning outcomes (Guskey, 1989). Teachers value student growth as evidence of an intervention's success. None of the interviews discussed student learning outcomes, which points to an 'initiation phase' in the use of the environment. Teachers are still involved in finalizing construction and are not yet actively monitoring learning outcomes. So, while Jones and Hayes (1980) indicate that involvement in planning has a positive impact on teacher commitment, that involvement during this phase also limited participants' reference points during this case study (the temporary limit being that they were still involved in construction and not yet fully engaged in using innovations in their classrooms). Bolster (1983) and Huberman (1995) clearly identify that an increased level 
of engagement in using the space for teaching is necessary before beliefs and practices change. This is rather like a renovation multitasking scenario; simultaneously finishing renovations and making use of the renovation's characteristics are not supportable synchronously.

\section{General Synthesis}

A cross-case synthesis is intended to find patterns, similarities, and differences across a range of cases. While the patterns that I noticed did not relate closely to my intended questions, I found that the comparisons allowed a meaningful understanding of the premature nature of my inquiries. The stories allowed me to investigate the experiences of these teachers who were dealing with faulty wiring, broken ceiling tiles, and unpredictable thermostats. The three-dimensional inquiry space (Clandinin \& Connelly, 2000) of this study helped me truly understand that the participants were not avoiding my inquiries. Some had yet to have experiences that allowed for them to begin a change in their beliefs and practices. Others had some past experience which allowed for discussion. These similarities and differences also helped highlight a continuum of change that might be found in future observations and interviews.

Participant stories highlighted similarities and differences depending on their experience or current interactions with the new space. Different levels of expertise, such as a strong background in STEAM or a greater number of experiences with varied environments, was evident in the topics that a particular participant felt comfortable addressing. On the other hand, an investment in building a community and 
communicating with one another was a primary concern that all participants shared. The participants in this case study acted under both the stress of change and with enthusiasm for a challenge. While participants rejected some of the space's affordances and expectations, they were eager to embrace other opportunities offered by the space. They were all clearly excited to use the space and interested in becoming successful with the makerspace and STEAM initiative.

The excitement around the STEAM initiative, in the wider context of $21^{\text {st }}$-century skills, can be seen in the planning of student-centered and problem-based learning situations. Participants, towards the end of the study, shared ideas on ways to encourage student collaboration and engage the community. They were also using terminology from wider social discourse on $21^{\text {st }}$-century skills, such as digital literacy, critical thinking, and problem-solving. While still in the nascent stages, participants were heading towards Rotherham and Willingham's (2009) description of $21^{\text {st }}$-century skills teaching beliefs and practices.

\section{Implications}

What does this mean for the school? Since the primary research questions were difficult to answer, given the emergent nature of the experiences of the participants, the main conclusion I reached was that the school should temper expectations during transitional and initial phases of change. Community members were eager to inquire after the results of the building, and relating a reasonable timeline to constituents for expectations of change will be significant in future efforts. Administrators need to seek 
ways of preventing discouragement amongst teachers experiencing an innovation of this scale.

Besides allowing sufficient time, it is vital to plan for staff development as part of the building plan in order for teachers to function effectively (James, Applefield, \& Martinez, 2001). Because this activity involves creating and working as a team, administrators should provide time for community-building (Lave \& Wenger, 1991; Wenger 2003). In this case, and according to Lave \& Wenger (1991), some of the elements of community building were already operational. Participants were engaged in dialogue with each other and with outsiders, had varied opportunities or levels of participation, and were growing dynamically and responding to challenges and opportunities. They were also beginning to weave familiar experiences and divergent thinking into the community. Public and private spaces as well as regular experiences were also initiating. As the work continues, a study could be conducted to determine effective potential strategies for such efforts.

Teachers also need the opportunity to reflect on their experiences in light of their beliefs and practices in order to identify inconsistencies. Since teachers see their success through student behaviors and activities, this may need to occur at the end of a whole teaching cycle (Fullan \& Miles, 1992; Harootunian \& Yargar, 1980). This might be a semester, a unit of study, or even the end of a full year. Some sort of definition of experience, girded by a time or experience element, would provide teachers with a construct for better reflecting on student experiences. It is unrealistic to have expected 
deep inquiry and shifts in beliefs and practices within a few months of the renovation. Instead, we needed to embark on a new cycle of learning so that teachers could witness and respond to student experiences. The process of change, as I understand it from the parity of teacher's interview responses, requires both time and opportunity to see through student experiences. In line with Riel \& Polin (2004), teachers in this context were unable to obtain explicit knowledge of how the space functioned since it was not always functional. Brown, Ryan \& Creswell (2007) found that reflection, while sometimes alleviating stress, still requires time.

Despite the stress of teaching in the midst of new construction and seeking to support the STEAM initiative, the teachers freely expressed their hopes and expectations. Another study might seek out pertinent details to find out where the perceptions of the teachers align with the desired outcomes of the experience. Given Guskey \& Sparks’ (1996) social cognition model, this may provide clarity on the change process and help inform future efforts to facilitate change. Measuring positive actions responded to by secondary positive reactions against frequency of hostile actions and reactions might provide guidance in facilitating additional efforts. It was clear that the teachers were already engaging in positive forms the reciprocity that Guskey and Sparks (1996) described.

Continuing research into the relationship between the space, the teachers, and their implementation of 21 st-century skills would also be useful. I found much of the dialogue that touched on 21 st-century skills to be fairly shallow in the interviews. A 
study of the frequency and success of practices that privilege these skills would be interesting. Long-term, understanding the interaction of the space, practice, and goals of the environmental design will impact the school's decisions. Having specific understanding of which affordances in the space were most successfully used would also influence future construction.

In more general terms, collecting data about the types, frequency, and quality of professional development would be useful. Teachers were coordinating as a community of practice, but they were also beginning to seek knowledge fulfillment in areas where they felt they had a deficit in relation to the program goals. Analysis of the experiences in training (as compared to the outcomes in terms of shifting practices) would be helpful to administrators trying to maximize program and teacher success. Jones and Dexter (2014) state that teachers' learning occurs in multiple ways: formal, informal and independent. If research could relate the effectiveness of these types of learning, decisions could be made earlier in the process about what types of professional development resources are most useful.

\section{Suggestions for Practices and Policy}

Results from this study highlight a need for continued research on this topic. It seems that teachers in the new space should be supported and offered the opportunity to complete a cycle of teaching in the space. Administrators should be aware of the stress caused by major changes. Specifically, administrators should find ways of supporting and involving teachers in the process of change. An environmental change, paired with a 
program change, may be exciting and rewarding, but it also carries significant stressors. It is important that policies are put in place that acknowledge stressors, fulfil professional learning needs, and offer opportunities to reflect on the process. These may provide teachers with valuable support that ultimately helps them succeed in adopting the intended beliefs and practices of the innovation.

The most challenging aspect of this innovation lies in the navigation of stressors and supports. Changing the physical environment created both a challenge and opportunity, where all aspects of Bandura's (1989) social cognitive theory could be seen as in flux. The physical environment was definitely both changed and changing. Combine with the makerspace, which could be seen as introducing an entirely new curricular experience, and the new social context (where teachers who were not proximal to one another now shared close physical space), this might be described as a change to all three domains. Behaviorally the way the participants were teaching. Cognitively and personally, they were developing a new version of their community. This disruption of these other two domains seems inconsequential compared the major disruption of the physical space, and yet this definitely increased the challenge.

The renovation process itself (i.e., the construction work) may have also had an impact on teacher's reactions to the makerspace. Jenkins and Calhoun (1989) identified lack of control over activities and outcomes as a source of teacher stress. Educators experienced stresses associated with the construction project. Additional identified sources of teacher stress included task overload, role conflict, and unpredictable change. 
All of these stressors exist on a regular basis during a renovation construction project, according to Giachino (1992). The combined factors of significant parental and donor interest, and the difficulty teachers had in articulating their experience, made this study valuable for the school. Having an understanding of the stressors helped identify unanticipated themes that contributed to teachers' narrative constructions.

This research allowed educators to articulate barriers they encountered in their efforts to achieve more integrated learning environments for students. Several studies indicated that, while under stress, constructive reflection may help alleviate some of the burden (Brown, Ryan \& Creswell, 2007; Folkman., 2008; Masicampo \& Baumeister, 2007; Ortner, Kilner, \& Zelazo, 2007; Roeser \& Pinela, 2014). The research into reflective practices as a mitigator of stressors amongst teachers points to the importance of understanding the significance of an experience. Through this study educators gained an initial framework that allowed for the contemplation of the experience and helped them gain greater mindfulness of the stressors. I am interested in this study as a potential model for managing future initiatives. This disciplined and systematic approach to understanding curricular decisions and supporting educators in gaining insights into 21 stcentury skills, issues of equity in their classroom, and how to use open-ended environments effectively served teachers directly involved in this study. Teachers not involved in the study may also have benefited through peer dialogues or observations.

The informal and formal structures that fostered collegiality also helped to mitigate teacher stress. Community attitudes around embracing the stress, accepting 
mistakes, and showing gratitude did much to ameliorate the tensions caused by construction. Proximity led to informal meetings to help and support one another. Even eating lunch together, aided by proximity and share office space, profited teachers by increasing opportunities to consider stressors. Embracing stress, potential an odd statement, means acknowledging the difficulty incurred on teachers by the project. Acknowledgement helped teachers reframe problems as challenges and invited requests for help and feedback. Simultaneously administrators and teachers were quick to express gratitude for offered help and collaboration, further diffusing tension and provoking harmony. Teachers are members of a makerspace and need the same consideration as the students.

Schools, in general, can benefit from this research in order to better time their own data collections. Evaluation should occur after a new semester, year, or whatever time period marks a full teaching cycle at the school. I expect that richer data points would result from such a choice.

Planning should occur at the administrative level to account for celebratory and 'feature' uses of the new space. Policies need to be in place that ensure rooms can be used congruently with their intended purpose. Additionally, extra uses of the space should place an emphasis on facilitating the intended purpose. Community excitement and fervor should not prohibit teachers from experimenting with how the construction is used. Communication with the school community is a critical step to ensure the new space is celebrated, used appropriately, and understood properly. 
The findings from this study support the importance of practices that foster collegial working environments. The findings show that teachers were successful in initial formation of a community of practice and that it was a considerable factor in their ability to focus on the goals of the space. Wenger (2007) described a community of practice as a group of people with a common concern: a domain, a community, and a practice. In this case the domain that the participants shared was Innovation Alley and the makerspace. As a community they had begun working together; participants helped each other and shared information. Finally, in their practice, they had begun sharing experiences, resources and tools. Over time the relationships and sustained interaction should see a greater accumulation of knowledge and resources, and either bear out the community of practice or see its end.

To support this community of practice, school leaders can provide formal activities such as planning times, staff-led professional development, and professional learning community support. These initiatives should come in the form of planned policy. Formal professional learning should also be provided to the administrators, who should be informed about the benefits of establishing practices that promote and encourage collegiality among faculty. These two factors will support knowledge-building and help create routines for the community.

As the process moved forward I noticed that the collegial culture fed on support for the teachers' time, shared responsibility for the space, and deliberate discourse into instruction in IA. Administrators honored the additional time the new environment took 
from the teachers and offered release from some duties, early release as occasion allowed, and, when possible, flexibility in scheduling. Limiting teacher time in onesize-fits-all training and substituting planning time for teachers to organize together also built in the collaborative experience and collective responsibility for the team. Additionally, proximity and share planning times strengthened collegial relationships. This all made frank conversations about instruction easier and increase the team's mutual appreciation of criticism, praise, and ideas. Additional practices may have also influence this tighter bonding as colleagues, these were the most transparent and all contain elements that could be deliberately facilitated.

It will also help to recognize that "legitimate peripheral participation" (Lave and Wenger 1991: 29) comes in multiple forms. New faculty will gradually move towards greater participation in the community. Additionally, there are multiple ways to participate in the community of practice (Wenger, 2007). While some of the participants will be fully engaged with most details, others will act as observers or responded to requests. Supporting varied levels of participation should strengthen the community and increase the utility of the shared knowledge.

One of my major concerns was the remarks that seemed to seek to avoid understanding the space. Upitis (2004) described teachers as seeking control when they imposed prior notions of space use and rejected new opportunities. Under the theme of consciously relating to the environment as a teaching and learning tool, I saw teachers gaining control by articulating their ideas. The second theme (indirectly experiencing 
environmental influence on teaching and learning, while not articulating the connection) relates more to the idea that there might be a lack of comfort. This might be due to lack of control, concerns, lack of knowledge, or some other unknown factor. If the influence of the space creates discomfort, this may increase a desire to return to conventional space organization. This poses the question of whether a teacher in this state needs support in order to transition out of discomfort and into feeling in control before achieving the goals of the project. Project success hinges on teacher beliefs and practices. Understanding the difference between feelings of loss of control versus temporary dissatisfaction with construction quality may be important in supporting teachers through projects like the addition of the makerspace.

Lastly, a thorough understanding of program goals should be part of the preparation for all teachers in this case. The dichotomy of knowledge in terms of $21 \mathrm{st}-$ century skills, understanding of the programmatic goals of the Innovation Alley project, and how to use the space may contribute to misunderstanding and frustration. A practice of inclusion in the process of decision making, perhaps without decision making authority but with a voice in suggesting ideas, would help reduce stress (Chambers, 2008). Less-than-optimal involvement meant that teachers were more apt to reject aspects of the space and were less aware of their responsibilities (Jones \& Hayes, 1980). By actively engaging teachers, at least at the level of understanding, the opportunity for the environment to impact teacher beliefs and practices improves.

\section{Future Research}


As I have already stated, there are a plethora of opportunities for future research. Primarily, continuing the narrative inquiry should resolve many of the limitations described in these results. Replication would also be of benefit. While not measured in this study, the literature indicates there are positive benefits resulting from the reflective nature of the interviews (Creswell, 2007; Clandinin \& Connelly, 1986; Chambers, 2008). Additionally, repeating the study will help in identifying ideal data collection periods. This will contribute to the literature around architectural innovations, as well as providing improved models of self-analysis for schools engaged in such innovations.

Another area for future research should include comparison groups for this study. This might include innovations that do not include architectural changes, architectural changes without the intention of programmatic change, and group types with and without makerspaces as a component. Comparison groups would strengthen the findings and help determine the value of each component. They would also clarify whether the results were unique to this experience or are true across multiple populations and situations. These are critical questions to answer and will influence policy decisions.

The findings in this study support Upitis' (2004) framing of stress as impacting potential for change. Future research may test levels stress and the balance of stressors to progress towards a desired outcome. The findings here imply that stressors during construction may limit (at least during the period of the case study) opportunities for the development of teacher beliefs and practices. Further research needs to be conducted to further support or refute the limits of Upitis' expectation of stress leading to more 
traditional teaching methods (2004). Future studies should investigate whether various interventions versus no intervention helps with reducing stressors and facilitating change. Studies might investigate and measure how professionals in other, non-school educational spaces (such as museums) experience changes to both physical and instructional practices.

An opportunity for further study relates to discovering when teachers become comfortable in a space after change. It was clear in my findings that the teachers were still experiencing frustrations with the construction process. During my study, the context and practice of the community of teachers I interviewed was one of sawdust and new construction woes. Identifying when the participants moved from this transition period into a state of comfort, and what characterizes that transition, might be useful in further projects.

This study took place in a small independent elementary school. Future researchers should conduct replication studies in similar and different school contexts with respect to size, geographic location, teacher demographics, and socio-economic opportunity. Replicating the study with different variables will help strengthen the current findings, provide confirming or refuting evidence, strengthen the overall field.

\section{Concluding Remarks}

This study was significant for several reasons. First, the findings in this study offered an opportunity to hear the stories of teachers actively engaged in teaching in a new environment and supporting a new curricular effort. The study also provided rare 
insights into the stressors associated with working in a space under construction. The findings demonstrated participants' excitement and desire to be active contributors to the goals of the space, even while under stress. Schools shift populations and curriculum with more frequency than they engage in changing physical space. With changes in space comes a restructuring of ideas and opportunities by the people using the environment. Understanding how this affects the practices and beliefs of teachers influences our planning and consideration of an expensive investment in teaching and learning opportunities. We have the fiscal and social responsibility, as school leaders and educators, to make informed choices that offer the most benefit in terms of high-impact teaching and learning experiences for students.

Personally, during this study I realized that the story was not one of space influencing pedagogy - at least, not yet. This was a study revealing the importance of timing, and also a recommendation to study the time it takes for change to have clearly observable impacts. My assumptions were greatly challenged by this case study, chiefly the assumption that the specific case might be enough to make future decisions about construction at the school. I believe in the continuation of the narrative and, while I limited the scope of this dissertation to the specific case, I have found the continued research and support of the faculty fascinating. I also, mistakenly, assumed that participation would be higher. Early interest in participating, when I first embarked on this research, left me concerned that I would not be able to support the voices of all the teachers. Finally, I assumed the themes would be easy to identify and that my coding 
would easily reveal cognizant details about teacher beliefs and practices in the space. Instead I found it difficult to categorize the different experiences in a way that both privileged individual voices and indicated potentially greater understandings. This experience reinforces my role as a practitioner-researcher as one where I should continually challenge and query my methods, results, and presumptions.

\section{Epilogue}

While I felt, during the case study, many of my questions were left unanswered, the study took place two years ago. Over these last two years I have seen teachers gain comfort with both the space and the instructional practices. The makerspace and making as an activity pervade the space. Before participants were unsure what it would look like and what would be acceptable. Over time the teachers have adapted. Iteration on incorporating STEAM, the makerspace, and features of the environment are ongoing but have resulted in the growth of the makerspace. The makerspace has claimed a specific room but teachers have also claimed and adopted the makerspace concept for their own classrooms.

In contending with the space I described the teachers as mediated by the space as they coped with the change. Now that the space is dust free, teachers turned this around to mediate the space for the learning experiences of the students. As the space became finished the space was used more frequently. Additionally, the tools and experiences of the space have been adopted in other spaces not part of the original project. Classroom teachers have sought out the loan of tools. Grade levels have asked 
for makerspace experiences in the garden outside, in the woods, and at the athletics

field. Maker challenge and design inspiration cards are now requested as station tools in several classrooms.

The tools of the space have also grown. Well-known makerspace objects like a laser cutter, CNC router, vinyl cutter are available to students and teachers. Materials for tinkering and design fill bins along the wall while student projects in various stages litter every available surface. The makerspace and work in STEAM have claimed a part of the school's heart fostering programs like robotics expos, art exhibits, and a yearly maker day that includes the entire school community.

Teachers who spend the most time in the space quickly waned of their excitement over resource abundance (aka, the 'shiny new toy') but the community continues to exhibit signs of shiny new toy syndrome with most events using the space. My own insight is that this may be a reciprocal relationship as teachers become comfortable. I observed and reflected that as spaces became classifiable and thus safe to use, expressions of need or lacking in resources returned fairly quickly. Suddenly a pop-up space for video recording did not meet the new needs of the community and more advanced video and lighting equipment were required. New bookshelves were requests and obtained as experiments with the space found that flexible shelving was more necessary than flexible seating.

My research has also influenced the community. We are approaching a new capital project and already planning to circumvent some of the issues that my study 
highlighted while choosing professional development and supports most likely to enhance the experience during renovations. I look forward to replicating some of the study experiences that most supported teachers' in adapting to the space. Simultaneously I expect to refine my research and try to identify the transitions as teachers move from reacting to the environment towards acting on it to students' benefit. 


\section{REFERENCES}

Ackerman, E. (2001). Piaget's constructivism, Papert's constructionism: What's the difference?, Retrieved January 7, 2016 from http://learning.media.mit.edu/content/publications/EA.Piaget_Papert.pdf.

Addleson, M. (2000). What is good organization?: Learning organizations, community and the rhetoric of the "bottom line," European Journal of Work and Organizational Psychology, 9(2), 233-252. doi: 10.1080/135943200397969

Agar, M. H. (1996). The professional stranger: An informal introduction to ethnography, second edition. San Diego, CA: Academic Press.

Ahrentzen, S., \& Evans, G. (1984). Distraction, privacy, and classroom design. Environment and Behavior, 16(4), 437-454. doi: 10.1177/0013916584164002

Alsup, J. (2006). Teacher identity discourses: negotiating personal and professional spaces. Choice Reviews Online, 43(10), doi: 10.5860/choice.43-6016

Alterator, S. \& Deed, C. (2013). Teacher adaptation to open learning spaces. Issues in Educational Research, 23(3), 315-330. Retrieved from:

http://www.iier.org.au.proxy.lib.pdx.edu/iier23/alterator.html

Anderson, B. (2006). Imagined communities: Reflections on the origin and spread of nationalism. New York, NY: Verso.

Anderson, G. \& Arsenault, N. (1998). Fundamentals of educational research. London, England: Routledge Falmer. 
Angier, N. (2010, October 4). Stem education has little to do with flowers. New York Times. Retrieved from http://www.nytimes.com/2010/10/05/science /05angier.html.

Applefield, J. M., Huber, R., \& Moallem, M. (2001). Constructivism in theory and practice: Toward a better understanding. Wilmington, NC: Watson School of Education Press.

Babbie, E. (2007). The practice of social research. Belmont, CA: Thomson Wadsworth. Ball, A. (2000). Teachers' developing philosophies on literacy and their use in urban schools: A Vygotskian perspective on internal activity and teacher change. In C. D. Lee \& P. Smagorinsky (Eds.), Vygotskian perspectives on literacy research: Constructing meaning through collaborative inquiry (pp. 226-255). New York, NY: Cambridge University Press.

Bandura, A. (1977). Self-efficacy: Toward a unifying theory of behavioral change. Psychological Review, 84(2), 191-215.

Bandura, A. (1989). Human agency in social cognitive theory. American Psychologist, 44(9), 1175.

Barbash, S. (2012). Clear teaching: With direct instruction, Siegfried Engelmann discovered a better way of teaching. Arlington, VA: Education Consumers Foundation.

Bateson, M. (1994). Peripheral visions: Learning along the way. New York, NY: Harper Collins. 
Beattie, M. (1995). Constructing professional knowledge in teaching: A narrative of change and development. New York, NY: Teachers College Press.

Beck, R. (2009). The three r's plus: What today's schools are trying to do and why. Minneapolis, MN: University of Minnesota Press.

Bequette, J. W., \& Bequette, M. B. (2012). A place for art and design education in the STEM conversation. Art Education, 65(2), 40-47.

Bidwell, A. (2013). American students fall in international academic tests, Chinese lead the pack. US News. US News \& World Report, 3.

Blikstein, P. (2013). Digital fabrication and making in education: The democratization of invention. In J. Walter-Herrmann \& C. Büching (Eds.), FabLabs: Of machines, makers and inventors. 1-22. Bielefeld, Germany: Transcript.

Bogdan, R., \& Biklen, S. (2003). Qualitative research for education: An introduction to theories and methods (4th ed.). New York, NY: Pearson.

Bolivar, A. (2002). “De nobis ipse silemus?”: Epistemology of biographical narrative research in education. Revista Electrónica de Investigación Educativa, 4 (1-24).

Bolster, A. (1983). Toward a more effective model of research on teaching. Harvard Educational Review, 53(3), 294-308.

Brooks, J. G., \& Brooks, M. G. (1999). In search of understanding: the case for constructivist classrooms. Alexandria, VA: Association for Supervision and Curriculum Development. 
Brown, K., Ryan R., \& Creswell, J. (2007). Mindfulness: Theoretical foundations and evidence for its salutary effects. Psychological Inquiry, 18(3), 211-237.

Brum, A. F. (2015). O empoderamento através das narrativas memorialísticas: Ressignificando a prática Escolar. Master's Thesis, São Leopoldo, RS, Brasil: Faculdade EST.

Bruner, J., \& Anglin, J. (1973). Beyond the information given studies in the psychology of knowing selected. New York, NY: W.W. Norton.

Buomova, V. (2008). Traditional versus modern teaching methods: Advantages and disadvantages of each (Master's thesis). Masaryk University, Brno, Czech Republic.

Burke, B. (2014). The ITEEA 6E learning byDesign ${ }^{\mathrm{TM}}$ model: Maximizing informed design and inquiry in the integrative STEM classroom. Technology and Engineering Teacher, 73(6), 14-19.

Cadwell, L. B. (1997). Bringing Reggio Emilia home: An innovative approach to early childhood education. New York, NY: Teachers College Press.

Caine, R. N., \& Caine, G. (1994). Making connections: Teaching and the human brain. Alexandria, VA: Association for Supervision and Curriculum Development.

Calkins, L., Ehrenworth, M., \& Lehman, C. (2012). Pathways to the common core: Accelerating achievement. Portsmouth, NH: Heinemann. 
Carter, T. L. (2008). Millennial expectations and constructivist methodologies: Their corresponding characteristics and alignment. Action in Teacher Education, 30(3), 3-10.

Chambers, R. (2008). PRA, PLA and pluralism: practice and theory, in Peter Reason and Hilary Bradbury (Eds.) The Sage handbook of action research: Participative inquiry and practice, $2^{\text {nd }}$ ed., pp. 297-318. London,England: SAGE

Charmaz, K. (2006). Constructing grounded theory: A practical guide through qualitative analysis. Thousand Oaks, CA: SAGE.

Chiseri-Strater, E., \& Sunstein, B. (2006). What works?: A practical guide for teacher research. Portsmouth, NH: Heinemann.

Clandinin, D. J., \& Connelly, F. M. (1996). Stories of experience and narrative inquiry. Educational Researcher, 19(5), 2-14.

Clandinin, D. J., \& Connelly, F. M. (2000). Narrative inquiry: Experience and story in qualitative research. San Francisco, CA: Jossey-Bass.

Coffey, A., \& Atkinson, P. (1996). Making sense of qualitative data: Complementary research strategies. Thousand Oaks, CA: SAGE.

Coles, R. (1989). The call of stories: Teaching and the moral imagination. Boston, MA: Houghton Mifflin.

Collopy, R. (2003). Curriculum materials as a professional development tool: How a mathematics textbook affected two teachers' learning. The Elementary School Journal, 103(3), 287. doi:10.1086/499727 
Connelly, F. M., \& Clandinin, D. J. (1986). On narrative method, personal philosophy and narrative unities in the study of teaching. Journal of Research in Science Teaching, 23(4), 293-310.

Connelly, F.M., \& Clandinin, D.J., (Eds.). (1999). Shaping a professional identity: Stories of educational practice. New York, NY: Teachers College Press.

Cooper, I. (1981). The politics of education and architectural design: the instructive example of British primary education. British Educational Research Journal, 7(2), $125-136$.

Craig-Lees, M. (2001). Sense making: Trojan horse? Pandora's box? Psychology and Marketing, 18(5), 513-526.

Creswell, J. W. (1998). Qualitative inquiry and research design: Choosing among five traditions. Thousand Oaks, CA: SAGE.

Creswell, J. W. (2007). Qualitative inquiry and research design. Thousand Oaks, CA: SAGE.

Cunningham, D. (2006). The seven principles of constructivist teaching: A case study. The Constructivist, 17(1) 1-24.

Daggett, W. R., \& Gendron, S. (2010). Common core state standards initiative: Classroom implications for 2014. New York, NY: International Center for Leadership Education.

Dahlberg, G., Moss, P., \& Pence, A. (1999). Beyond quality in early childhood education and care: Postmodern perspectives. London, England: Palmer Press. 
Dangel, J. R. (2013). An analysis of research on constructivist teacher education. Education, 17(2), 1-15.

Danielson, C., \& McGreal, T. L. (2000). Teacher evaluation to enhance professional practice. Alexandria, VA: Association for Supervision and Curriculum Development.

De Corte, E., Vershaffel, L. and Depaepe, F. (2008). Unravelling the relationship between students' mathematics-related beliefs and the classroom culture. European Psychologist, 13, 24-36. doi:10.1027/1016-9040.13.1.24

Denzin, N., \& Lincoln, Y. (1994). Handbooks of qualitative research. Thousand Oaks, CA: SAGE.

Denzin, N. K. (2006). "Strategies of multiple triangulation.” In A. Bryman (Ed.), Mixed methods, Vol. 2. (pp. 297-313). London: SAGE.

DeVries, R. (2002). What is constructivist about constructivist education? Association of Constructivist Teachers Journal, 15(1), 1-20.

DeWalt, K. M., DeWalt, B. R., \& Wayland, C. B. (1998). Participant observation. In H. R. Bernard (Ed.), Handbook of methods in cultural anthropology (pp. 259-299). Walnut Creek, CA: AltaMira Press.

Dewey, J. (1938). Experience and education. New York, NY: Touchstone.

Dewey, J. (1980). Art as experience. New York, NY: Perigree Books. (Original work published in 1934) 
Dewey, J. (2007). Experience and education. New York, NY: Simon and Schuster. (Original work published in 1938)

Dougherty, D., (2005). The making of make. Make Magazine, 1, 7.

DuFour, R., DuFour R., Eaker, R., \& Many, T. (2006). Learning by doing: A handbook for professional learning communities at work. Bloomington IN: Solution Tree.

Eisner, E. (1998). The enlightened eye: Qualitative inquiry and the enhancement of educational practice. Upper Saddle, NJ: Prentice Hall.

Elbaz, F. (1983). Teacher thinking: A study of practical knowledge. New York, NY: Nichols.

Elliott, J. (2005). Using narrative in social research: Qualitative and quantitative approaches. London, England: SAGE.

Evanshen, P., \& Faulk, J. (2011). A room to learn: Rethinking classroom environments. New York, NY: Gryphon House.

Faber, B. (1998). Toward a rhetoric of change. Journal of Business and Technical Communication, 12(2), 217-243.

Fang, Z. (1996). A review of research on teacher beliefs and practices. Educational Research 38(1), 47-65. doi: 10.1080/0013188960380104

Ferguson, R., Faulkner, D., Whitelock, D., \& Sheehy, K. (2014). Pre-teens’ informal learning with ICT and Web 2.0. Technology, Pedagogy and Education. 24(2) 247265. doi: 10.1080/1475939X.2013.870596 
Ferrier, J. (1998), An investigation into the diffusion of innovation in technical and further education: Implementing e-mail through action research. Published Thesis, Deakin University, Victoria, Canada.

Flick, U. (2002). An Introduction to qualitative research. London: Sage Publications.

Folkman, S. (2008). The case for positive emotions in the stress process. Anxiety, Stress, and Coping: An International Journal, 21(1), 3-14.

Freire, P. (1982). Creating alternative research methods. Learning to do it by doing it. In B. Hall, A. Gillette, \& R. Tandon (Eds.) Creating knowledge: A monopoly. society for participatory research in Asia (pp. 29-37) New Delhi, India: Society for Participatory Research in Asia.

Freire, P. (1998). Pedagogy of freedom: Ethics, democracy and civic courage. Oxford, England: Rowman \& Littlefield.

Friedman, T. L. (2005). The world is flat: A brief history of the twenty-first century. New York, NY: Farrar, Straus and Giroux.

Froebel, F. W. (1974). The education of man (W. N. Hailman, Trans.). New York, NY: D. Appleton \& Company (Original work published in 1826).

Fromm, E. (1976). To have or to be. New York, NY: Bloomsbury Academic.

Fullan, M., \& Hargreaves, A. (1993). Teacher development and educational change. New York, NY: Routledge.

Fullan, M. G., \& Miles, M. B. (1992). Getting reform right: What works and what doesn't. Phi Delta Kappan, 73(10), 745-752. 
Galvão, C. (2005). Narrativas em Educação. Ciência \& Educação (Bauru), 11, 327-345. https://doi.org/10.1590/S1516-73132005000200013

Gardner, H. (1994). Forward: Complementary perspectives on Reggio Emilia. In C. Edwards, \& L. F. Gandini (Eds.), The hundred languages of children: The Reggio Approach to early childhood education. Norwood, NJ: Ablex.

George, M. D., \& Bragg, S. (1996). Shaping the future: New expectations for undergraduate education in science, mathematics, engineering, and technology. (NSF 96-139). Arlington, VA: DIANE

Gergen, K. J. (1998). Narrative, moral identity and historical consciousness: a social constructionist account. In J. Straub (ed.) (1998), Identitat und historishces Bewusstsein, 3(9) 99-299. Frankfurt, Germany: Suhrkamp.

Giachino, J. (1992). Men at work; kids in class. American School and University, 64(12), $24-25$.

Gill, P.B., (2001). Narrative inquiry: Designing the processes, pathways and patterns of change. Systems Research and Behavioral Science, 18(4), 335-344.

Gislason, N. (2007). Placing education: The school as architectural space. Paideusis, 16(3), 5-14. Retrieved from http://journals.sfu.ca/paideusis/index.php/paideusis/article/view/87

Glesne, C. (2011). Becoming qualitative researchers: An introduction. (4th ed.) Boston, MA: Pearson Education. 
Glover, P., \& Hope, H. (2015). Technology, globalisation and the future of work in Europe: Essays on employment in a digitised economy, London, England: IPPR

Gray, A. (1995). The road to knowledge is always under construction: A life history journey to constructivist learning, Master's thesis. University of Saskatchewan, Saskatchewan, Canada.

Greene, M. (1995). Releasing the imagination: Essays on education, the arts, and social change. San Francisco, CA: Jossey-Bass.

Guskey, T. R. (1989). Attitude and perceptual change in teachers. International Journal of Educational Research, 13(4), 439-453.

Guskey, T. R., \& Sparks, D. (1996). Exploring the relationship between staff development and improvements in student learning. Journal of Staff Development, $17(4), 34-38$.

Halverson, E. R., \& Sheridan, K. (2014). The maker movement in education. Harvard Educational Review, 84(4), 495-504.

Harootunian, B., \& Yarger, G. P. (1980). Teachers' conceptions of their own success. Current Issues, (Research/Technical 400-78-0017). Washington, DC: ERIC Clearinghouse on Teacher Education.

Hausfather, S. (2001). Where's the content? The role of content in constructivist teacher education. Educational Horizons, 80(1), 15-19.

Heckman, J. J., \& LaFontaine, P. A. (2010). The American high school graduation rate: Trends and levels. The Review of Economics and Statistics, 92(2), 244-262. 
Heil, D. R., Pearson, G., \& Burger, S. E. (2013, June). Understanding Integrated STEM Education: Report on a National Study. Paper presented at 2013 ASEE Annual Conference, Atlanta, GA. Retrieved from https://peer.asee.org/22664.

Heller, R., Calderon, S., \& Medrich, E. (2003). Academic achievement: What does research tell us? Atlanta, GA: Southern Regional Education Board. Retrieved from http://www.sreb.org.

Horm-Wingerd, D., \& Hyson, M. (Eds.). (2000). New teachers for a new century: The future of early childhood professional preparation. Washington, DC: National Institute on Early Childhood Development and Education.

Horne, S. C. (1999). Classroom environment and its effects on the practice of teacher. Published Thesis, University of London, London, England.

Horne-Martin, S. (2002). The classroom environment and its effects on the practice of teachers. Journal of Environmental Psychology, 22(1/2), 139-156.

Horne-Martin, S. (2004). Environment- behaviour studies in the classroom. Journal of Design and Technology Education, 9(2), 77-89.

Howard, G. R. (1999). We can't teach what we don't know: White teachers, multiracial schools. New York, NY: Teachers College Press.

Huberman, M. (1995). Networks that alter teaching: Conceptualizations, exchanges and experiments. Teachers and Teaching, 1(2), 193-211. 
Jacobs, J., \& Buechley, L. (2013). Codeable objects: Computational design and digital fabrication for novice programmers. In Proceedings of the SIGCHI Conference on Human Factors in Computing Systems (pp. 1589-1598). Paris, France: ACM.

James, M., Applefield, R., \& Martinez, M. (2001). Constructivism in theory and practice: Toward a better understanding. High School Journal, 84(2), 35-53.

Jenkins, S., \& Calhoun, J. (1989). Teacher stress: Issues and intervention.

Jones, L. L., \& Hayes, A. (1980). How valid are surveys of teacher needs? Educational Leadership, 37(5), 390-393.

Jones, M. G., \& Brader-Araje, L. (2002). The impact of constructivism on education: Language, discourse, \& meaning. American Communication Journal, 5(3), 1-10.

Jones, W. M., \& Dexter, S. (2014). How teachers learn: the roles of formal, informal, and independent learning. Educational Technology Research and Development, 62(3), 367-384.

Kafai, Y. B., Peppler, K. A., \& Chapman, R. N. (2009). The computer clubhouse: constructionism and creativity in youth communities. New York, NY: Teachers College Press.

Kahn, R., \& Connelly, C. (1957). The dynamics of interview. Oxford, England: Wiley. Khalid, A., \& Azeem, M. (2012). Constructivist vs traditional: Effective instructional approach in teacher education. International Journal of Humanities \& Social Science, 2(5), 170-177. 
Klem, A. M., \& Connell, J. P. (2004). Relationships matter: Linking teacher support to student engagement and achievement. Journal of School Health, 74(7), 262-273.

Lantz, H. B. (2009). What is STEM education? Retrieved from: http://www.currtechintegrations.com/pdf/STEMEducationArticle.pdf

LaRochelle, M., Bednarz, N., \& Garrison, J. (2009). Constructivism and education. New York, NY: Cambridge University Press.

Lave, J. (1988). Cognition in practice: Mind, mathematics and culture in everyday life. New York, NY: Cambridge University Press.

Lave, J., \& Wenger, E. (1991). Situated learning: legitimate peripheral participation. New York, NY: Cambridge University Press.

The Library as Incubator Project. (2013). American Library Association Conference 2013 Wrap-up. Retrieved from: http://www.libraryasincubatorproject.org/?p = 11056 .

Lincoln, Y., \& Guba, E. (1985). Naturalistic inquiry. Newbury Park, NJ: SAGE. Manzo, K (2000). Lessons of a century. Bethesda, MD: Editorial Projects in Education. Marlowe, B. A., \& Page, M. L. (2005). Creating and sustaining the constructivist classroom. Thousand Oaks, CA: Corwin.

Marshall, C., \& Rossman, G. (1999). Designing qualitative research (3rd ed). Thousand Oaks, CA: SAGE.

Martin, L. (2015). The promise of the maker movement for education, Journal of PreCollege Engineering Education Research (J-PEER), 5(1), 4. doi: 10.7771/21579288.1099 
Martinez, S. L., \& Stager, G. (2013). Invent to learn: Making, tinkering, and engineering in the classroom. Torrance, CA: Constructing Modern Knowledge Press.

Masicampo, E. J., \& Baumeister, R. F. (2007). Relating mindfulness and self-regulatory processes. Psychological Inquiry, 18(4), 255-258.

Mason, J. (2002). Qualitative researching (2nd ed.) London, England: SAGE

McNess, E. (2009). Conversations across cultures: The narrative construction of the primary class teacher in England and Denmark. In S. Trahar (Ed.), Narrative research on learning: Comparative and international perspectives (pp. 145-165). Oxford, United Kingdom: Symposium Books.

Mehan, H. (1983) Social constructivism in psychology and sociology. Sociologie et Societes. 14(2), 77-96.

Melhuish, C. (2011). Methods for understanding the relationships between learning and space. In A. Boddington \& J. Boys (Eds.), Re-Shaping learning: A critical reader (pp. 19-31). Rotterdam, Netherlands: Sense.

Merriam, S.B. (2009). Qualitative research: A guide to design and implementation. San Francisco, CA: Jossey-Bass.

Miller, H. (2008). Rethinking the classroom: Spaces designed for active and engaged learning and teaching. Zeeland, MI: Herman Miller.

Mischler, E. (1986). Research interviewing: Context and narrative. Cambridge, MA: Cambridge University College. 
Montessori, M. (1965). The Montessori method: Scientific pedagogy as applied to child education in "the children's houses" with additions and revisions. (Translated from the Italian by Anne E. George). Cambridge, MA: R. Bentley.

Newman, D., Griffin, P., \& Cole, M. (1989). The construction zone: Working for cognitive change in schools. Cambridge, UK: Cambridge University Press.

Noddings, N. (2006). Happiness and education. New York, NY: Cambridge University Press.

Norman, D. (1980). Twelve issues for cognitive science, Cognitive Science, 4, 1-32.

Ormrod, J. E., (2012). Human learning. Boston, MA: Pearson

Ortner, C. N., Kilner, S. J., \& Zelazo, P. D. (2007). Mindfulness meditation and reduced emotional interference on a cognitive task. Motivation and Emotion, 31(4), 271283.

Palmer, P. (1983). To know as we are known: Education as a spiritual journey. New York, NY: Harper Collins.

Papert, S. (1980). Mindstorms: Children, computers, and powerful ideas. New York, NY: Basic Books.

Partnership for 21st Century Skills. (2013). P21 Common Core toolkit: A guide to aligning the Common Core State Standards with the framework for 21st century skills. Washington, DC: Joseph Bishop. 
Pea, R. (1993). Practices of distributed intelligence and designs for education. In G.

Salomon (Ed.), Distributed cognitions: Psychological and educational considerations (pp. 47-87). Cambridge, UK: Cambridge University Press.

Pea, R. D., \& Gomez, L. M. (1994). Distributed multimedia learning environments: Why and how? Interactive Learning Environments, 2(2), 73-109.

Piaget, J. (1977). The development of thought: Equilibration of cognitive structures. New York, NY: Viking Press.

Pink, S. (2007). Doing visual ethnography: images, media and representation in research. Thousand Oaks, CA: SAGE.

Piro, J. (2010). Going from STEM to STEAM: The arts have a role in America's future, too. Education Week, 29(24), 28-30.

Polkinghorne, D. (1995). Narrative configuration in qualitative analysis. International Journal of Qualitative Studies in Education, 8(1), 5-23.

Polkinghorne, D., (1998), Narrative knowing and the human sciences, Albany, NY, State of New York University Press.

Prince, M. (2004). Does active learning work? A review of the research. Journal of Engineering Education, 93(3), 223-231.

Reese, J. (2001). The origins of progressive education. History of Education Quarterly, 41(Spring), 1-24. 
Resnick, M., Maloney, J., Monroy-Hernández, A., Rusk, N., Eastmond, E., Brennan, K., \& Kafai, Y. (2009). Scratch: programming for all. Communications of the ACM, $52(11), 60-67$.

Resnick, M., Ocko, S., \& Papert, S. (1988). LEGO, Logo, and design. Children's Environments Quarterly, 5(4), 14-18.

Richert, A.E. (2002). Narratives that teach: Learning about teaching from the stories teachers tell. In N. Lyons \& V.K. LaBoskey (Eds.) Narrative inquiry in practice: Advancing the knowledge of teaching (pp. 48-62). New York, NY: Teachers College Press.

Riel, M., \& Polin, L. (2004). Online learning communities: Common ground and critical differences in designing technical environments. In S. A. Barab, R. Kling, and J. H. Gray (Eds.), Designing for virtual communities in the service of learning (pp. 16-50). Cambridge, UK: Cambridge University Press.

Riessman, C.K. (1993), Narrative analysis. Newbury Park, CA: SAGE.

Rinaldi, C. (2001). Introduction. In H. K. Gardner, C. Guidici, C. Rinaldi, \& M. Krechevsky (Eds.), Making learning visible: Children as individual and group learners (pp. 25-31). Cambridge, MA: Project Zero.

Rinaldi, C. (2006). In dialogue with Reggio Emilia: Listening, researching and learning. New York, NY: Routledge. 
Rivlin, L. G., \& Rothenberg, M. (1976). The use of space in open classrooms. Environmental psychology: People and their physical settings, New York, NY: Holt, Rinehart \& Winston.

Roeser, R.W., \& Pinela, C. (2014). Mindfulness and compassion training in adolescence: A developmental contemplative sciences perspective. New Directions in Youth Development, 2014(142), 9-30.

Rogoff, B. (1994). Developing understanding of the idea of communities of learners. Mind, Culture, and Activity, 4, 209-229.

Root-Bernstein, R., \& Root-Bernstein, M. (2011) From STEM to STEAM to STREAM: Writing as an essential component of science education. Psychology Today. Retrieved from: http://www.psychologytoday.com/blog/imagine/201103/stemsteam-stream-writing-essentialcomponent-science-education

Rotherham, A. J., \& Willingham, D. T. (2010). 21st-Century Skills. American Educator, 17(1), 17-20.

Sanders, M. (2006). A rationale for new approaches to STEM education and STEM education graduate programs. Paper presented at the 93rd Mississippi Valley Technology Teacher Education Conference, Nashville, TN.

Sanders, M. (2009). STEM, STEM education, STEM mania. Technology Teacher, 68(4), 20-26.

Sanders, M., \& Wells, J. (2005). STEM graduate education/research collaboratory. Paper presented to the Virginia Tech faculty, Virginia Tech., Blacksburg, VA 
Sanders, M. E. (2008). STEM, STEM education, STEMmania. The Technology Teacher, $68(4), 20-26$.

Schreurs, B., Van den Beemt, A., Prinsen, F., Witthaus, G., Conole, G. \& de Laat, M. (2014). An investigation into social learning activities by practitioners in open educational practices. International Review of Research in Open and Distance Learning, 15(4), 1-20.

Seidman, I. E. (1998). Interviewing as qualitative research: A guide for researchers in education and the social sciences (2nd ed.) New York: Teachers College Press.

Sheridan, K., Halverson, E., Litts, B., Brahms, L., Jacobs-Priebe, L., \& Owens, T. (2014). Learning in the making: A comparative case study of three makerspaces. Harvard Educational Review, 84(4), 505-531.

Sleeter, C.E. (2001). Epistemological diversity in research on preservice teacher preparation for historically underserved children. Review of Research in Education, 25, 209-250.

Sousa, D. A., \& Pilecki, T. (2013). From STEM to STEAM: Using brain-compatible strategies to integrate the arts. Thousand Oaks, CA: Corwin Press.

Soy, S. K. (1997). The case study as a research method. (Unpublished paper). University of Texas, Austin. Retrieved from Devilbis (2014).

Sprague, D., \& Dede, C. (1999). Constructivism in the classroom: If I teach this way, am I doing my job? International Society for Technology in Education, 27(1), 6-17. 
Stacey, S. (2011). The unscripted classroom: Emergent curriculum in action. St. Paul, MN: Red Leaf Press.

Stake, R. E. (2006). Multiple case study analysis. New York, NY: Guilford Press.

The Marzano Center. (Producer). (2013). Building a bridge between Common Core and the art and sciences of teaching framework. Retrieved from http://www.marzanocenter.com

The New London Group. (1996). A pedagogy of multiliteracies: Designing social futures. Harvard Educational Review, 66(1), 60-93.

Upitis, R. (2004). School architecture and complexity. Complicity: An International Journal of Complexity \& Education, 1(1), 19-38.

Usher, R. (2002). Putting space back on the map: Globalisation, place and identity. Educational Philosophy and Theory, 34(1), 41-55.

Villegas, A.M., \& Lucas, T. (2002). Educating culturally responsive teachers: A coherent approach. Albany, NY: State University of New York Press.

Vygotsky, L. S. (1978). Mind in society: The development of higher psychological processes. Cambridge, MA: Harvard University Press.

Wagner, T. (2001). Leadership for learning: An action theory of school change. Phi Delta Kappan, 82(5), 378-383.

Weinstein, C., \& David, T. (Eds.). (1987). Spaces for children. New York, NY: Plenum Press. 
Weissmann, J. (2013). The Ph.D. bust: America's awful market for young scientists in 7 charts. The Atlantic, 20. Retrieved from: www.theatlantic.com/business/archive/2013/02/the-phd-bust-americas-awfulmarket-for-youngscientists-in-7-charts/273339/

Wells, J. G. (2008). Potentials of integrative STEM education in technology education. Paper presented at the Mississippi Valley Technology Teacher Education Conference, St. Louis, MO.

Wells, J., \& Ernst, J. (2012). Integrative STEM education. Blacksburg, VA: Virginia Tech: Invent the Future, School of Education. Retrieved from www.soe.vt.edu/istemed/

Wenger, E. (2003). Communities of practice: Learning, meaning, and identity (1st paperback. ed., Learning in doing: Social, cognitive, and computational perspectives). Cambridge, MA: Cambridge University Press.

White, H. (2011). STEM to STEAM: The future of American innovation. Retrieved from http://steam-notstem.com/articles/whitepaper/

Wilson, B. (1996). Constructivist learning environments: Case studies in instructional design. Englewood Cliffs, NJ: Educational Technology.

Woolley, B., \& Woolley, A. W. (2004). Construct validity of a self-report measure of teacher beliefs related to constructivist and traditional approaches to teaching and learning. Educational and Psychological Measurement, 64, 319-331. 
Architectural Makerspace STEAM Impact Case Study

Yin, R.K. (2003). Case study research: Design and methods. Thousand Oaks, California: Sage. 


\section{Appendix A}

\section{Demographic Survey}

Name:

Chosen pseudonym:

Educational level (circle one of the following):

High School or GED Associates Degree(s) Bachelor's Degree(s) Master's degree(s)

Did any of your formal educational experiences address Makerspaces or STEAM? If yes, explain what:

Number of years in the field of elementary education:

Number of years at The Apple Tree School:

Number of years working in STEAM education:

Number of renovations or classroom moves you have experienced:

On a scale of 1-10 ( 1 being the lowest, 10 the highest), how would you rate your satisfaction with the Innovation Alley project to this point)? 


\section{Appendix B}

Interview Protocol

\section{Interview One Questions}

What is a good teacher?

How would you describe your beliefs regarding teaching?

What is a good student?

Describe your preparation for teaching:

Discuss your previous teaching space and how you feel about its success and your ability to use it?

What would you consider the most important to your practice as an educator?

\section{Interview Two Questions}

What is your understanding of the Innovation Alley Project at this point?

How does Innovation Alley make you think about teaching and learning?

How does it support your ideas and beliefs of teaching and learning?

How does the makerspace fit into the curriculum of your current classroom?

What aspects of the renovation do you feel most comfortable with?

Discuss the new space and how it fits or does not fit with your teaching practice:

How does the makerspace or STEAM initiative help or not help your progress in learning how to use the space? 
What teaching practices to you find yourself relying on most currently?

Does anything about the space influence your beliefs about teaching?

\section{Interview Three Questions}

What would further support your understanding of the makerspace or Innovation Alley?

What materials would further support your work in Innovation Alley?

What training would help you accomplish your teaching goals in the new space?

Describe a future lesson or experience you plan to use with students:

Describe changes you plan to make to the space in the future:

What teaching practices would you like to use more often? 


\section{Appendix C}

Interview Question and Research Question Alignment

\section{Central Research Question \\ What influence does the physical \\ addition of the makerspace have \\ on teaching and learning beliefs \\ and practices of primary school \\ educators at a K-8 independent \\ school on the East Coast of the \\ United States?}

\begin{tabular}{|l|l|}
\hline & Interview One Questions \\
\hline SQ 1 & What is a good teacher? \\
\hline SQ 3 & $\begin{array}{l}\text { How would you describe your beliefs regarding } \\
\text { teaching? }\end{array}$ \\
\hline SQ 1, 3 & What is a good student? \\
\hline SQ 1 & Describe your preparation for teaching: \\
\hline SQ 2 & you feel about its success and your ability to use \\
& it? \\
\hline SQ 1 & What would you consider the most important to \\
& your practice as an educator? \\
\hline
\end{tabular}

\section{Sub-Question 1 (SQ 1) \\ What are the beliefs, practices and experiences of primary educators related to the change in} $S Q 2,3$

SQ 2
Interview Two Questions

What is your understanding of the Innovation Alley

Project at this point?

How does Innovation Alley make you think about teaching and learning? 


\begin{tabular}{|c|c|c|}
\hline \multirow[t]{4}{*}{$\begin{array}{l}\text { the physical environments as } \\
\text { teaching and learning tools? }\end{array}$} & SQ 1 & $\begin{array}{l}\text { How does it support your ideas and beliefs of } \\
\text { teaching and learning? }\end{array}$ \\
\hline & SQ 3 & $\begin{array}{l}\text { How does the makerspace fit into the curriculum } \\
\text { of your current classroom? }\end{array}$ \\
\hline & SQ 2 & $\begin{array}{l}\text { What aspects of the renovation do you feel most } \\
\text { comfortable with? }\end{array}$ \\
\hline & SQ 2 & $\begin{array}{l}\text { Discuss the new space and how it fits or does not } \\
\text { fit with your teaching practice: }\end{array}$ \\
\hline Sub- Question 2 (SQ2) & SQ 3 & $\begin{array}{l}\text { How does the makerspace or STEAM initiative } \\
\text { help or not help your progress in learning how to } \\
\text { use the space? }\end{array}$ \\
\hline \multirow{2}{*}{$\begin{array}{l}\text { In what ways do educators } \\
\text { perceive the redesign as changing } \\
\text { how they use physical space? }\end{array}$} & SQ 2 & $\begin{array}{l}\text { What teaching practices to you find yourself } \\
\text { relying on most currently? }\end{array}$ \\
\hline & SQ 2 & $\begin{array}{l}\text { Does anything about the space influence your } \\
\text { beliefs about teaching? }\end{array}$ \\
\hline Sub-question 3 (SQ3) & & Interview Three Questions \\
\hline \multirow{2}{*}{$\begin{array}{l}\text { What beliefs and practices, related to } \\
21 \text { st-century skills of collaboration, } \\
\text { creativity, critical thinking, and }\end{array}$} & SQ 1 & $\begin{array}{l}\text { What would further support your understanding of } \\
\text { the makerspace or Innovation Alley? }\end{array}$ \\
\hline & SQ 1, 3 & $\begin{array}{l}\text { What materials would further support your work in } \\
\text { Innovation Alley? }\end{array}$ \\
\hline
\end{tabular}




\begin{tabular}{|l|l|l|}
\hline \multirow{2}{*}{$\begin{array}{l}\text { communication, do educators identify } \\
\text { as part of the new space? }\end{array}$} & SQ 1, 3 & $\begin{array}{l}\text { What training would help you accomplish your } \\
\text { teaching goals in the new space? }\end{array}$ \\
\cline { 2 - 3 } & SQ 2 & $\begin{array}{l}\text { Describe a future lesson or experience you plan to } \\
\text { use with students: }\end{array}$ \\
\hline SQ 1, 3 & $\begin{array}{l}\text { Describe changes you plan to make to the space } \\
\text { in the future: }\end{array}$ \\
\hline SQ 2 & What teaching practices would you like to use \\
& more often?
\end{tabular}

